

\section{La presente obra está bajo una licencia de:}

\section{http://creativecommons.org/licenses/by-nc-sa/3.0/deed.es MX}

\section{Atribución-No Comercial-Licenciamiento Reciproco 3.0 Unported}

Eres libre de:

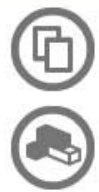

copiar, distribuir y comunicar públicamente la obra

hacer obras derivadas

Bajo las condiciones siguientes:

Atribución - Debes reconocer la autoria de la obra en los términos

especificados por el propio autor o licenciante.

No comercial - No puedes utilizar esta obra para fines comerciales.

D Licenciamiento Reciproco - Si alteras, transformas o creas una obra a

partir de esta obra, solo podrás distribuir la obra resultante bajo una licencia

igual a ésta.

\section{Esto es un resumen fácilmente legible del: texto legal (de la licencia completa)}

\section{En los casos que sea usada la presente} obra, deben respetarse los términos especificados en esta licencia.

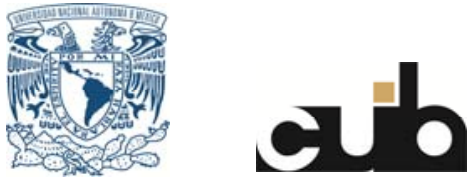




\section{Centro Universitario deInvestigaciones}

Bibliotecológicas.

Cronología 1981-2006 


\title{
Centro Universitario de Investigaciones Bibliotecológicas. Cronología 1981-2006
}

\author{
Universidad Nacional Autónoma de México
} 2007 
Publicación conmemorativa del 25 aniversario del Centro Universitario de Investigaciones Bibliotecológicas, 1981-2006.

Compilador:

Jaime Ríos Ortega

Apoyo en la recopilación de datos bistóricos:

Javier Jiménez Tierradentro

Zuemi A. Solís y Rivero

Zindy E. Rodríguez Tamayo

Diseño de portada:

Mario Ocampo Chávez

DR (C) UNIVERSIDAD NACIONAL AUTÓNOMA DE MÉXICO

Ciudad Universitaria, 04510, México, D.F.

Impreso y hecho en México 


\section{Contenido}

Presentación . ......................... 1

Jaime Ríos Ortega

CENTRO UNIVERSITARIO DE INVESTIGACIONES

BibLIOTECOLÓgICAS.

Cronología 1981-2006 • • • • • • • • • • • • • • • • • • 5 


\section{Presentación}

I 1 Centro Universitario de Investigaciones Bibliotecológicas

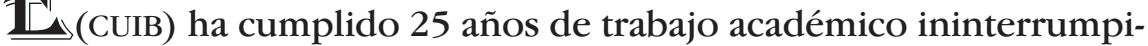
do. El decreto de creación fue publicado en la Gaceta de la Universidad Nacional Autónoma de México el 14 de diciembre de 1981 y, desde esta fecha, el CUIB ha llevado a cabo esfuerzos importantes para consolidarse y lograr un incuestionable reconocimiento de su liderazgo en diferentes países de habla hispana.

En efecto, el CUIB es una entidad de investigación y docencia que tiene gran influencia académica en las diferentes escuelas de Bibliotecología de varios países latinoamericanos y, por supuesto, en las escuelas de nuestro país. El CUIB también ha contribuido a través de la producción de conocimiento original, la formación y actualización de recursos humanos y la difusión de los resultados de la investigación bibliotecológica al trabajo académico y profesional de diferentes entidades académicas, asociaciones civiles, así como de instituciones públicas y privadas.

El CUIB ha realizado esfuerzos institucionales con planes a futuro a fin de dar solidez y perspectiva al desarrollo del Centro. En este sentido, puede decirse que los objetivos centrales del CUIB han sido instituir las funciones sustantivas que de modo consuetudinario ha realizado con respecto a la disciplina, la universidad y la nación.

Como se sabe, estas funciones sustantivas se refieren al cultivo del conocimiento original en la disciplina bibliotecológica, la docencia y difusión de la cultura. Gran parte del trabajo del CUIB ha consistido en organizar y fortalecer las estructuras académicas y administrativas 
que han hecho posible cumplir con estas funciones. Esto ha sido tarea que ha llevado varios años y ha implicado el trabajo de varios colegas y académicos que han creído en el CUIB como un proyecto fundamental para la Bibliotecología y para el país.

La cronología desglosada en este documento, presenta las diferentes acciones que el CUIB ha realizado para asegurar su mejor desempeño institucional y el cumplimiento de sus objetivos. También pretende ser una rememoración de las personas y los actos que en muchos sentidos han sido determinantes para la vida académica del CUIB.

No es un relato histórico, ni tampoco un recuento de hechos. En cambio, sí es una memoria institucional, metafóricamente hablando, que recupera el conjunto de decisiones y actuaciones que a la postre han sido esenciales para perfilar los rasgos académicos que hoy posee el CUIB. El lector de esta cronología, fácilmente observará que una vez establecidos los órganos colegiados con los cuales habría de funcionar el CUIB, el siguiente paso fue conformar el conjunto de instrumentos normativos de la vida institucional del Centro. Posteriormente, se dieron las primeras acciones para organizar la investigación y las áreas intelectuales en que habría de desenvolverse el trabajo de los investigadores. Posteriormente, quedaron establecidos los medios y las áreas institucionales para la difusión de los productos de investigación y, por supuesto, la organización de actividades para la formación y consolidación de los investigadores, así como para la actualización de recursos humanos provenientes de diferentes partes del país y de otros países.

El programa editorial del CUIB es otro hecho fundamental para la disciplina bibliotecológica, como también lo fue la fundación de la revista Investigación Bibliotecológica. Asimismo, la mención de los espacios en que el CUIB ha desarrollado sus funciones y los momentos en que los ha transformado y mejorado, son referentes importantes. Otro aspecto interesante de la vida del CUIB ha sido su constante internacionalización, ya sea a través de la formación de los propios investigadores, o bien, por medio de la organización de diferentes actividades académicas, de entre las cuales destaca el Coloquio Internacional, los seminarios y la conformación de redes de investigación, 
así como el establecimiento de convenios con organismos internacionales.

Un aspecto no menos trascendente ha sido la conformación de la biblioteca del CUIB y el constante enriquecimiento de su acervo y la ampliación de sus servicios. Una vez que nació a la vida académica no se ha detenido y, sin ella, es impensable la vida intelectual del Centro. Por tanto, con justicia, la biblioteca requiere un espacio importante en la cronología.

Así como se pueden destacar algunos puntos esenciales, es factible identificar otros más, pero de continuar así, el recuento no termina. Cabe señalar que el ideal de consignar todo aquello que ha sido significativo para el CUIB, por momentos ha sido una tarea ardua y de angustia contenida ya que todo el tiempo se padece el temor de omitir un hecho, una acción o un dato relevante. Por ello, se trabajó intensamente con los archivos del CUIB y se recurrió a diversas fuentes. Sin embargo, existe la conciencia y el reconocimiento de la insuficiencia; por ello, en retrospectiva, la cronología no está clausurada y, en prospectiva, esperamos que los años venideros den mucho material para integrar en las subsecuentes cronologías.

Es interesante observar, con base en la cronología que más adelante se detalla, que cuando una institución de investigación y formación de recursos humanos, como es el caso del CUIB, logra instituir sus funciones sustantivas, varias de sus acciones parecen reiterativas. Sin embargo, esa forma sólo es artificial, ya que una institución de indagación permanentemente está abierta al conocimiento nuevo, así como siempre está atenta a continuar el cultivo de problemas clásicos y de frontera. En tal sentido es atractivo revisar la transformación de los intereses intelectuales de la comunidad bibliotecológica y el impacto del mundo disciplinario; aspectos como estos pueden detectarse en la cronología.

¿De qué se ha compuesto la vida académica del CUIB y cómo se ha constituido? La lista es larga: investigadores, técnicos académicos y trabajadores; coloquios, seminarios, talleres, cursos, libros de autor, la revista Investigación Bibliotecológica, las compilaciones y los diferentes productos editoriales; el uso de tecnologías de información y comunicación, reuniones foráneas, cuerpos colegiados e instrumen- 
tos normativos; cambios de sede y remodelaciones, espacios educativos y espacios de reconocimiento al mérito académico y laboral, proyectos individuales e interinstitucionales, visitas de investigadores extranjeros y alumnos de otros países, profesores extranjeros y nacionales, vinculación con entidades académicas y asociaciones profesionales, biblioteca, usuarios y celebraciones. La lista continúa, pero los actores y los procesos involucrados en la vida y la historia del Centro dejan huella permanente, gracias a sus aportaciones y a su trabajo.

De este modo, la cronología que se ha elaborado es también conmemoración y reconocimiento a todos aquellos que han formado parte orgánica del CUIB y, de un modo u otro, gracias a su trabajo, han contribuido a consolidar una entidad académica reconocida y en expansión.

La cronología del CUIB es una cadena sucesiva de actores, tiempos y movimientos, de productos e interacciones. Dicho de otro modo: es una cronología que consigna una parte muy importante de la historia del CUIB. Por tanto, es una pieza clave para revisar el pasado y perfilar el futuro.

Finalmente, pensemos con serenidad: sólo han pasado 25 años del CUIB. A continuación recorramos y adentrémonos a esta historia, ya sea para revivir, para reconocer o para entender.

Jaime Ríos Ortega 


\section{Centro Universitario de Investigaciones Bibliotecológicas. Cronología 1981-2006}

1981

Diciembre 14. Se crea el Centro Universitario de Investigaciones Bibliotecológicas (CUIB) por acuerdo del Rector de la Universidad Nacional Autónoma de México (UNAM) el Señor Octavio Rivero Serrano, con una plantilla académica de ocho investigadores en el área de Bibliotecología adscritos a la Coordinación Académica de la Dirección General de Bibliotecas y seis técnicos académicos de la misma dirección que se integran a un Programa de Formación de Investigadores. Diciembre 14. Publicación del acuerdo de creación del CUIB en la Gaceta UNAM, el cual incluye las siguientes funciones:

A) Realizar investigaciones teóricas y metodológicas relacionadas con todos los aspectos de las ciencias bibliotecológicas prioritariamente.

B) Como resultado de su esfuerzo de investigación, diseñar modelos alternativos de organización bibliotecaria, de catalogación, clasificación y automatización de la información, así como de la diseminación de los conocimientos pertinentes adecuados a las necesidades de los usuarios.

C) Atender Programas de Investigación que contemplen la formación del personal académico de alto nivel e implementar y contri- 
buir a la implantación de programas de formación de especialistas en materia de Bibliotecología.

D) Prestar al Rector de la Universidad, al Secretario General, al Director General de Bibliotecas y a las dependencias universitarias que lo requieran, el asesoramiento del caso en materia de Bibliotecología y desarrollar programas de investigación convenidos con instituciones nacionales y extranjeras.

Diciembre 14. Se conforma la plantilla académica integrada por los investigadores: Estela M. Morales Campos, José Adolfo Rodríguez Gallardo, Elisa Margarita Almada de Ascencio, Martha Alicia Añorve Guillén, Ana María Magaloni de Bustamante, María Trinidad Román Haza, María Luisa Garza Ávalos y Ofelia Solís Valdespino.

\section{2}

En este primer año el Centro Universitario de Investigaciones Bibliotecológicas trató de establecer las bases formales de su estructura a fin de tener un campo propicio para la investigación; otro de los objetivos fue el proporcionar al personal un ambiente agradable para propiciar el trabajo diario y creativo.

Se tiene en imprenta el primer libro que se publica por investigadores del CUIB como resultado del trabajo académico iniciado por este Centro, este primer libro que lleva como título: Estudio comparativo de los códigos de catalogación más usados en México de la Mtra. Estela M. Morales es parte de los trabajos de investigación y traducciones publicados este año; que permitirán resolver el problema de la bibliografía que para estos momentos es mayoritariamente escrita en inglés, facilitando de este modo la lectura al lector hispano.

Enero 14. Se da el nombramiento del primer Director del Centro al maestro José Adolfo Rodríguez Gallardo y se establece que el Centro tendrá como sede el primer piso del patio central del Antiguo Colegio de San Ildefonso.

Febrero. Se designa a la Mtra. Estela M. Morales Campos como Secretaria Académica del CUIB.

Febrero. Se integra una comisión formada por las licenciadas Ma. Trinidad Román y Ma. Luisa Garza Ávalos para que elaboren un ante- 
proyecto de reglamento, mismo que se discutió y aprobó en el seno del Consejo Interno.

Febrero 16. Se elige el primer Consejo Interno, quedando de la siguiente manera:

Presidente: Mtro. José Adolfo Rodríguez Gallardo

Secretario: Mtra. Estela M. Morales Campos

Vocales: $\quad$ Lic. Martha A. Añorve Guillén

Mtra. Ma. Luisa Garza Ávalos

Sra. Yadira Lugo Toledo

Dra. Ana Ma. Magaloni de Bustamante

Lic. Ma. Trinidad Román Haza

Mayo 23. La investigadora Ana María Magaloni de Bustamante obtiene el grado de Doctor en Biblioteconomía por el Simmons College. Library School of Library \& Information Science. Boston, Massachusetts.

Julio. Se imparte el Seminario sobre Metodología de la Investigación organizado por la Mtra. Estela M. Morales.

Julio 28 y 29. Se realiza el I Coloquio sobre Investigación Bibliotecológica organizado por el CUIB. En éste se dan a conocer los programas de investigación que se desarrollan en México, además de que se da a conocer la problemática general que afrontan los investigadores y las instituciones que patrocinan en las investigaciones, así como las investigaciones que realizan sus trabajos en forma independiente.

Septiembre 8 al 11. Se efectúa el Seminario conjunto México-Francia sobre bancos de datos, el cual fue realizado por la embajada de Francia y la Secretaría de Programación y Presupuesto, el cual contó con la participación del CUIB en su actividad de trabajo con instituciones nacionales y extranjeras.

Octubre 6 al 10. Se desarrolla del Primer Encuentro de Bibliotecarios de la UNAM. Este encuentro responde a la idea de abrir un espacio de reflexión y de diálogo, en el que se ensayará una prospectiva de la biblioteca universitaria en sus dimensiones de planeación de servicios, automatización y de educación continua, buscando con esto desarrollar el "significado y alcance de la biblioteca universitaria en la sociedad mexicana”. Este encuentro fue coordinado por la Dirección General de Bibliotecas y en el que el CUIB participa en el for- 
talecimiento de los conocimientos de trabajo interno que la UNAM ofrece a la sociedad.

Noviembre 3 al 9. La Coordinación de Humanidades/UNAM y la Coordinación General de Estadística, Geografía e Informática de la Secretaria de Programación y Presupuesto organizan el Seminario de introducción al manejo de sistemas y servicios de información estadística y geografía, contando con la participación de la investigadora Elisa Margarita Almada.

Diciembre 16. Se aprueba el anteproyecto de reglamento por el Consejo Técnico.

1983

Enero. La Lic. E. Margarita Almada de Ascencio es nombrada Directora del Programa Justo Sierra en la Coordinación de Humanidades de la UNAM.

Enero. A partir de este año se comienza a integrar la biblioteca del CUIB, la que cuenta con una colección formada de 960 libros, 28 títulosde publicaciones periódicas en micropelículas, 127 títulos de publicaciones periódicas, 3 periódicos diarios, 54 títulos de tesis, 1725 documentos de archivo documental. Cabe destacar que la colección apoya los actuales programas de investigación y proporciona una gran cantidad de información sobre una gran cantidad de tópicos relacionados con la Bibliotecología mexicana.

Enero 3. Ingreso de la Lic. Elsa Margarita Ramírez Leyva como investigadora del CUIB.

Febrero. Ingreso del Lic. Roberto Garduño Vera como investigador del CUIB.

Marzo 14 al 16. El CUIB, Consejo Británico y la Facultad de Filosofía y Letras organizan el curso Planning Library Buildings.

Junio 14 al 16 y Julio 20 al 22. El CUIB organiza el I Seminario sobre conservación y restauración de material bibliográfico. (primera publicación del CUIB)

Julio. Por medio de los convenios e intercambio establecido con el Instituto Biblioteca Nacional de Venezuela, en el que se recibió la vi- 
sita del Ing. Jorge Fernández coordinador de informática, para intercambiar información en el área de automatización de bibliotecas. Septiembre 26 y 27. Se realiza el II Coloquio sobre Investigación Bibliotecológica: Problemas de investigación bibliotecológica, en el que se abordó la problemática de investigación en diferentes campos de la Bibliotecología; dicho evento fue organizado por la Mtra. Estela M. Morales y el Mtro. Adolfo Rodríguez.

Septiembre 28. Se lleva a cabo la mesa redonda sobre Bibliotecas públicas urbanas organizada por la Lic. Elsa M. Ramírez.

Octubre 17. El CUIB realiza la primer mesa redonda sobre la Problemática de asiento de autores personales de bibliotecas mexicanas: el impacto de la adopción del capítulo 22 de AACR-2.

Octubre 26 al 28. El Centro imparte el I Seminario sobre tecnología educativa aplicada a la bibliotecología en el que participan los investigadores del CUIB.

Octubre 28. Se desarrolla la mesa redonda sobre Estrategias didácticas para capacitación de bibliotecarios a distancia.

Octubre 28. Se organiza en el Centro la mesa redonda sobre el Estado Actual y prioridades de investigación sobre el sistema de clasificación.

Noviembre 7. Se realiza la mesa redonda sobre Bibliotecas de la Universidad: modalidades, funciones y servicios, la cual es organizada por Martha A. Añorve.

Noviembre 9. Cambios en el Consejo Interno, el cual queda integrado de la siguiente manera:

Presidente: Mtro. Adolfo Rodríguez Gallardo

Secretario: Mtra. Estela M. Morales Campos

Vocales: $\quad$ Lic. Martha A. Añorve Guillén

Mtra. Ma. Luisa Garza Ávalos

Sra. Rebeca Hernández Rangel

Lic. Elsa M. Ramírez Leyva

Lic. Ma. Trinidad Román Haza

Diciembre. Por medio de los convenios establecidos con Francia el Centro recibió la visita de la especialista Thérese Bally de la Misión Interministerial para la Información Científica y Técnica y la Dirección de Bibliotecas, Museos e Investigación Científica, para conocer 
su programa de investigación, y precisar información sobre el Catálogo Colectivo de Publicaciones Periódicas y detallar el proyecto de un Curso México-Francia en el área de la investigación científica.

Diciembre 1 y 2. El Centro organiza el Seminario sobre políticas y procedimientos de selección de Bibliotecas Mexicana.

Diciembre 8 y 9. Se efectúa la primera Reunión de Evaluación del Centro en la ciudad de la Trinidad, Tlaxcala, con el fin de evaluar las actividades realizadas y la retroalimentación correspondiente, a fin de reforzar los nuevos programas a realizar. Se llegó al acuerdo donde se reconocen buenos resultados en general, pero que con la experiencia y el esfuerzo adquirido se permitirá mejorar en los programas del CUIB, además se destacó la necesidad de evaluar las actividades trimestralmente.

\section{4}

Enero 24. El CUIB organiza la primer mesa redonda: sobre la Problemática del asiento de autores corporativos y nombres geográficos en bibliotecas mexicanas: el impacto de la adopción de los capítulos 2 y 24 de AACCR-2.

Febrero 1. Ingreso de la Lic. María del Carmen Negrete Gutiérrez como investigadora del CUIB.

Abril 12. El CUIB organiza la mesa redonda: La definición de la Biblioteca pública en México.

Junio 5 y 6. Se desarrolla en el Centro la mesa redonda: Evaluación de los programas de enseñanza de la clasificación de la Biblioteca del Congreso de los Estados Unidos.

Junio 7. Se desarrolla en el Centro la mesa redonda sobre Bibliotecas Universitarias, Organizado por Lic. Martha A. Añorve Guillén .

Junio 7. El CUIB organiza el II Encuentro sobre capacitación bibliotecaria a distancia.

Junio 6, 13, 20 y 27. El Centro organiza las conferencias sobre Automatización de bibliotecas en los países de Alemania, Inglaterra y Francia.

Junio 18 al 22. El CUIB /SECOBI-CONACYT-CICH /Embajada de Francia organizan el curso Banco de datos bibliográficos, en el que parti- 
cipan los investigadores Roberto Abell, Roberto Garduño y María Luisa Garza gracias a los convenios e intercambios establecidos con diversas instituciones nacionales y extranjeras.

Julio 26 y 27. Realización del III Coloquio sobre Investigación Bibliotecológica, La investigación bibliotecológica y su relación con el uso de modelos matemáticos, en el que participaron como ponentes los investigadores: Martha A. Añorve, Ana María Magaloni y Heshmatallah Korramzadeh, en el que destacaron el análisis de la investigación bibliotecológica que se efectúa actualmente y su relación con el uso de modelos matemáticos.

Agosto 3 al 7. El Centro organiza en el marco de la Semana de Cooperación México Francia la mesa redonda: Análisis, manejo y consulta a bancos de datos franceses.

Agosto 6 al 24. El CUIB/Organización de Estados Americanos, en su naciente programa de intercambio académico de 1984-85, realiza el primer curso: Programa para formación de investigadores en el área de bibliotecología para América Latina, en el cual se buscó como principal objetivo el formar recursos humanos capaces de desarrollar investigación dentro del área de la Bibliotecología, propias y adecuadas a las problemáticas de cada uno de sus países. Por su parte los investigadores del CUIB tuvieron reuniones de trabajo con los participantes del curso, en los cuales expusieron los principales aspectos de sus investigaciones.

Agosto 6 al 24. Por medio del Proyecto CUIB/Organización de Estados Americanos 1984-1985, se contó con la visita de investigadores de tres universidades latinoamericanas que participaron en el curso: Programa para la formación de investigadores en el área de bibliotecología para América Latina; los investigadores son: Mtra. Rocío E. Herrera de la Escuela Interamericana de Bibliotecología de la Universidad de Antioquia, Colombia; Lic. Ramón Pereyra de la Universidad Mundial Dominicana, Santo Domingo, República Dominicana; Lic. Francisco J. Bringas de la Universidad Central de Venezuela, Venezuela.

Agosto 16. La Mtra. Estela M. Morales organiza e imparte la conferencia Aspectos generales sobre la formación de bibliotecólogos en Colombia, Republica Dominicana y Venezuela. 
Septiembre 25. El CUIB organiza la I Mesa Redonda sobre la Formación Docente del Bibliotecario Profesional.

Octubre 15 al 26. Desarrollo del primer curso Formadores de Información Bibliográfica Automatizada, el cual tuvo como objetivo el proveer a los participantes de los elementos necesarios sobre los procesos involucrados en el manejo de la información bibliográfica automatizada. Este curso fue organizado por: CUIB/Estela M. Morales, Consejo Nacional de Ciencia y Tecnología/Enzo Molino y Dirección de Bibliotecas, Museos e Investigación Científica-Misión Interministerial para la Información Científica (Francia)/Roland Rebois. Este evento contó con la participación de 4 investigadores franceses: Raimundo Beca, Roland Duchase, Bruno Louchouarn y Roland Rebois; mientras que por el Centro participaron: Charlotte Bronsoiler, Rosalba Cruz, Margarita Chávez, Elena Duquer, Roberto Garduño, Armando González, Ismael González, Luis Guadarrama, Enzo Molino, Estela M. Morales, Jaime Pontigo, Luis Torres y Juan Voutssás.

Noviembre 15 al 30. Estancia académica de la Mtra. Estela M. Morales en las ciudades de Lima en Perú, Bogotá, Manizales y Medellín en Colombia con el fin de realizar estudios sobre los centros bibliotecarios y archivísticos de Perú y Colombia, así como compilar bibliografía latinoamericana en Bibliotecología, que daría origen a la integración de la base de datos INFOBILA.

Noviembre 29 y 30. El CUIB organiza la II Mesa Redonda sobre la Formación Docente del Bibliotecario Profesional. Planteamiento Curricular.

Diciembre 3 y 4. Se realiza la segunda Reunión de Evaluación del Centro en Oaxtepec, Morelos, en el que se reconoce el interés por llevar una reunión general periódica de actividades realizadas por el Centro, con el fin de contar con información objetiva que permita la retroalimentación de los resultados obtenidos para orientar los trabajos y eventos que se realizan; en general hubo consenso en cuanto a que se lograron progresos considerables, se consideró el recibir cursos de actualización sobre metodología, estadística y ciencias relacionadas con el procesamiento de datos, además de invitar a especialistas de otras áreas que guarden relación con el campo de la Bibliotecología. 
1985

Enero. El Mtro. Adolfo Rodríguez Gallardo es comisionado como Director de la Dirección General de Bibliotecas UNAM.

Enero. La Lic. E. Margarita Almada de Ascencio es comisionada como Directora del Centro de Información Científica y Humanística, UNAM.

Febrero. Asume el cargo de Directora del Centro Universitario de Investigaciones Bibliotecológicas la Mtra. Estela M. Morales Campos. En su discurso de posesión de cargo, la Mtra. Morales se comprometió a acrecentar y consolidar los logros alcanzados en los proyectos de investigación para ofrecer a la Universidad, y al país, soluciones y alternativas avanzadas en el campo de la Bibliotecología y de la Información; además de colaborar en programas de trascendencia nacional; contemplar la formación de personal académico de alto nivel y difundir las investigaciones de profesionistas y estudiantes nacionales o extranjeros.

Febrero. Cambios en el Consejo Interno, el cual quedó integrado de la siguiente forma:

Presidente: Mtra. Estela M. Morales Campos

Secretario: Lic. Elsa M. Ramírez Leyva

Vocales: Lic. Martha A. Añorve Guillén

Lic. Ma. Luisa Garza Ávalos

Sra. Rebeca Hernández R.

Dr. Heshmatallah Khorramzadeh

Lic. Ma. Trinidad Román Haza

Febrero. El Lic. Filiberto Felipe Martínez Arellano es designado Secretario Técnico en la Dirección General de Bibliotecas UNAM.

Marzo 29. Se desarrolla en el CUIB la I Reunión nacional sobre normalización del sistema de clasificación de la Biblioteca del Congreso de los Estados Unidos, el cual apoya a las bibliotecas de instituciones de Educación Superior y oficiales que tienen colecciones en derecho y los planes de estudio de la licenciatura y maestría en bibliotecología de las instituciones que ofrecen la carrera. Organizado y conducido por la investigadora Ma. Luisa Garza. 
Abril 22 al 25. Dentro del Programa de Intercambio Académico de la UNAM la Mtra. Estela M. Morales visita la Ciudad de la Habana, en la cual se firmaron los convenios de canje de publicaciones, de asesorías, de estancias de estudio, así como también cursos de formación de investigadores, posgrado y actualización.

Junio 27 a Julio 17. Visita del Mtro. Adolfo Rodríguez a los países de Argentina, Brasil y Uruguay con el fin de promover el segundo curso Programa para la formación de investigadores en el área de bibliotecología para América Latina, además de recabar información y materiales bibliográficos para la base de datos de INFOBILA.

Julio 19. Se efectúa en el Centro la II Reunión nacional sobre normalización del sistema de clasificación de la Biblioteca del Congreso de los Estados Unidos, el cual fue organizado por la Lic. Ma. Luisa Garza.

Julio 29 al 31. Se realiza el IV Coloquio sobre Investigación Bibliotecológica: Métodos y técnicas de la investigación social aplicados a la bibliotecología, el cual contó con la participación del Director del Instituto de Investigaciones Filosóficas de la UNAM, León Olivé, con la ponencia: Los valores y la investigación social. En dicha ponencia el autor afirma que los valores cognoscitivos, éticos o estéticos juegan un papel imprescindible en la investigación científica, por lo que se pone en duda si son imprescindibles en la investigación social. Agosto 2. Se desarrolla en el Centro la mesa redonda: La Biblioteca Pública en el Ámbito de la Lectura, organizado por la Lic. Elsa M. Ramírez y Ma. Trinidad Román.

Agosto 5 al 23. El CUIB organiza el segundo curso Programa para formación de investigadores en el área de bibliotecología para América Latina, el cual tuvo como objetivo general la formación de recursos humanos capaces de desarrollar investigaciones dentro del área de la Bibliotecología propias y adecuadas a la problemáticas de cada uno de los países participantes; en dicho curso participaron profesores de: Argentina, Bolivia, Brasil, Colombia, Costa Rica, Panamá, Venezuela, Paraguay y México. Cabe señalar que los investigadores del Centro tuvieron reuniones de trabajo con los participantes del curso, en las que se hizo la exposición de los principales aspectos 
de sus investigaciones, tendiendo lazos amistosos y sobre todo ampliar las relaciones de trabajo en el área bibliotecológica.

Agosto 5 al 23. Se desarrolla el segundo curso sobre Metodología de la Investigación Aplicada a la Bibliotecología el cual fue organizado por el CUIB/Organización de Estados Americanos.

Agosto 8, 13 y 15. Se desarrolla el ciclo de conferencias: La Bibliotecología en América Latina, en el que se destaca la participación de los becarios latinoamericanos asistentes al curso sobre Metodología de la Investigación, organizado por las investigadoras Estela M. Morales y Elsa M. Ramírez.

Septiembre. Ingreso del Lic. Filiberto Felipe Martínez Arellano como investigador del CUIB.

Septiembre 2 al 13. Se desarrolla el segundo curso: Formadores de Información Bibliográfica Automatizada, el cual fue organizado por el CUIB/ Embajada de Francia/Consejo Nacional de Ciencia y Tecnología. En este curso participaron dos catedráticos franceses y veinte nacionales, contando con nivel académico óptimo ya que provienen de los más importantes centros bibliotecológicos y de información de Francia y de la Republica Mexicana.

Noviembre 1 al 12. La Lic. Elsa M. Ramírez efectúa una visita por los países de Puerto Rico, Panamá y Costa Rica, con el fin de promover el curso Metodología de la Investigación que se llevara a cabo en 1986; además de seleccionar y adquirir material bibliográfico para el banco de datos INFOBILA, así como promover las publicaciones del Centro. Noviembre 7. Se desarrolla en el CUIB la mesa redonda: Las bibliotecas en la vida de México, de Carranza a nuestros días.

Noviembre 8. Se realiza la III Reunión nacional sobre normalización del sistema de clasificación de la Biblioteca del Congreso de los Estados Unidos, organizado por la investigadora Ma. Luisa Garza. Noviembre 8. El Centro organiza la conferencia el Centro Universitario de Investigaciones Bibliotecológicas para profesores del Departamento de Bibliotecología de la Universidad de Panamá. Panamá. Noviembre 26 y 27. De acuerdo a los resultados de la votación -con base al Reglamento Interno del CUIB (Cap. III, Art. II, Inciso ch)- el Consejo Interno de este Centro quedó integrado de la siguiente forma: 
Presidente: Mtra. Estela M. Morales Campos

Secretario: Lic. Elsa M. Ramírez Leyva

Vocales: $\quad$ Lic. Martha A. Añorve Guillén

Lic. Roberto Garduño Vera

Lic. Ma. Trinidad Román Haza.

Lic. Ofelia Solís Valdespino

Sra. Rebeca Hernández Rangel

Diciembre 3 y 4 . Se realizó, en la Unidad de Seminarios "Ignacio Chávez" de Ciudad Universitaria, la tercera Reunión de Evaluación del Centro; esta reunión se realiza cada año con el fin de exponer brevemente el avance de las investigaciones, la participación y asistencia del personal académico, y de hacer un balance positivo de las actividades desarrolladas por todos sus miembros. Con el análisis de estos asuntos se trató de evaluar el grado de madurez que ha alcanzado el Centro.

Diciembre 3 al 13. Como resultado del Programa de Intercambio Académico de la UNAM con el Ministerio de Educación Superior de Cuba, el Lic. Salvador Gorbea Portal visitó el Centro desarrollándose un programa de actividades con las que se intercambiaron experiencias en cuanto a la metodología de la investigación, los sistemas automatizados y bancos de datos con los que ha colaborado el CUIB; el Lic. Gorbea dictó la conferencia Educación Bibliotecológica en Cuba.

Diciembre 10. El Dr. Heshmatallah Khorramzadeh organiza la mesa redonda: Selección, evaluación y descarte de materiales bibliográficos: aproximaciones cuantitativas.

1986

Abril. El Centro organiza la IV Reunión nacional sobre normalización del sistema de clasificación de la Biblioteca del Congreso de los Estados Unidos organizado por Roberto Abell y Ma. Luisa Garza.

Abril 28 a Mayo 2. Se desarrollan las XVIJornadas Mexicanas de Biblioteconomía (AMBAC), en las que participa como organizador y moderador el Mtro. Adolfo Rodríguez Gallardo en la mesas redonda: Bibliotecas Universitarias, mesa redonda: Perspectivas de Automa- 
tización de Bibliotecas con el tema de mesa: Futuro de la Administración Bibliotecaria en México.

Mayo 28. Se reúnen en las instalaciones del Consejo Nacional de Ciencia y Tecnología los representantes legales de las instituciones y empresas involucradas en el quehacer bibliográfico, bibliotecario, de difusión documental, automatización y edición de libros, para iniciar actividades con vista a la creación de Normas Oficiales Mexicanas en el campo del manejo documental. Como resultado de esta reunión se formó el Comité Consultivo de Normalización en Documentación el cual quedó estructurado conforme a lo previsto en la Ley General de Normas del 7 de Abril de 1961 y su reglamento dispuesto en el Manual de Operaciones de los Comités Consultivos de Normas, quedando constituido por miembros de las siguientes instituciones: CUIB-UNAM, Consejo Nacional de Ciencia y Tecnología, Instituto de Investigaciones Eléctricas, Secretaria de Comercio y Fomento Industrial, Data Consult y la Asociación Mexicana de Bibliotecarios A.C.

Agosto. Publicación del primer número de la revista semestral Investigación Bibliotecológica: archivonomía, bibliotecología e información editada por el CUIB, UNAM, la cual tiene como primer director a la Mtra. Estela M. Morales Campos. En su primer número la revista incluye: informes de investigaciones, terminadas o en proceso, artículos sobre los temas derivados de la formación académica y la actividad docente de nuestros investigadores que propician el conocimiento sobre Bibliotecología e Información.

Agosto 4 al 22. El CUIB/Organización de Estados Americanos organizan el tercer curso sobre el Programa para formación de investigadores en el área de Bibliotecología para América Latina, el cual contó con la participación de profesores de Argentina, Bolivia, Brasil, Colombia, Cuba, Costa Rica, Guatemala, Nicaragua, Panamá, Paraguay, Perú, Uruguay y México. Como finalidad de este evento se impuso la investigación entre los asistentes para proporcionarles una visión de las principales características de la metodología y técnica de la investigación social y su aplicación en los problemas de la Bibliotecología. Agosto 8, 13 y 15. Se desarrolla en el Centro el Ciclo de conferencias sobre investigación, educación, servicios y procesos bibliotecológicos 
y de información en América Latina, en el cual destaca la participación de un nutrido número de profesores latinoamericanos. Agosto 25 al 26. Se realiza en el CUIB el V Coloquio sobre Investigación Bibliotecológica, el cual contó con la destacada participación del Dr. Reynaldo Ayala bibliotecario de la Universidad de San Diego con la ponencia: Perspectivas de un Investigador. En este coloquio se buscó enriquecer las metodologías empleadas en las investigaciones de campo de la Bibliotecología y Ciencia de la Información; además de conocer las experiencias en el área y la difusión de los resultados de las investigaciones de la especialidad.

Septiembre. Por medio del convenio establecido con España, el Centro recibió la visita del Lic. Francisco Herránz Navarra quien trabaja en la Biblioteca de la Universidad de Granada como Jefe de la Biblioteca de Biblioteconomía y Documentación. Durante el tiempo que permaneció en el Centro observó el funcionamiento y conoció las investigaciones del mismo; entre otras actividades tuvo las de visitar centros de información, estudiar los programas de Bibliotecología de la escuelas y compararlas con los sistemas europeos; además asistió al curso Formadores de Información Bibliográfica Automatizada; asimismo, el Centro le proporcionó apoyo de infraestructura y le contactó diferentes visitas de interés.

Septiembre. Por medio del convenio firmado con Cuba, el Centro recibió la visita de la Dra. María Elena Dorta-Duque de la Universidad de la Habana y de la Oficina Regional de Cultura de la Organización de las Naciones Unidas para la Ciencia, la Educación y la Cultura para América Latina y el Caribe. Su estancia se gestionó con la finalidad de elaborar un plan de trabajo de investigación para optar al grado de doctor en Bibliotecología, por lo que el Centro le proporcionó un asesor en su tesis, adiestramiento a través de cursos y apoyo de infraestructura. El título tentativo de su tesis fue: Lenguaje de búsqueda informativa.

Octubre. Las investigadoras Estela M. Morales y Elsa M. Ramírez organizan la conferencia sobre el Programa de la biblioteca española, destacándose la participación del becario español Francisco Herranz. Octubre 6 al17. El CUIB/ Consejo Nacional de Ciencia y Tecnología/ Centro Científico Francés organizan el tercer curso Formadores de 
Información Bibliográfica Automatizada. En esta ocasión se contó con la asistencia de profesores de diversos países como: Panamá, Nicaragua, España y Cuba, entre otros; además se recibió la colaboración de dos profesores franceses Anne Garard y Roland Rebois.

Octubre 9. Cambios en el Consejo Interno, el cual quedó integrado de la siguiente manera:

Presidente: Mtra. Estela M. Morales Campos

Secretario: Lic. Elsa M. Ramírez Leyva

Vocales: $\quad$ Lic. Martha A. Añorve Guillén

Lic. Roberto Garduño Vera

Lic. Ma. Trinidad Román Haza

Dr. Heshmatallah Khorramzadeh

Srita. Verónica Ortega Hernández

Octubre 20 al 31. Por medio de los convenios establecidos con Gran Bretaña, y en este caso gracias al Consejo Británico, la Mtra. Estela M. Morales visitó diferentes lugares de la Gran Bretaña con el fin de establecer programas de colaboración en investigación y promover actividades que se llevan a cabo en el Centro.

Noviembre. El Centro organiza la I Reunión del Comité de Análisis sobre clasificación del Congreso de los Estados Unidos, el cual estuvo organizado por el Mtro. Roberto Abell.

Noviembre 1. Ingreso de la Lic. Rosa María Fernández Esquivel como investigadora del CUIB.

Noviembre 12 al 14. El CUIB/Asociación de Bibliotecarios de Instituciones de Enseñanza Superior y de Investigación desarrollan el Seminario de ABIESI. El impacto de la crisis en las bibliotecas de enseñanza superior investigación, el cual fue organizado por las investigadoras Estela M. Morales, Elsa M. Ramírez y la Directiva de ABIESI.

\section{7}

Marzo 2 al 6. Co-organización del CUIB-Asociación Mexicana de Bibliotecarios A.C. para la realización de las XVIIIJornadas Mexicanas de Biblioteconomía, celebradas en el auditorio Simón Bolívar en el antiguo edificio de la Escuela Nacional Preparatoria; esto como respuesta del programa de colaboración con otros organismos, en esta 
ocasión están presentes en la Mesa Directiva de la AMBAC los investigadores más sobresalientes del Centro: Estela M. Morales como Vice-presidente, Enrique Molina como Tesorero, José Adolfo Rodríguez como Consejero Técnico, Maria Concepción Barquet como presidenta y vocal de la Comisión de Elecciones. En dichas Jornadas se desarrollaron las ponencias: I. El desenvolvimiento de la tecnología y su influencia en el concepto de la biblioteca del siglo XX y II. La promoción de la bibliotecas públicas en el año 2000; el Panel: Las bibliotecas universitarias. Los retos a los que se enfrentarán en el siglo XXI; y la mesa redonda: Legislación Bibliotecaria.

Mayo. A partir de este mes se le denomina Novedades Bibliotecológicas a las tablas de contenido de publicaciones periódicas que ingresan a la biblioteca del CUIB e información que llega ocasionalmente del banco del libro de Venezuela, sobre reseñas de libros y/o artículos de revistas; así como, el calendario sobre reuniones profesionales que aplica la Dirección General de Bibliotecas o algún otro tópico de interés. A partir de este mismo mes este servicio se extendió a otras instituciones como: a la Dirección General de Bibliotecas de la UNAM, al Centro de Investigación Científica y Humanística, a las dos escuelas de Bibliotecología de la Ciudad de México, además de la maestría.

Mayo 8. Se realiza la primera ponencia del Seminario de Investigación en el cual los investigadores inscritos al programa Formación de investigadores expondrán a lo largo del año el avance de sus investigaciones y de trabajos de tesis respectivamente. De los 18 seminarios, tres se destinaron a la presentación de proyectos de tesis a nivel licenciatura, uno a nivel maestría, así como dos informes sobre viajes de estudio a Brasil, Venezuela y España.

Junio 16. Cambios en el Consejo Interno, el cual quedó integrado de la siguiente manera:

Presidente: Mtra. Estela M. Morales Campos

Secretario: Lic. Elsa M. Ramírez Leyva

Vocales: $\quad$ Lic. Martha A. Añorve Guillén

Lic. Roberto Garduño Vera

Lic. Ma. Trinidad Román Haza

Lic. Ofelia Solís Valdespino

Sra. Verónica Ortega Hernández 
Junio 16. Dentro del desarrollo del Consejo Interno del CUIB en esta fecha destaca, dentro de otras actividades, la de iniciar las pláticas con miras a la elección de los 16 representantes responsables de la organización del Congreso Universitario. También el Consejo supervisó y coordinó las elecciones del 3 de diciembre para elegir a los representantes de los investigadores ante la Comisión Organizadora del Congreso Universitario.

Junio 27. El Centro desarrolla la II Reunión del Comité de Análisis sobre la clasificación del Congreso, el cual fue organizado por los investigadores Roberto Abell y Filiberto Felipe Martínez Arellano.

Septiembre 3 y 4. Se desarrolla el VI Coloquio de Investigación Bibliotecológica. En esta ocasión se realizan tres paneles en donde participaron profesionales de diferentes disciplinas; éstos estuvieron organizados y coordinados por investigadores del CUIB especialistas en el tema, de los cuales destacaron los temas sobre: I. Formación de lectores, II. Normalización y problemas de frontera de investigación, y III. La clasificación en las bibliotecas mexicanas: inecesidad del usuario o fastuosidad del bibliotecólogo?.

Septiembre 8. Se desarrolla en el Centro la mesa redonda El papel de los Comités de las de la Bibliotecas Universitarias en la selección de materiales bibliotecológicos, el cual contó con la planeación, organización y conducción de la Lic. Ma. del Carmen Negrete.

Octubre 13 al 30. Se realiza el cuarto curso internacional Formadores de Información Bibliográfica Automatizada. En dicho curso se estableció como objetivo el proporcionar a los asistentes los conceptos y elementos que constituyen las partes esenciales en el diseño, producción, análisis, manejo y uso de sistemas automáticos de información bibliográfica. Este curso contó con la participación de profesores de: Uruguay, Cuba, Guatemala y Venezuela, en el ámbito internacional; mientras que en lo nacional se contó con la participación de profesores de distintas universidades de la República Mexicana, además de contar con la participación de profesionales de instituciones de educación superior e investigación como son: la UNAM, Instituto Politécnico Nacional, Secretaría de Educación Pública y Consejo Nacional de Ciencia y Tecnología. 
Octubre 13 al 30. Dentro de los convenios establecidos entre el CUIB y la Organización de Estados Americanos, se le otorgó la beca de inscripción al cuarto curso internacional Formadores de Información Bibliográfica Automatizada a la Lic. María Cristina Aguilar Salvatore de la Universidad de la República de Uruguay, y al Lic. Álvaro Agudo del Banco del Libro de Venezuela.

Octubre 28. El Centro desarrolla el curso Formatos internacionales de intercambio de información bibliográfica, el cual fue impartido por el investigador Roberto Garduño.

Noviembre 30. Publicación del libro coeditado entre el CUIB-UNAM /Secretaría de Educación Publica titulado: Directorio de bibliotecas de universidades oficiales de la República Mexicana, esta obra fue escrita por la investigadora Martha Alicia Añorve Guillén.

Noviembre 30 a Diciembre 4. Estancia académica de la Mtra. Estela M. Morales y la Lic. Elsa M. Ramírez a la ciudad de San José de Costa Rica como resultado de los convenios establecidos con la Organización de Estados Americanos para proseguir con los programas de cooperación con otras universidades; asisten como ponentes al II Simposio Internacional: La biblioteca ante el año 2000. Realizado por la Universidad de dicha ciudad. Además participan, en el marco del simposio, en reuniones de trabajo con algunos de los participantes del segundo y tercer curso de adiestramiento de investigadores en Bibliotecología, contando con la participación de investigadores de América Latina.

\section{8}

Marzo 20. Por medio del convenio establecido entre México y Cuba la Lic. Marta A. Añorve Guillén fue a participar como ponente en el 1er Taller de Bibliotecas Universitarias de América Latina y el Caribe, organizados por la Universidad de la Habana, Cuba y como participante en el curso Dirección de Bibliotecas Universitarias durante la primera semana de Abril.

Marzo 6. La Mtra. Estela M. Morales Campos organiza la mesa redonda: Las obras de consulta mexicanas; sus usuarios y sus editores, en la Feria Internacional del Libro. AMBAC. 
Abril. Cambios en el Consejo Interno, el cual quedó integrado de la siguiente manera:

Presidente: Mtra. Estela M. Morales Campos

Vocales: $\quad$ Lic. Elsa M. Ramírez Leyva

Mtro. Adolfo Rodríguez Gallardo

Lic. Ma. del Carmen Negrete Gutiérrez

Abril 15. La Lic. Martha Añorve imparte en el marco del Seminario de Investigación su informe sobre el 1er Taller de Bibliotecas Universitarias de América Latina.

Mayo 17. Se realiza la primera junta con todo el personal académico y administrativo, la que llevó a cabo en las instalaciones del Consejo Interno Ampliado para la conducción de los Seminarios de Diagnóstico, el cual quedó integrado por:

Consejo Interno:

Presidente: Mtra. Estela M. Morales Campos

Secretaria: Lic. Elsa M. Ramírez Leyva

Vocales: Mtro. Roberto Abell Benett

Lic. Martha A. Añorve Guillén

Lic. María Trinidad Román Haza

Lic. Zuemi A. Solís Rivero

y por el personal elegido para apoyar en la organización y conducción de los Seminarios:

Académico: Lic. María del Carmen Negrete

Sra. Verónica Ortega

Administrativo: Srita. Eréndira Álvarez

Mayo 23. Se integra la comisión encargada de elaborar el reglamento de funcionamiento del Seminario de Diagnóstico, la cual fue conformada por: Lic. Ma. del Carmen Negrete, Lic. Ofelia Solís, Zuemi A. Solís y la Srita. Eréndira Álvarez.

Junio 8. Desarrollo del Seminario de Diagnóstico del Centro, en el que se presentaron las ponencias inscritas y de acuerdo al tema fueron organizadas de la siguiente manera:

Tema I: Reflexiones Generales sobre la Dependencia:

- Participación de los Centros de Investigación en el Consejo Universitario. 
Centro Universitario de Investigaciones Bibliotecológicas. Cronología ...

- Vinculación del Artículo 51 del Estatuto del Personal Académico: El caso del CUIB.

- La Biblioteca en la vida académica del Centro Universitario de Investigaciones Bibliotecológicas.

- El personal administrativo (sindicalizado) y sus condiciones de trabajo.

- Una apreciación sobre las funciones sustantivas de la Dependencia.

Tema II: Reflexiones Generales sobre la Universidad:

- Crecimiento, financiamiento e investigación.

Julio 20. Se inicia el empacado del material de la biblioteca por motivo del cambio de domicilio del CUIB a la Torre II de Humanidades en Ciudad Universitaria. El servicio normal para los usuarios externos se reanudó hasta el 26 de septiembre, utilizando este tiempo en la mudanza y en poner en servicio los libros que donó la Dirección General de Bibliotecas, así como para reacomodar y dar un nuevo orden alfabético a las tarjetas del kardex y los fascículos de publicaciones periódicas.

Agosto. La Lic. Elsa M. Ramírez Leyva a solicitud de la Escuela de Bibliotecología de la Universidad Centroamericana de Nicaragua fue a impartir el curso Estudio de Usuarios, además de ofrecer una conferencia.

Octubre 17 al 22. Por medio del convenio establecido entre México y Cuba, la Mtra. Estela Morales Campos fue invitada a ese país a participar como ponente y asistente al evento Info 88: Congreso Internacional de Información Científica y Técnica organizado por la Academia de Ciencias de la Habana.

Octubre 17 al 28. Realización del quinto curso Formadores de Información Bibliográfica Automatizada teniendo como objetivos principales el proporcionar a los asistentes los conceptos y elementos que constituyen las partes esenciales en el diseño, producción, análisis y manejo de bancos de datos de información bibliográfica, así como de los sistemas de recuperación automatizada de la información. En este curso participaron profesores de: Cuba y Nicaragua; así como diferentes entidades de la República Mexicana, entre las que se encuentran de: Guadalajara, Guanajuato, Nuevo León, San Luis Po- 
tosí y Toluca. También asistieron profesionales de nuestra Universidad y otras dependencias e instituciones del Distrito Federal. Cabe mencionar que en este curso se logró un convenio con el Consejo Nacional de Ciencia y Tecnología para proporcionarle becas a tres profesores de escuelas de Bibliotecología del país, además de las 18 becas de inscripción proporcionadas por este Centro a diferentes instituciones del país.

Octubre 17 al 28. El Centro recibió la visita de la Lic. Silvia Forzarate, la cual fue becada para participar en el $V$ Curso Formadores de Información Bibliográfica Automatizada gracias al convenio de Intercambio Académico establecido entre México y Cuba.

Octubre 28. El Rector de la Universidad el Dr. Jorge Carpizo y el coordinador de humanidades el Dr. Humberto Muñoz declararon oficialmente inauguradas las nuevas instalaciones del Centro, que consta de 18 cubículos de investigador, área para biblioteca, cómputo, publicaciones, difusión, cursos y administración.

Octubre 28. La Mtra. Estela Morales ofrece un discurso por motivo del nuevo cambio de instalaciones, de San Ildefonso a Torre II de Humanidades, en una reunión que contó con la presencia de las autoridades, colegas, amigos y compañeros. En dicho discurso utilizó cuatro palabras que están presentes en toda festividad: los recuerdos, el añorar, desear y reflexionar. Ella recordó los antecedentes del Centro cuando iniciaron las investigaciones bibliotecológicas en la Dirección General de Bibliotecas, la cual sería la base del personal que conformarían posteriormente al CUIB; añoró cómo en esas instalaciones de San Ildefonso se cuestionaron el ser y quehacer de la Bibliotecología; su primer deseo fue el de aprovechar al máximo nuestras capacidades y los recursos humanos, físicos y financieros para cumplir plenamente con nuestras funciones, además de promover el trabajo interdisciplinario y apoyar a otros organismos fuera de la UNAM, y por último, deseó el mejorar los recursos tanto en calidad como en cantidad; y en la parte de las reflexiones pidió contar con un espacio especifico para realizar con todo rigor científico la investigación bibliotecológica.

Noviembre. Publicación del libro coeditado entre el CUIB-UNAM /Instituto Nacional de Bellas Artes/ Secretaría de Educación Pública 
Centro Universitario de Investigaciones Bibliotecológicas. Cronología ...

titulado: Hacia una bibliografía en castellano del Cine, esta obra fue escrita por Helena Almoina Fidalgo.

Noviembre 7 al 11. El CUIB, la Biblioteca Benjamín Franklin y la Embajada de los Estados Unidos organizan el Seminario Acceso a la información en Bibliotecas Universitarias, el cual fue impartido por el Mtro. Roberto Seal. Este seminario se logró gracias al convenio establecido entre el Centro y la Embajada de Estados Unidos.

\section{9}

Enero 13. Publicación del libro coeditado entre el CUIB-UNAM/Asociación Nacional de Universidades e Instituciones de Educación Superior titulado: Manual para obtener indicadores como apoyo a la evaluación de servicios bibliotecarios en instituciones de educación superior, esta obra fue escrita por el investigador Rafael Pagaza García con la colaboración de Víctor M. Valdovinos Luna.

Enero 13. Publicación del libro coeditado entre el CUIB-UNAM/ Asociación Nacional de Universidades e Instituciones de Educación Superior titulado: Manual para evaluar la satisfacción de usuarios en bibliotecas de instituciones de enseñanza superior de la República Mexicana, esta obra fue escrita por el investigador José Alfredo Verdugo Sánchez.

Febrero. La Mtra. Estela M. Morales Campos es nombrada Bibliotecaria Mexicana del Año en el Segundo Encuentro Nacional de Profesores y Estudiantes de Bibliotecología celebrado en la Escuela de Bibliotecología del Centro Regional Universitario de Veragua y la Asociación Latinoamericana de escuelas de Bibliotecología y Ciencias de la Información de Veragua, Panamá.

Marzo 3. Se desarrolla en el marco del Seminario de Investigación la ponencia Bases de datos bibliográficas elaboradas en México.

Julio 20 y 21. El CUIB realiza el VII Coloquio de Investigación Bibliotecológica que tuvo como objetivos el intercambiar experiencias en temas bibliotecológicos que son estudiados en el Centro y en otras dependencias e instituciones, además de temas que inciden en la temática bibliotecológica; de este modo se enriquece el trabajo de las investigaciones del Centro y de otras disciplinas. En dicho coloquio se 
presentaron tres mesas redondas con los siguientes investigadores participantes: Estela M. Morales, organiza y conduce la mesa: Legislación Bibliotecaria; María del Carmen Negrete, organiza y conduce la mesa: Selección de materiales documentales; Elsa M. Ramírez organiza y Ramiro Lafuente participan en la mesa: La biblioteca publica en México: ¿una utopía?

Agosto 1. La investigadora Catalina Naumis Peña es comisionada como Secretaria Propietaria de la Mesa Directiva del Colegio Nacional de Bibliotecarios.

Septiembre 7. Ingreso de la Lic. Patricia Hernández Salazar como investigadora del CUIB.

Septiembre 22. Se organiza en el marco del Seminario de Investigación la ponencia Vocabularios controlados para el banco de datos INFOBILA.

Octubre. Cambios en el Consejo Interno, el cual quedó integrado de la siguiente manera:

Presidente: Mtra. Estela M. Morales Campos.

Secretaria: Lic. Elsa M. Ramírez Leyva.

Vocales: $\quad$ Mtro. Roberto Abell Benett.

Lic. Martha A. Añorve Guillén.

Lic. Roberto Garduño Vera.

Lic. Eduardo Salas Estrada.

Lic. Zuemi A. Solís Rivero.

Octubre. Se designa a la Mtra. Estela M. Morales Campos como Investigador Nacional Nivel II en el área de Humanidades por el Sistema Nacional de Investigadores. SEP/Consejo Nacional de Ciencia y Tecnología.

Octubre 2 al 13. El Centro realizó los trámites necesarios para que a través de la Dirección General de Intercambio Académico viniera el Dr. Eramis de la Cruz Bueno Sánchez a impartir el curso sobre Metodología científica de la investigación, el cual fue orientado a investigadores y técnicos académicos de este Centro inscritos en el Programa de Formación de Investigadores. El objetivo del curso fue: hacer una presentación de diversos aspectos concernientes a la fundamentación teórica de la metodología de la investigación científica. En dicho curso se trataron los siguientes temas: I. Discusión de 
la problemática de la metodología de la investigación científica; II. Los componentes de la investigación; III. Representatividad científica; IV. Abstracción e idealización, modelación y modelos; V. Información e investigación científica; VI. La formación como objeto de investigación, entre otros.

Octubre 9 y 10. El Colegio Nacional de Bibliotecarios organiza el Primer Seminario Nacional de Bibliotecarios Titulados de México, en el que participan: la Mtra Estela Morales con la ponencia: Status, imagen e identidad del bibliotecario; Lic. José Alfredo Verdugo con la ponencia: Consideraciones sobre el bachillerato técnico en Biblioteconomía en México; mientras que Filiberto Felipe Martínez Arellano, José Adolfo Rodríguez y Eduardo Salas participan en la mesa redonda: La técnica de la información: un reto para la formación de recursos bumanos.

Octubre 16 al 27. El CUIB, Dirección General de Intercambio Académico y Consejo Nacional de Ciencia y Tecnología organizan el sexto curso Formadores de Información Bibliográfica Automatizada. En dicho curso se contó con la participación de investigadores de varias universidades del país además de participantes de otras instituciones interesadas en este curso, gracias al apoyo recibido de la Dirección General de Intercambio Académico. La universidades invitadas fueron: Universidad Autónoma de Colima, Universidad Autónoma de Chihuahua, Universidad Autónoma de Hidalgo, Universidad Autónoma de Puebla, Universidad Autónoma de San Luis Potosí, Universidad Autónoma de Yucatán, Universidad Autónoma de Zacatecas, Universidad Guadalajara, Universidad de Sonora y la Universidad de San Nicolás de Hidalgo, Michoacán. Mientras que las instituciones a las que se les otorgaron las becas fueron: Centro de Estudios sobre la Universidad, Centro de Estudios Superiores de la CTM, Centro de Información Científica y Humanística, Centro de Investigaciones Interdisciplinarias en Humanidades, El Colegio de México, Escuela Nacional de Biblioteconomía y Archivonomía, Dirección General de Bibliotecas, Dirección General de Cómputo Académico, Instituto de Investigaciones Filosóficas, Unidad de Bibliotecas de Investigación Científica, Universidad de Guadalajara, Universidad de San Luis Potosí, Universidad de Nuevo León y la Universidad de Sonora; además de dos invitadas latinoameri- 
canas: La Lic. Olga María Rodríguez de la Universidad de Costa Rica y la Lic. María Cristina Ego-Aguirre de la Universidad del Pacífico de Perú. Noviembre 6. Se le otorga a la Mtra. Estela M. Morales Campos la Medalla Gabino Barrera del nivel de posgrado en el Anfiteatro Simón Bolívar del Antiguo Edificio de San Ildefonso.

\section{0}

Se designa a la Mtra. Rosa María Fernández Esquivel como Investigador Nacional Nivel I por el Sistema Nacional de Investigadores.

Enero 14. Cambios en el Consejo Interno, el cual quedó integrado de la siguiente manera:

Presidente: Mtra. Estela M. Morales Campos.

Secretaria: Lic. Elsa M. Ramírez Leyva.

Vocales: $\quad$ Mtro. Roberto Abell Benett.

Lic. Martha A. Añorve Guillén.

Lic. Roberto Garduño Vera.

Lic. Eduardo Salas Estrada.

Lic. Zuemi A. Solís Rivero.

Enero 15 a Febrero 28. El Consejo Interno tuvo un intenso trabajo con miras a la realización del Congreso Universitario, por lo cual la Comisión Organizadora del Congreso Universitario acordó la ampliación de los Consejos Internos y estableció los procedimientos respectivos para la elección de los representantes; los cuales fueron elegidos para organizar: el Foro Local, emitir convocatoria, presidir cada una de las mesas de debate, nombrar integrantes del Comité Electoral Local; llevar a cabo las elecciones de los presidentes de debates, insacular a los miembros responsables de las casillas para la elección de delegados al Congreso y preparar las actas con los resultados de la elección de candidatos al Congreso.

Febrero 19. Se emite la Convocatoria Local del CUIB para la Elección de Delegados al Congreso, se registraron para tal efecto tres miembros del área de la Investigación:

- Lic. Roberto Garduño

- Lic. Ramiro Lafuente

- Lic. Eduardo Salas 
Centro Universitario de Investigaciones Bibliotecológicas. Cronología ...

De estos tres candidatos los que obtuvieron el mayor número de votos y por lo tanto ganadores de esta contienda electoral fueron: Lic. Roberto Garduño con 21 sufragios a favor, delegado que participó en la Mesa 11 Patrimonio, Financiamiento y Presupuesto; mientras que al Lic. Ramiro Lafuente le correspondieron 19 sufragios a favor, quien participó en la Mesa 2 Formación Académica y Profesiones. Además, el Lic. Garduño fue designado miembro de la Comisión de Información, su actividad consistió en la edición del Diario del Congreso, en el que se daban a conocer las propuestas que surgieron en cada una de las mesas de trabajo.

Febrero 26 y 27, y Marzo 1. El CUIB realiza el Foro Local de la Dependencia en el que se discutirán las bases para el Consejo Universitario, en el que se presentaron cuatro mesas con las siguientes ponencias: Mesa I: La evaluación de la investigación en el contexto de la ciencia, La investigación bibliotecológica y su realización en el sector productivo, Algunas consideraciones sobre investigación y docencia, Investigación y estudio de postgrado; Mesa II: La investigación: su uso y destino, El técnico académico, la investigación y la reforma universitaria, Puntos de vista sobre la formación de investigadores, El programa de formación de investigadores del Centro Universitario de Estudios Bibliotecológicos y el departamento de apoyo a la investigación; y Mesa III: Universidad y sociedad: la universidad del futuro, La crisis económica y sus efectos en las instituciones de educación superior, Las formas de ingreso, promoción y estabilidad laboral: algunos comentarios y El sistema bibliotecario de la UNAM y su proyecto de reglamento general.

Abril. La Mtra. Rosa María Fernández Esquivel es designada Coordinadora de la Biblioteca Nacional UNAM.

Mayo. Por motivo del VIII Coloquio de Investigación Bibliotecológica la Dirección General de Intercambio Académico y el Centro firman un acuerdo en el que se le otorgó el apoyo de estancia para participantes del mismo, ya que en esta ocasión fueron invitados especialistas de varios países de América Latina como: Saray Córdoba de la universidad de Costa Rica; Emilio Setién de la Universidad de la Habana, Cuba; Ofelia Aguilar de la Universidad de San Carlos Guatemala; Alicia López de la Universidad Centroamericana de Managua, 
Nicaragua y Ana Ma. Cherro de la Universidad de la Republica del Uruguay. Cabe hacer mención que la nicaragüense Alicia López, también fue apoyada por esta institución para participar en el curso Formadores de Información Bibliográfica Automatizada.

Mayo 2 al 4. Como parte de la colaboración del Centro con asociaciones profesionales de bibliotecarios se le brindó el apoyo a la Asociación Mexicana de Bibliotecarios A.C. y la Dirección General de Bibliotecas de la UNAM en la organización de las XXIJornadas Mexicanas de Biblioteconomía, las que se efectuaron en el Auditorio "Alfonso Caso" de Ciudad Universitaria, este evento fue organizado por la Lic. Ma. Concepción Barquet, la Mtra. Estela M. Morales y el Mtro. Adolfo Rodríguez Gallardo.

Mayo 7. El CUIB-USIS organizan el Seminario de nuevas tecnologías en la educación bibliotecológica, en el que participa un nutrido número de miembros del Centro.

Junio 18 al 21. Se desarrolla el curso La clasificación de documentos: aspectos normativos impartido por el CUIB, siendo este el primero de tres que se impartieron para investigadores de otras universidades de acuerdo al programa de Intercambio Académico establecido con otras instituciones del país. En este primer curso participaron: Rosa Ma. Rodríguez González de la Universidad Autónoma de San Luis Potosí y Lubia Arias González de la Universidad Juárez Autónoma de Tabasco.

Junio 21. Se designa al Mtro Adolfo Rodríguez Gallardo como Miembro de la Coordinación de la Red Nacional de Bibliotecas de Instituciones de Educación Superior, Asociación Nacional de Universidades e Instituciones de Educación Superior.

Junio 25 y 26. El CUIB realiza el VIII Coloquio de Investigación Bibliotecológica, el cual fue apoyado por la Organización de Estados Americanos a través del Proyecto de Adiestramiento de Investigadores para facilitar la estancia otorgándoles becas a de tres investigadores latinoamericanos: Rocío Herrera Cortés de la Universidad de Antioquia, Colombia; Zayda Sequeira Ortiz de la Universidad de Costa Rica y Francisco Javier Bringas de la Universidad Central de Venezuela.

Junio 27 y 28. Se desarrolla un ciclo de conferencias en el marco del VIII Coloquio de Investigación Bibliotecológica, el cual es organiza- 
do por la Mtra. Estela M. Morales y la Lic. Elsa M. Ramírez presentándose las siguientes ponencias: Antecedentes y perspectivas de las bibliotecas públicas en: Costa Rica, Cuba, Uruguay y Venezuela y Metodología de la Investigación.

Junio 27 y 28. Se desarrolla el ciclo de mesas redondas en el marco del VIII Coloquio de Investigación Bibliotecológica, el cual es organizado por la Mtra. Estela M. Morales y la Lic. Elsa M. Ramírez presentándose las siguientes mesas: La asignatura de bibliotecas públicas en la licenciatura de bibliotecología y La teoría de la organización bibliográfica.

Junio 29. La Mtra. Estela M. Morales organiza y conduce el Seminario de Investigación Bibliotecológica, el cual se llevó a cabo en las instalaciones del CUIB y contó con la participación de investigadores de distintas universidades de América Latina como: Cuba, Costa Rica, Colombia, Guatemala, Nicaragua, Uruguay y Venezuela.

Julio 1. Se designa a la Mtra. Jane Margaret Russell Barnard como Investigador Nacional Nivel I por el Sistema Nacional de Investigadores.

Julio 12. Presentación de la Mtra. Rosa Ma. Fernández en el programa "Hoy Mismo" y el Canal 9 de televisión abierta en el que habla sobre: La exposición de José Ma. Velasco en la Biblioteca Nacional; esto responde a las actividades de difusión que desarrolla el Centro a lo largo de todo el año, en el que se participa en diferentes medios de comunicación como programas de T.V., radio y prensa con el fin de difundir las actividades, información de objetivos, áreas de investigación y proyectos que se realizan en el Centro que deben ser conocidos por la comunidad bibliotecaria.

Septiembre 3 al 14. Por medio del apoyo que presta el CUIB a otras instituciones, la Lic. Emma Norma Romero imparte el curso Introducción a la Clasificación de Mevil Dewey, el cual fue impartido en la Biblioteca del Congreso.

Octubre 15 al 26. El CUIB organiza el séptimo curso Formadores de Información Bibliográfica Automatizada, el cual contó con la participación de distintos ponentes de varias universidades de la República Mexicana; cabe señalar que para este curso la Dirección General de Intercambio Académico del Centro otorgó becas de estancia para diez 
profesores invitados de las universidades: Gustavo Barrera Leos de la Universidad Autónoma de Coahuila, Ma. Georgina Carvajal Santillán de la Universidad de Colima, Magnolia Solís López de la Universidad Autónoma de Chiapas, Martina Patricia Flores de Martínez de la Universidad Juárez del Estado de Durango, Rosalía del Carmen Macías de Villar de la Universidad de Guanajuato, Raúl Javier Moya Cantú de la Universidad Autónoma de Nuevo León, Cervando Javier López Meraz de la Universidad Autónoma de San Luis Potosí, Olivia Carrillo Macías de la Universidad Autónoma de Sinaloa, Rosa Virginia Gómez Sánchez de la Universidad Juárez Autónoma de Tabasco y Ma. Alejandra López Márquez de la Universidad Autónoma de Tlaxcala.

Noviembre 12 al 14. Se imparte en el Centro el curso Los formatos internacionales de intercambio de información bibliográfica automatizada y su función en el control bibliográfico.

Diciembre 4 al 8. Participación de la Mtra. Estela M. Morales como ponente en la $9^{a}$ Reunión Interamericana de Bibliotecarios y Documentalistas Agrícolas en Costa Rica. La participación de la Mtra. Morales en este encuentro fue apoyada por la Organización de Estados Americanos, la cual le otorga la beca de estancia en dicho evento gracias a los convenios firmados entre el Centro y dicha institución.

Diciembre 5. Se comisiona al Mtro. Rodolfo Rodríguez Gallardo como Secretario del Consejo del Sistema Bibliotecario de la UNAM.

\section{1}

Febrero 4 al 8. Como resultado de los convenios e intercambios establecidos entre el Centro y países latinoamericanos, la Lic. Elsa M. Ramírez participó en el Tercer Encuentro Nacional de Profesores y Estudiantes de Bibliotecología. Tendencias de la Investigación Bibliotecológica en la Universidad de Panamá, Varaguas, Panamá; en la que dictó dos conferencias sobre: La formación de recursos bumanos y Asociaciones de Bibliotecología.

Abril. Se designa al Mtro. Filiberto Felipe Martínez Arellano como Investigador Nacional Nivel I por el Sistema Nacional de Investigadores. 
Abril 3 al 26. Como resultado de los convenios e intercambios establecidos con países latinoamericanos el Centro recibió la Estancia de Investigación del Ing. José Antonio Araujo del Centro Nacional de Investigaciones Científicas / Ministerio de Educación Superior de Cuba, en la que se le asesoró y coordinó el desarrollo de su proyecto titulado: Modelo de catalogación y clasificación asistido por computadora.

Abril 20. Cambios en el Consejo Interno, el cual quedó integrado de la siguiente forma:

Presidente: Mtra. Estela M. Morales Campos.

Secretaria: Lic. Elsa M. Ramírez Leyva.

Vocales: $\quad$ Lic. Martha A. Añorve Guillén.

Lic. Ma. del Carmen Negrete.

Lic. Eduardo Salas Estrada.

Lic. Emma Norma Romero Tejeda.

Mayo 28. La Lic. Elsa M. Ramírez y la Lic. Zuemi A. Solís organizan la conferencia El CUIB y su programa de vinculación-docencia.

Junio. Participación de la investigadora María del Carmen Negrete Gutiérrez en la organización de la Primera Asamblea General Ordinaria del Colegio Nacional de Bibliotecarios, organizada bajo los auspicios de la UAM-Unidad Azcapotzalco.

Julio 1. Se designa al Mtro. José Adolfo Rodríguez Gallardo como Investigador Nacional Nivel I por el Sistema Nacional de Investigadores.

Julio 15 y 16. Se realiza el IX Coloquio de Investigaciones Bibliotecológicas, el que tuvo como objetivo discutir y profundizar las múltiples y diversas aseveraciones sobre la formación del usuario de la información a diferentes niveles. Las pláticas ahondaron en interrogantes que mostraron la situación actual de las aristas más sobresalientes de las investigaciones bibliotecológicas. En esta ocasión se presentaron tres mesas redondas con los siguientes títulos: Terminología: necesidades de elaboración de instrumentos léxico-gráficos en español, organizada y moderada por la Lic. Blanca Castañón; Situación actual y perspectivas de las bases de datos bibliográficas mexicanas, organizada y moderada por el Lic. Roberto Garduño y $E l$ 
usuario de la información: ¿su formación es necesaria?, organizada y moderada por el Lic. José Alfredo Verdugo.

Agosto 13 al 24. Como resultado de los convenios e intercambios establecidos con países latinoamericanos el Centro recibió la Estancia de Investigación de la Mtra. Laura Hurtado Galván del Centro de Documentación / Centro de Investigación y Promoción para el Campesinado; en la que se le brindó asesoría en su tesis doctoral La profesionalización en ciencias de la información desde el Estado y desde la sociedad: América Latina, 1960-1990 y consultar la biblioteca y las bases de datos con las que cuenta el CUIB.

Agosto 14 al Septiembre 20. Como resultado de los convenios e intercambios establecidos con universidades de Estados Unidos, el Centro recibió la Estancia de Investigación de la Lic. Jovita Angélica Guillén de la Universidad de Washington, Estados Unidos; en el que se le facilitó la visita a las instalaciones para realizar sus prácticas en el área de servicios de información especializados, así como conocer y visitar diversas bibliotecas y centros de información y documentación. Septiembre 2 al 4. El Centro desarrolla el curso Elementos para estructurar teorías de información en la investigación bibliotecológica, en el que participan los investigadores Blanca Ma. Castañon y José Alfredo Verdugo.

Septiembre 9 al 27. El CUIB-Dirección General de Intercambio Académico-UNAM/ Organización de Estados Americanos organizan el $\mathrm{IV}$ Curso de Metodología de la Investigación Bibliotecológica, el cual está enmarcado en el proyecto de Formación de Investigadores en Bibliotecología e Información para América Latina; el objetivo general de este encuentro fue el de propiciar e impulsar la investigación bibliotecológica y de la información, tanto teórica como aplicada. Con este fin, se le proporcionaron a los participantes los elementos metodológicos y técnicos de la investigación y su relación con la Bibliotecología.

Septiembre 9 al 27. El CUIB a través del proyecto de Adiestramiento de Investigadores de la Organización de Estados Americanos recibió la participación de sus profesores de América Latina en el IV Curso de Metodología de la Investigación Bibliotecológica; los cuales son: Lic. Olga Cecilia Velásquez Arango de la Escuela Interamericana de 
Bibliotecología de la Universidad de Antioquia, Colombia; Mtra. Belinda Salas Sánchez y la Mtra. Alice Miranda Arguedas de la Escuela de Bibliotecología, Documentación e Información de la Universidad de Costa Rica, Costa Rica; Lic. Salvador Berrios Ramos de la Facultad de Ciencias y Humanidades, Departamento de Letras, Carrera de Bibliotecario de la Universidad de El Salvador, El Salvador; Lic. Tania Aracy Ardón Mayorga y la Lic. Sonia Lydia Yac García de la Escuela de Bibliotecología de la Universidad de San Carlos, Guatemala; Lic. Alicia Haydú López Castillo de la Carrera de Bibliotecología de la Universidad Centroamericana de Managua, Nicaragua; Mtro. Víctor Ubaldo Mendieta Ortíz de la Facultad de Humanidades de la Universidad de Panamá, Panamá.

Septiembre 20. CUIB-UNAM/Asociación Latinoamericana de Escuelas de Bibliotecología y Ciencias de la Información organizan la Reunión de la Asociación Latinoamericana de Escuelas de Bibliotecología y Ciencias de la Información.

Octubre 14 al 25. Se realiza el octavo curso de Formadores de Información Bibliográfica Automatizada, el cual lleva como objetivo el proporcionar a los asistentes los conceptos y elementos que constituyen las partes esenciales en el diseño, construcción y manejo de bancos de datos de información bibliográfica, así como el uso de sistemas de recuperación automatizada. Por medio de las gestiones de la Dirección General de Intercambio Académico se logró la participación de once especialistas de las siguientes universidades del país: Ma. Imelda García Velasco de la Universidad Autónoma de Aguascalientes, Edda Isela Cruz Santini de la Universidad Autónoma de Campeche, Claudia Carolina Guerra Cuéllar de la Universidad Autónoma de Coahuila, José Luis Almanza Sandoval de la Universidad Autónoma de Chihuahua, Martín Salvador González Esparza de la Universidad De Guanajuato, Ma. de la Luz Rico Rodríguez de la Universidad Juárez del Estado de Durango, Juan Manuel López Bueno de la Universidad Autónoma de Nayarit, Ma. Abelia Rocha Ramírez de la Universidad Autónoma de Querétaro, Socorro Amada Mendoza Leos de la Universidad Autónoma de San Luis Potosí, Daniel Tovar Casas de la Universidad Autónoma de Tamaulipas y Rosana Valdez de la Universidad Autónoma de Zacatecas. 
Octubre 24. El CUIB organiza la Demostración del Banco de INFOBILA, en el que se da a conocer el registro de artículos de publicaciones periódicas, tesis, monografías y trabajos presentados en Congresos, Conferencias, Seminarios y documentos diversos con los que cuenta este banco.

Noviembre 11 al 15. Como resultado de los convenios e intercambios establecidos entre el Centro y países latinoamericanos, la Lic. Elsa M. Ramírez asesoró al Colegio de Bibliotecología de la Universidad de El Salvador en el Diseño Curricular de la Licenciatura en Bibliotecología e impartió el curso: Introducción al estudio de usuarios de bibliotecología.

Noviembre 21. Como resultado de los convenios e intercambios establecidos entre el Centro y países latinoamericanos la Mtra. Estela M. Morales participó en el Primer Congreso de Bibliotecología en la Facultad de Humanidades de la Universidad de Panamá; en la mesa redonda: Información y educación, metas del bibliotecólogo.

Noviembre 25 al 27. Se desarrolla en el Centro, el curso Educación de la información en universidades mexicanas en el que se tuvo como objetivo: Definir los conceptos básicos sobre la educación de la información, así como analizar sus diferentes procesos y distintas formas y prácticas, principalmente en el nivel licenciatura.

Diciembre 3. Conmemoración del X Aniversario del CUIB. En el acto estuvieron presentes distintas autoridades de la Máxima Casa de Estudios. El rector José Sarukhán entrego 11 reconocimientos a académicos y administrativos del CUIB. Asimismo, el Mtro. J. Adolfo Rodríguez, Director fundador del centro, al hacer uso de la palabra puntualizó la importancia de la investigación bibliotecológica en México. Por su parte la Mtra.Estela M. Morales, titular de la dependencia, señaló los logros alcanzados durante esta primera década de trabajo; manifestó que estos avances son el resultado de un trabajo de equipo e invitó a quienes lo conforman a continuar con el mismo entusiasmo que han mostrado.

Diciembre 3. Desarrollo de las Jornadas Académicas en el marco del X Aniversario del Centro Universitario de Investigaciones Bibliotecológicas, en el que se presentaron las ponencias: I. Indagación sobre la investigación bibliotecológica, II. Administración de 
Centro Universitario de Investigaciones Bibliotecológicas. Cronología ...

la investigación bibliotecológica, Investigación y Servicio y III. La investigación bibliotecológica como soporte teórico del desarrollo de la Red Nacional de Bibliotecas publicas; además de la mesa redonda: El nombre de la rosa y las bibliotecas.

\section{2}

Enero. Da inicio la primera Reunión de Trabajo de la Comisión de Catalogación y Clasificación de la Red Universitaria de Televisión y Video, la cual estuvo integrada de 12 reuniones que se organizaron a lo largo del año por las siguientes instituciones: CUIB, Dirección General de Bibliotecas, Centro de Información Científica y Humanística, Centro Universitario de Estudios Cinematográficos, Escuela Nacional de Música y Canal 11.

Febrero 10 al 21. Por medio de los intercambios establecidos con Cuba, el Centro contó con la estancia de la Dra. Concepción Díaz Mayans, Asesora de la Red de Bibliotecas Universitarias de Cuba, durante este tiempo impartió el curso: Educación de Usuarios además de intercambiar experiencias con los investigadores especialistas en el área de educación de usuarios y responsables de la investigación La información en el uso de recursos de información para estudiantes de primer ingreso a la licenciatura en universidades públicas mexicanas. Finalmente a la Dra. Mayans se le donaron publicaciones del Centro. Febrero 19 al 28. Con motivo del intercambio académico entre diversos países latinoamericanos, el Lic. Roberto Garduño visitó la Universidad de Panamá, Panamá, para impartir el curso a nivel posgrado: Diseño de base de datos en el Colegio de Bibliotecología dentro del marco Comunicación información y autonomía.

Marzo 12. El CUIB celebra la cuarta Reunión de Evaluación del Centro, la cual estuvo precedida por la Mtra. Estela M. Morales. El objetivo de dicha reunión fue el de evaluar las acciones realizadas durante 1992, así como un análisis también de 1984 a 1992 y definir la orientación de la investigación bibliotecológica; el aspecto que mayor relevancia tuvo fue el relacionado con el impacto social de la investigación bibliotecológica a través de productos derivados de los proyectos de investigación. 
Abril. La Mtra. Rosa María Fernández Esquivel es comisionada Directora de la Biblioteca de la H. Cámara de Diputados.

Mayo 28. El CUIB organiza la conferencia: Vinculación de la Investigación con la Docencia.

Junio 9 y 11. El Centro organiza la mesa redonda El Centro Universitario de Investigaciones Bibliotecológicas y sus programas de vinculación docencia.

Junio 26. Participación de la investigadora María del Carmen Negrete Gutiérrez en la organización de la Segunda Asamblea General Ordinaria del Colegio Nacional de Bibliotecarios, organizada bajo los auspicios de la Sociedad Mexicana de Geografía y Estadística.

Junio 29. El CUIB-UNAM/Colegio Nacional de Bibliotecarios A.C./Instituto de Capacitación Penitenciaria de la Dirección General de Reclusorios y Centros de Readaptación Social del Departamento del Distrito Federal organizan el coloquio Los servicios de información, el sistema penitenciario y los derechos bumanos, organizado por la Mtra. Estela M. Morales.

Julio 14 y 15. Por motivo del intercambio con el Colegio de Bibliotecólogos de Costa Rica la Lic. Susana Sander imparte la conferencia: $L a$ formación teórico profesional del Bibliotecólogo; además de participar en el Primer Congreso de Humanidades de dicho colegio.

Julio 14 y 15. Se organizó el X Coloquio de Investigación Bibliotecológica. La importancia de este acto académico consiste en permitir a la comunidad bibliotecológica y áreas afines conocer los avances de algunas de las investigaciones del Centro, así como también permite establecer la interdisciplinariedad de la Bibliotecología, ya que siempre se ha buscado contar con distinguidos académicos de otras áreas que abordan los mismos problemas pero con diferentes perspectivas. En esta ocasión se desarrollaron tres mesas redondas tituladas: I. ¿Qué estudia la bibliotecología?, II. ¿Cómo enseñar bibliotecología? y III. ¿La literatura bibliotecológica puede formar, deformar, conformar?

Octubre. Se comisiona a la Q.F.B. Elisa Margarita Almada de Ascencio como Miembro del Consejo Asesor Internacional de Engineering Index, E.U.A. 
Octubre. Se comisiona a la Mtra. Estela M. Morales Campos como miembro del Consejo Técnico de la Asociación Mexicana de Bibliotecarios, A.C.

Octubre. Se designa a la Mtra. Estela Mercedes Morales Campos y a la Q.F.B. Elisa Margarita Almada de Ascencio, la Cátedra Extraordinaria Maestros en el Exilio Español en la Facultad de Filosofía y Letras, División de Estudios Profesionales de la Coordinación de Bibliotecología de la UNAM.

Octubre 5. Por medio de los intercambios establecidos con diversas instituciones cubanas la Lic. Blanca Castañón viajó a ese país con el objetivo de proporcionar una asesoría a la Biblioteca del Instituto Superior Técnico de Holguín, sobre problemas de asignación de materias, recuperación por epígrafes y palabras clave e impresión de fichas en el sistema automatizado para libros CATALOSA. Además la Lic. Castañón intercambió experiencias y posibles aplicaciones de propuestas y sistemas que investiga el CUIB, para mejorar el análisis temático, optimizar sistemas de representación temática ya desarrollados, así como ampliar y mejorar el desarrollo de archivo de autoridades para epígrafes y tesauros.

Octubre 5 al 9. Por medio de la International Federation of Library Association y su Advancement of Librarianship in the Third World Programme, se realizó la reunión de trabajo Presente y futuro de INFOBILA y dentro de este marco se desarrolló la mesa redonda Literatura bibliotecológica y su uso; contando con la participación de especialistas de las siguientes instituciones: Dr. Antonio Miranda, Director del Instituto de Brasileño de información en Ciencia y Tecnología; Mtra. Rocío Herrera, Profesora de la Escuela Interamericana de la Universidad de Antioquia, Colombia; Mtro. Héctor Gómez, Profesor del Instituto Profesional de Santiago, Escuela de Bibliotecología de Santiago de Chile; Mtra. Saray Córdoba, Coordinadora de Investigación de la Universidad de Costa Rica; Dr. Emilio Setién, Profesor de la Universidad de la Habana e Investigador Auxiliar de la Biblioteca Nacional "José Martí", Cuba; y Mtra María Bonilla, Profesora de la Escuela de Bibliotecología de Perú y Directora de la Biblioteca de la Universidad del Pacífico. 
Octubre 15. Por motivo del intercambio académico con Cuba la Lic. Ma. del Carmen Negrete visitó la Biblioteca Nacional de Ciencias y Tecnología del Instituto de Información Científica y Tecnología de la Academia de Ciencias de Cuba, La Habana, donde participó en el Seminario sobre desarrollo de colecciones.

Octubre 19 al 30. Se realiza en las instalaciones del Centro el noveno curso Formadores de Información Bibliográfica Automatizada; el cual tuvo como objetivo el proporcionar a los asistentes los conceptos que constituyen las partes esenciales en el diseño, construcción y manejo de los bancos de datos de información bibliográfica, así como el uso de sistemas de recuperación automatizada de la información. En esta ocasión hubo un mayor número de participantes gracias al gran interés despertado por el curso en años anteriores, por lo que se contó con la participación de 17 profesionales de universidades e instituciones de la provincia de nuestro país, dos de Guatemala y 12 de diversas dependencias del Distrito Federal.

Octubre 19 al 30. Gracias a los convenios establecidos entre el CUIB, la Dirección General de Intercambio Académico y, en esta ocasión, con la Asociación Nacional de Universidades e Instituciones de Educación Superior, se logró la participación de 17 maestros becados para el noveno curso Formadores de Información Bibliográfica Automatizada de las siguientes universidades: Laura Elena Ventura Hernández de la Universidad Autónoma de Aguascalientes, Carlos Alberto Carrillo Rodríguez de la Universidad Autónoma de Campeche, J. Reyes Rosas Barajas de la Universidad Autónoma de Colima, Guadalupe Guerrero González de la Universidad Autónoma de Chiapas, Enrique Durstewitz Martha de la Universidad Autónoma de Chihuahua, Pedro Bonifacio Pavón de la Universidad Autónoma del Estado de México, Salvador Leyva García de la Universidad Autónoma del Estado de Morelos, Dora Díaz Ceballos de la Universidad Autónoma de Guerrero, Esperanza Gómez Zambrano de la Universidad de Guadalajara, Marco Antonio Venegas Amaya de la Universidad Autónoma de Nuevo León, Francisco de la Cruz de la Universidad Autónoma de Zacatecas, Diana Eugenia González Ortega del Instituto Tecnológico de Sonora, Arturo Yamamoto Vergara de la Universidad Autónoma de Baja California, Juana Ma. González Colunga de la Uni- 
versidad Autónoma de San Luis Potosí, Angélica Luis Ramírez de la Universidad Autónoma de Puebla y Lorena Aguilar Luna de la Universidad Autónoma de Tlaxcala.

Noviembre 15. Por medio del intercambio académico establecido con diversas instituciones cubanas la Lic. María del Carmen Negrete fue invitada a participar en el Seminario sobre Desarrollo de Colecciones, organizado por la Biblioteca Nacional de Ciencias y Tecnología del Instituto de Información Científica y Tecnológica de la Academia de Ciencias de Cuba.

Noviembre 18. El CUIB realizó un homenaje in Memoriam al Mtro. Roberto Abell en el auditorio "Mario de la Cueva" de Ciudad Universitaria, en este acto se presentó la ponencia Mtro. Roberto Abell: Su influencia para la adopción del Sistema de Clasificación L:C: en las bibliotecas mexicanas, en el que se recordó la labor del maestro como profesor y su calidad como investigador, además de reconocer el gran legado de su productividad en el área.

Noviembre 26. El Centro, por medio de la Biblioteca Benjamín Franklin, recibió la visita del Mtro. S. Michael Malinconico, quien dictó el seminario Intercambio de Servicios de Información a través de redes: perspectiva. Este destacado investigador fue profesor de estudios de información en la Universidad de Alabama, decano y profesor de la Escuela de Cómputo, Información y Bibliotecología del Instituto Patt y profesor adjunto en la Escuela de Servicios Bibliotecológicos de la Universidad de Columbia, por mencionar algunos de sus cargos.

Diciembre. Publicación de los libros coeditados entre el CUIB-UNAM/ Red Nacional de Bibliotecas Públicas/Consejo Nacional para la Cultura y las Artes titulado: Edición conmemorativa del $X$ aniversario del Centro Universitario de Investigaciones Bibliotecológicas; tomo I: En torno a la Investigación Bibliotecológica, y tomo II: En torno a la Biblioteca y sus Desarrollos, estas obras fueron compiladas por las investigadoras Estela Mercedes Morales Campos y Elsa Margarita Ramírez Leyva. 
1993

Abril. Se comisiona al Lic. Filiberto Felipe Martínez Arellano como Presidente del Consejo Directivo del Colegio Nacional de Bibliotecarios A. C.

Abril. Se envían las bases de la revista Investigación Bibliotecológica: Archivonomía, Biblioteconomía e Información para ser sometida a evaluación según la convocatoria expedida por el Consejo Nacional de Ciencia y Tecnología en este año.

Mayo 1. Ingreso del Lic. Salvador Gorbea Portal como investigador del CUIB.

Mayo 12. A través del Consejo Británico el Centro ofreció la conferencia Conspectus: instrumento para la colaboración entre las bibliotecas de instituciones de investigación, dictada por la Mtra. Ann E. Wade.

Mayo 16. Ingreso del Ing. Juan Voutssás Márquez como investigador del CUIB.

Junio 21. La Mtra. Estela M. Morales Campos pronunció en el auditorio "Mario de la Cueva" de Ciudad Universitaria su IV Informe de Actividades correspondiente al periodo 1992-1993. La Mtra. Morales comenzó refiriéndose a 11 líneas de investigación, de las cuales 5 fueron iniciadas, 22 se encontraban en proceso y 5 habían concluido. Informó que la investigación Bibliotecológica del CUIB descansa en cuatro unidades de apoyo: Biblioteca, Cómputo, Publicaciones e Investigación y Docencia. El intercambio académico fue otro rubro destacado por la Mtra. Morales, habló de la relación con las distintas escuelas de Bibliotecología, la participación de los docentes del Centro en distintos eventos a los que han sido invitados en todo el país y en el extranjero; además de felicitar a todo su equipo de trabajo por el apoyo otorgado durante su gestión.

Julio. Se comisiona al Ing. Juan Voutssás Márquez como Director del Centro de Información Científica y Humanística, UNAM.

Julio . Cambios en el Consejo Interno, el cual quedó conformado de la siguiente forma:

Presidente: Lic. Elsa M. Ramírez Leyva.

Secretario: Lic. Martha A. Añorve Guillén. 
Vocales: $\quad$ Lic. Ma. del Carmen Negrete Gutiérrez.

Lic. Eduardo Salas Estrada.

Lic. Emma Norma Romero Tejeda.

Julio 2. La Lic. Elsa M. Ramírez Leyva tomó posesión como Directora del CUIB. En su discurso expresó estar consciente de la compleja y delicada tarea que se tenía por realizar, refiriéndose posteriormente a la destacada labor realizada por los anteriores directores del Centro, trabajo que le permitiría "consolidar los esfuerzos que han hecho posible la buena marcha del Centro y fortalecer, con nuevas aportaciones, los proyectos presentes y los trabajos futuros que requieran colaboración como parte de nuestra Universidad y nuestra sociedad".

Julio 23. Se comisiona a la Lic. Elsa M. Ramírez Leyva como miembro del Consejo Técnico de Humanidades.

Agosto. Se comisiona a la Mtra. Estela M. Morales Campos como Representante de la Coordinación de Humanidades/UNAM ante el Consejo de Posgrado.

Agosto. Se comisiona a la Q.F.B. Elisa Margarita Almada de Ascencio como Miembro del Consejo Asesor del Consejo Nacional de Ciencia y Tecnología, CONACYT.

Agosto 6, 13, 20 y 27. El Centro organiza el Seminario de Reorganización de los Diferentes Departamentos del CUIB.

Septiembre. Se le otorga la beca del Programa Fulbright-García Robles al investigador Filiberto Felipe Martínez Arellano para realizar estudios de Doctorado en la Universidad Estatal de Nueva York en Buffalo, Estados Unidos.

Septiembre. Se comisiona a María del Carmen Negrete Gutiérrez como Presidenta de la Comisión de Hacienda en el Colegio Nacional de Bibliotecarios, A.C.

Octubre 18 al 29. El CUIB organiza el décimo curso Formadores de Información Bibliográfica Automatizada, el cual contó con el apoyo de la Dirección General de Intercambio Académico de la UNAM al otorgar diez becas para investigadores de distintas universidades de la República; además de contar con la participación de distinguidos profesores de las siguientes instituciones: Word Trade Center, Comisión Nacional de los Derechos Humanos, El Colegio de México, Ase- 
sores Especializados en Información y Documentación y distintas dependencias de la UNAM.

Octubre 26 y 27. El CUIB celebra el XI Coloquio de Investigación Bibliotecológica, al cual acudieron distintos investigadores de las siguientes instituciones: Centro de Estudios Clásicos del Instituto de Investigaciones Filológicas-UNAM, Departamento de Coordinación Técnica de la Dirección General de Bibliotecas del Consejo Nacional para la Cultura y las Artes, Colegio de Literatura de la Escuela Nacional Preparatoria Plantel 8-UNAM, Carrera de Comunicación de la Facultad de Ciencias Políticas y Sociales-UNAM, Biblioteca de la Universidad Iberoamericana, Biblioteca de la Universidad Anáhuac y Biblioteca del Tecnológico de Monterrey del Campus Lago de Guadalupe.

Noviembre 1. Ingreso del Dr. Miguel Ángel Rendón Rojas como investigador del CUIB.

Noviembre 11. El CUIB-Facultad de Filosofía y Letras-Colegio de Bibliotecología-UNAM organizan la presentación del libro El Servicio de Consulta.

Noviembre 18. Co-organización del CUIB y la Facultad de Filosofía y Letras de la UNAM en la presentación del libro Los sistemas bibliotecológicos de clasificación.

Diciembre. El CUIB-Dirección General de Bibliotecas-Centro Universitario de Estudios Cinematográficos/Escuela Nacional de Música/Canal 11 organizan la segunda Reunión de Trabajo de la Comisión de Catalogación y Clasificación de la Red Universitaria de Televisión y videos.

Diciembre 15. Se comisiona a la Mtra Estela M. Morales Campos como Presidenta de la Comisión Dictaminadora en la Dirección General de Bibliotecas.

1994

Se designa al Dr. Miguel Ángel Rendón Rojas como Investigador Nacional Nivel I por el Sistema Nacional de Investigadores.

Febrero 1. Cambios en el Consejo Interno, el cual quedó constituido de la siguiente forma:

Presidente: Lic. Elsa M. Ramírez Leyva. 
Centro Universitario de Investigaciones Bibliotecológicas. Cronología ...

Secretario: Lic. Martha A. Añorve Guillén.

Vocales: $\quad$ Lic. Roberto Garduño Vera.

Lic. Ma. del Carmen Negrete Gutiérrez.

Lic. Emma Norma Romero Tejeda.

Lic. Eduardo Salas Estrada.

Febrero 7 al 11. Por medio del Intercambio Académico con los Estados Unidos el Centro recibió la visita del Dr. Edwin S. Gleaves con el fin de impartir el curso Navegando la Internet, cabe señalar que el Dr. Gleaves es un destacado bibliotecólogo y archivista de la Universidad de Tennessee, USA.

Febrero 10. El CUIB organiza la conferencia: La internet y su futuro: implicación para la docencia y la investigación.

Marzo 3 y 4. El Mtro. Adolfo Rodríguez Gallardo organiza y participa en la XV Feria Internacional del Libro (Dirección General de Bibliotecas-UNAM), en la masa redonda: Nuevas Tendencias en la Obtención de Documentos.

Mayo. Se designa como Socio Honorario de la Asociación Mexicana de Bibliotecarios, A.C. al Mtro. Adolfo Rodríguez Gallardo.

Mayo 16. La Mtra. Estela M. Morales Campos es condecorada con la Medalla al Mérito Académico de las Asociaciones Autónomas del Personal Académico de la Universidad Nacional Autónoma de México (AAPAUNAM).

Junio 7, 9, 13 y 15. El CUIB/Universidad Autónoma Metropolitana organizan el seminario La Hermenéutica boy en las Ciencias Sociales y Humanidades, en el que se impartieron las siguientes mesas redondas: I. Introducción a la Hermenéutica, II. Algunos problemas dentro de la Hermenéutica, III. El debate bermenéutico contemporáneo en las Ciencias Sociales: Ricoeur, Gadamer y Habermas y IV. La Hermenéutica y su relación con otras escuelas filosóficas: dialéctica, lógica formal y existencialismo.

Julio 7 y 8. Se desarrolla el XII Coloquio de Investigación Bibliotecológica, el cual contó con la conferencia: El fundamento ontológico de las clasificaciones; y las mesas redondas: I. En busca de una metodología para la enseñanza de la clasificación L. C, basada en sus principios, II. La función de la biblioteca en el proceso de formación $y$ III. Lenguajes de indización libres o controlados. 
Agosto. La Mtra. Estela M. Morales Campos participa como organizadora del Foro Abierto de la Sección de América Latina y el Caribe de la 61 Conferencia General de IFLA. Estambul, Turquía.

Octubre 17 al 28. Se desarrolla el onceavo curso Formadores de Información Bibliográfica Automatizada, en el que se impartieron las siguientes conferencias: I. La Biblioteca Virtual, II. Inteligencia Artificial: Sistemas Expertos, Internet, Sesión Práctica Demostrativa, III. Posibilidades en el Almacenamiento y IV. Uso en el CD ROM.

Octubre 19. Se le otorga a la Mtra. Estela M. Morales Campos la ratificación el nombramiento para reintegrar la Comisión Dictaminadora del Centro de Información Científica y Humanística de la Coordinación de la Investigación Científica de la UNAM.

Diciembre 1. Ingreso de la Lic. Georgina Araceli Torres Vargas como investigadora del CUIB.

\section{5}

Enero. Publicación del libro coeditado entre el CUIB-UNAM/Instituto de Documentación e Información Científica y Tecnológica titulado: Directorio de Redes y Sistemas de Información y Comunicación en América Latina y el Caribe, esta obra fue coordinada por María Enriqueta González Toledo.

Enero 3. Ingreso del Lic. Juan José Calva González como investigador del CUIB.

Febrero 1.Cambios en el Consejo Interno, el cual quedó constituido de la siguiente forma:

Presidente: Lic. Elsa M. Ramírez Leyva

Secretario: Lic. Martha A. Añorve Guillén

Vocales: $\quad$ Lic. Roberto Garduño Vera

Lic. Susana Sander Villarino

Lic. Ignacio Rodríguez Sánchez

Febrero 23. El Centro organiza la conferencia Los derechos de propiedad intelectual, la cual fue impartida por el investigador norteamericano Kenneth Wasch. 
Mayo. Participación de la investigadora María del Carmen Negrete Gutiérrez en la Comisión de Biblioteconomía y Bibliografía de la Asociación Mexicana de Bibliotecarios, A.C.

Mayo 11. El Centro organiza la conferencia Informática Jurídica, impartida por la investigadora peruana Violeta Angulo Morales.

Mayo 16 al 19. El CUIB organiza el curso La literatura infantil en el desarrollo social y efectivo del niño de primaria, el cual fue impartido por el investigador Carlos Compton.

Junio 19 al 22. Por medio de los convenios establecidos con la Organización de Estados Americanos y la Organización de las Naciones Unidas para la Ciencia, la Educación y la Cultura, el Centro organiza la Reunión de Investigadores y Educadores de Iberoamérica y el Caribe en el Área de Bibliotecología y Ciencia de la Información. En esta reunión se trataron temas relacionados con la educación profesional, de posgrado, continua y a distancia e investigación y producción de literatura, todo ello en el contexto de las condiciones actuales y en el futuro, particularmente con el advenimiento de las nuevas tecnologías y telecomunicaciones, así como de los cambios económicos, políticos y sociales; agregando a esto perspectivas de nuevas formas de cooperación. Para esta reunión se desarrollaron las siguientes mesas redondas: I. Educación profesional y posgrado, en el que participaron Hugo Figueroa, Nahúm Pérez Paz y Elsa Barberena de México y Norma Barrios de Cuba; II. Educación continua, en el que participan Griselda Gómez de México y Gloria Ponjuán de Cuba; III. Investigación, en el que participan Ramiro Lafuente López de México y Rocío Herrera de Chile; IV. Literatura, en el que participan Martha A. Añorve Guillén de México y Carmen Pérez de Chile. Por su parte se contó con las conferencias: I. Informe de las acciones de Organización de las Naciones Unidas para la Ciencia, la Educación y la Cultura /PGI, para el desarrollo profesional en el área de información, la cual fue impartida por el representante de la Organización de las Naciones Unidas para la Ciencia, la Educación y la Cultura/PGI Isidro Fernández Aballí; y II. Las asociaciones de bibliotecarios y profesionales a fines de siglo en Iberoamérica y el Caribe, la cual fue impartida por Rosa Ma. Fernández E. de México. 
Por último se organizó la presentación del libro, La revista bibliotecológica y otros materiales en Iberoamérica y el Caribe.

Junio 19 al 22. En el marco de la Reunión de Investigadores y Educadores de Iberoamérica y el Caribe en el Área de Bibliotecología y Ciencias de la Información se desarrollaron grupos de trabajo con los siguientes temas: I. Educación a distancia, la cual fue dirigida por Rodolfo Herrero de México; II. Grupos de educación profesional, educación continua y educación a distancia, en el que participaron José López Yepes de España, Elsa Barber de Argentina, Roberto Garduño Vera y Ma. del Carmen Negrete de México; III. Grupos de posgrado, literatura e investigación, en el que participaron Rosario Horowitz de Venezuela, Mercedes Caridad de España, Miguel Ángel Rendón Rojas y Susana Sander Villarino de México.

Junio 23. Se desarrolla el XIII Coloquio de Investigación Bibliotecológica, el cual contó con las conferencias: I. El proceso de integración con Iberoamérica y II. La cultura bispanoamericana: una reflexión; y las mesas redondas: I. La Bibliotecología y la Tecnología, II. Vinculación Investigación Docencia, y III. Tendencia en la Bibliotecología de Iberoamérica y el Caribe: Educación e Investigación. En esta ocasión se recibieron investigadores de diferentes países como: Humberto Arango de Cuba, Félix de Moya Angsen de España, Carmen Pérez Ormeño de Chile, Carmen Villanueva de Perú, Antonio Miranda de Brasil, Rocío Herrera Cortés de Colombia, Elsa Barbarena Blásquez de México, Mercedes Caridad de España, Rosario Horowitz de Venezuela, Stella Maris Fernández de Argentina, Ana Cecilia Torres de Costa Rica, José López Yepes de España e Isidro Fernández Aballí como Consejero Regional de la Organización de las Naciones Unidas para la Ciencia, la Educación y la Cultura/ PGI. Además se contó con dos especialistas de la UNAM como Ricardo Melgar Bao y Ignacio Díaz Ruíz del Centro Coordinador y Difusor de Estudios Latinoamericanos.

Junio 26 al 28. El CUIB organiza el curso Evaluación de bibliotecas y servicios bibliotecarios, impartido por Frederic W. Lancaster de la Universidad de Illinois.

Junio 26 al 30. Se desarrolla el curso Gerencia de información en las organizaciones, el cual fue impartido por la Mtra. Gloria Ponjuán 
Centro Universitario de Investigaciones Bibliotecológicas. Cronología ...

del Instituto de Investigaciones Tecnológicas de la Academia de Ciencias de Cuba.

Agosto. Publicación del libro coeditado entre el CUIB-Coordinación de Humanidades-Instituto de Investigaciones Bibliográficas-UNAM/Asociación de Bibliotecas Nacionales de Iberoamérica titulado: Historia de las bibliotecas nacionales de Iberoamérica: pasado y presente, esta obra fue coordinada por José G. Moreno de Alba y Elsa M. Ramírez Leyva.

Agosto 16 a Septiembre 4. Por medio de los convenios establecidos con universidades españolas se imparte en el CUIB el curso Principales sistemas de clasificación documental por parte de la investigadora Rosa Sansegundo de la Universidad Carlos III de España.

Agosto 28 a Septiembre 1. Por medio de los convenios establecidos con instituciones españolas se imparte el curso Marketing de publicaciones especializadas (impresas y electrónicas), impartido por Ignacio García Díaz de la Comisión Interministerial de Ciencia y Tecnología de España.

Agosto 28 a Septiembre 1. El Centro organiza el Seminario Hispanoamericano sobre Estudios Métricos de la Información organizado por Martha A. Añorve, Salvador Gorbea y Elsa M. Ramírez, el cual contó con la participación de ponentes de Latinoamérica y España. En dicho seminario se impartieron las siguientes conferencias: I. Uso de indicadores científicos en investigación, impartida por Rosa Sancho de España y II. Experiencia española en el campo de los estudios métricos de la información, impartida por Eugenio Portela de España; además se desarrollaron tres mesas redondas: I. Los estudios métricos de la información en el programa curricular ciencia de la información en Hispanoamérica, en el que participaron los investigadores Ignacio García Díaz de Cuba, Judith Licea de Arenas de México y Eugenio Portela de España; II. El uso de la tecnología en los estudios métricos, en el que participaron los investigadores Alberto Castro Thompson y Héctor Delgado Andrade de México; y III. Investigación y producción científica de los estudios métricos de la información en Hispanoamérica, en el que participó el investigador Salvador Gorbea Portal de Cuba. 
Noviembre 6 al 10. Se realiza el curso Introducción a los estudios métricos de la Información, impartido por el investigador Salvador Gorbea Portal de la Universidad de la Habana, Cuba.

Diciembre 4 al 8. Se desarrolla el primer curso Formadores de Instrumentos Bibliográficos Automatizados, en donde se trataron los temas relacionados con la "Biblioteca Electrónica". Este curso se impartió en tres módulos con los siguientes temas: I. La biblioteca del futuro, documentos electrónicos y ambientes de redes, II. La formación de colecciones en los documentos electrónicos y III. Las nuevas formas de informarse; además de la conferencia: La biblioteca académica frente a la presencia de nuevas tecnologías de información y las telecomunicaciones, y la mesa redonda: Perspectivas y prospectivas del BBS (Bulletin Borrad System) y servicios de telecomunicaciones de información en México.

Diciembre 4 al 8. La Lic. Elsa M. Ramírez Leyva organiza y conduce INFOBILA: Segunda Reunión del Proyecto de Red Regional de Cooperación e Intercambio Latinoamericano, en el que se impartieron las siguientes conferencias: I. Infodiversidad y cooperación regional, impartida por Estela M. Morales Campos; II. Vocabulario controlado de Bibliotecología y Ciencia de la Información, impartida por Surya Peniche Cueva; III. Formatos Internacionales de Intercambio de Información Bibliográfica, impartida por Roberto Garduño Vera y IV. Tesauro en Ciencia de la Información, impartida por Lucy Espinosa Ricardo (Colombia).

\section{6}

Febrero 1. Cambios en el Consejo Interno, el cual quedó constituido de la siguiente forma:

Presidente: Lic. Elsa M. Ramírez Leyva.

Secretario: Lic. Martha A. Añorve Guillén.

Vocales: $\quad$ Lic. Roberto Garduño Vera.

Lic. Ma. del Carmen Negrete Gutiérrez.

Lic. Susana Sander Villarino.

Lic. Ignacio Rodríguez Sánchez. 
Centro Universitario de Investigaciones Bibliotecológicas. Cronología ...

Febrero-Marzo. Se desarrolla el Seminario sobre los aportes metodológicos obtenidos por la investigación de la actividad bibliotecaria en el Ministerio de Cultura de Cuba, el cual condujo el investigador Emilio Setién Quesada de Cuba.

Marzo 18 al 20. El Centro organiza el curso Teoría del Desarrollo de Colecciones impartido por la investigadora Isabel Fernández Santana (Instituto de Documentación e Información Científica y Tecnológica-Cuba).

Marzo 25 al 29. El Centro organiza dentro del Programa de formación de recursos bumanos en servicios bibliotecarios y de integración para la integración de la Red de Bibliotecas de Subsistema de Humanidades y Ciencias Sociales de la Coordinación de Humanidades el primer módulo, de cuatro que lo integran, más un curso que se impartirá a lo largo del año, Necesidades de información de las comunidades científicas; el cual fue organizado por el investigador Juan José Calva González.

Junio 10. El CUIB organiza el Seminario sobre la aplicación del método científico en la investigación bibliotecológica: singularidades, problemas y resultados, en el que participaron distintos investigadores de los siguientes países: Miguel A. Rendón de México, José López Yepes de España, Emilia Currás de España, Ramiro Lafuente López de México, Solange Puntel Mostafa de Brasil, Emilio Setién Quesada de Cuba, Sebastiao de Souza de Brasil y Nicolás Tripaldi de Argentina. Junio 10 al 14. Se imparte el curso Metodología de la Investigación en Bibliotecológica, dictado por el investigador Miguel Ángel Rendón Rojas.

Junio 18 al 20. Se desarrolla el XIV Coloquio de Investigación Bibliotecológica: problemas teóricos epistemológicos de la bibliotecología, en el que se presentó la conferencia magistral: La clasificación de los conocimientos en Ciencias y Humanidades del Dr. Pablo González Casanova, del Centro de Investigaciones Interdisciplinarias en Ciencias y Humanidades; las mesas redondas: I. Diferentes enfoques paradigmáticos de la ciencia bibliotecológica: unidad en diversidad o diversidad en la unidad, en la que participan José López Yepes de España, Solange Puntel Mostafa de Brasil, Adolfo Rodríguez Gallardo de México, Emilio Setién Quesada de Cuba y Sebastiao de 
Souza de Brasil; II. Tecnología y cambio de paradigma, en la que participan Emilia Currás de España, Felipe Lara Rosano y Roberto Garduño Vera de México y Nicolás Tripaldi de Argentina; III. Función social de la biblioteca y del bibliotecólogo, en la que participan Juan René García Lagunas de la Universidad Autónoma de San Luis Potosí, Jesús Lau de la Universidad Autónoma de Ciudad Juárez, Ana María Magaloni de Bustamante de la Secretaría de Educación Pública/ Dirección General de Bibliotecas, Jaime Portigo Martínez del Instituto de Investigaciones Estéticas y Bruno Revesz de Perú; además se contó con el debate abierto Epistemología de la Bibliotecología.

Junio 24 al 28. EL CUIB organiza el Encuentro Latinoamericano sobre bibliotecas, la lectura y el niño callejero, en el que destaca la participación del investigador de la Fundación de las Naciones Unidas para la Infancia Eduardo Rodríguez Silvo con la conferencia La situación de los niños de y en la calle: ¿problemas o personas?

Junio 24 al 28. El Centro desarrolla dentro del Programa de formación de recursos bumanos en servicios bibliotecarios y de integración para la integración de la Red de Bibliotecas de Subsistema de Humanidades y Ciencias Sociales de la Coordinación de Humanidades, el segundo módulo, de cuatro que lo integran más un curso que se impartirá a lo largo del año: Desarrollo de colecciones y diseno de servicios, el cual fue organizado por los investigadores Juan José Calva González y Ma. del Carmen Negrete Gutiérrez.

Julio 1. Ingreso del Lic. Jaime Ríos Ortega como investigador del CUIB.

Julio 10 al 12. Se imparte el curso Evaluación de revistas científicas por el investigador Salvador Gorbea Portal.

Agosto 1. Ingreso de la Lic. Lina Escalona Ríos como investigadora del CUIB.

Septiembre 1. El investigador Filiberto Felipe Martínez Arellano obtiene el Doctorado en Educación Superior y Bibliotecología por la State University of New York at Buffalo, USA.

Septiembre 9 al 13. Se desarrolla el Primer Congreso Interno de la Comunidad Científica del CUIB. Los investigadores y sus investigaciones, el cual fue organizado por las investigadoras Martha A. Añorve y Elsa M. Ramírez. 
Centro Universitario de Investigaciones Bibliotecológicas. Cronología ...

Septiembre 23 al 27. El Centro organiza el Seminario Latinoamericano sobre formación de usuarios de la información y los estudios de usuarios, en el que participan distintos investigadores latinoamericanos y del país como: Saray Córdoba de Costa Rica, Cristina Pérez Giffoni de Uruguay, Susana Romanos de Teratel de Argentina, Martha Sabelli de Uruguay, y Patricia Hernández Salazar de México.

Septiembre 23 al 27.El Centro desarrolla dentro del Programa de formación de recursos bumanos en servicios bibliotecarios y de integración para la integración de la Red de Bibliotecas de Subsistema de Humanidades y Ciencias Sociales de la Coordinación de Humanidades, se lleva a cabo el tercer módulo, de cuatro que lo integran, más un curso que se impartirá a lo largo del año: Formación de usuarios de la información, el cual fue organizado por la investigadora Patricia Hernández Salazar.

Septiembre 23 al 27. El CUIB-Escuela Nacional de Estudios Profesionales Acatlán-UNAM/Universidad Autónoma Metropolitana/Universidad Iberoamericana/Universidad Intercontinental/Universidad Panamericana/Grupo Editorial Miguel Porrúa, desarrollan el $I$ Encuentro Internacional de Investigaciones en Hermenéutica, el cual fue organizado por el investigador Miguel Ángel Rendón Rojas. Octubre 1. Se comisiona a la Lic. Elsa M. Ramírez Leyva como Vicepresidenta (en funciones de Presidenta) de la Asociación Mexicana de Bibliotecarios A.C.

Octubre 21 al 31. Se realiza el segundo curso Formadores de Instrumentos Bibliográficos Automatizados. El espacio documental en las Redes: la información y transferencia de colecciones de documentos electrónicos, el cual se desarrolló en los siguientes módulos: I. Diseño de Redes, con los temas: Tipologías e intercambio de información (caso CUIB), Diseño de red e intercambio de redes (caso CUIB) y Diseño de red e intercambio de redes (caso Universidad de Colima); II. Administración de Redes, con los temas: Administración de los sistemas, Demostración de servicios en red, Concepto de Dataware House, Concepto sobre tecnología, Integración de Datos al Web, Retos en la Integración; III. Servicios a través de redes, con los temas: Transferencia de datos a través de redes, Los documentos electrónicos, Diseño de servicios de redes, Los derechos de autor y 
Los servicios. La comunicación; y IV. Uso de redes por investigadores, con los temas: Búsqueda en línea por investigadores en el área de Humanidades, ¿Qué implica el informarse por redes?, ¿Cuándo se considera que se está bien informado a partir de las redes? y Problemas relativos al exceso de información en redes.

Noviembre. Da inicio el programa por medio del cual los investigadores del Centro podrán realizar estudios de doctorado, esto es producto de una larga búsqueda en la que se analizaron los programas de estudio de diferentes universidades con el fin de encontrar la universidad que ofreciera, en su programa de estudio, uno que estuviera más acorde a las necesidades del Centro; finalmente se eligió a la Universidad Complutense de Madrid en su Programa de Doctorado en Ciencias de la Información orientado a aspectos teóricos y metodológicos con la que el Centro estableció el convenio correspondiente.

Noviembre. Publicación del libro coeditado entre el CUIB-Colegio de Ciencias y Humanidades Naucalpan-UNAM/Colegio Nacional de Bibliotecarios, A.C. titulado: La lectura y los adolescentes, esta obra fue escrita por Sonia Araceli GarduñoVargas.

Noviembre 4. El CUIB desarrolla el Seminario de Gestión y Evaluación de Información en el que destaca la participación de la investigadora Cecilia Culebra del Instituto de Investigaciones Estéticas con la ponencia Cultura Organizacional.

Noviembre 25 al 29.El Centro desarrolla dentro del Programa de formación de recursos bumanos en servicios bibliotecarios y de integración para la integración de la Red de Bibliotecas de Subsistema de Humanidades y Ciencias Sociales de la Coordinación de Humanidades, el cuarto y último módulo: Seminario sobre gestión y evaluación de información, el cual fue organizado por el investigador Eduardo Orozco Silva de Cuba.

\section{7}

Marzo. Se comisiona al Ing. Juan Voutssás Márquez como Director de Sistemas de la Dirección General de Servicios de Cómputo Académico, UNAM. 
Centro Universitario de Investigaciones Bibliotecológicas. Cronología ...

Marzo 31 a Abril 11. El CUIB/Biblioteca Nacional de Venezuela/Universidad de Chile/ Universidad Javeriana de Bogotá, Colombia, organizan la Segunda Reunión de Trabajo: Tesauro Latinoamericano en Bibliotecología y Ciencias de la Información, realizado en Santiago de Chile.

Abril 4 a Noviembre 11. El Centro desarrolla el Seminario sobre reestructuración sobre las áreas de investigación del CUIB en el que participaron los investigadores con la siguientes ponencias: $\mathbf{L a} \mathbf{b i}$ bliotecología en México 1945-1995, en su contexto bistórico, politico y social, impartida por Rosa Ma. Fernández; Definición, objetivos y contenido del área de análisis y sistematización documental, impartida por Roberto Garduño; Modelos de la relación de los sistemas de información de conocimientos en información y sociedady sistemas de información, impartida por Salvador Gorbea; Descripción, objetivos y contenidos del área de Análisis y Sistematización de la Información Documental, impartida por Catalina Naumis; Fundamentos de las ciencias bibliotecológicas y de la información, impartida por Miguel Ángel Rendón; Área de información y sociedad y desglose de la línea de lectura, objetivos y descripción, impartida por Ma. Trinidad Román; Fundamentos de la bibliotecología y de la información, impartida por Susana Sander; y Área de tecnologías de la información, impartida por Araceli Torres.

Mayo 5 y 6. El CUIB y el Centro de Enseñanza de Lenguas Extranjeras organizan el taller Lineamientos metodológicos para la elaboración de programas multimedia para el aprendizaje de lenguas extranjeras.

Mayo 6 al 9. El CUIB desarrolla dentro del marco del Seminario-Permanente sobre Estudios Métricos de la Información, el Seminario-Taller: Modelación matemática de la actividad bibliotecaria en el que participaron investigadores de las siguientes universidades: Emilio Setién de la Biblioteca Nacional de Cuba; Nora A. Delgado de la Universidad de la Habana, Cuba; Elías Sanz de la Universidad Carlos III de Madrid, España; Rubén Urbizástegui de la Universidad de California, USA; Oscar Arriola de El Colegio de México; Ismael Herrera del Instituto de Investigaciones Matemáticas Aplicadas y Sistemas; y Álvaro Quijano de El Colegio de México. 
Centro Universitario de Investigaciones Bibliotecológicas. Cronología ...

Mayo 8. El CUIB-Centro de Enseñanza de Lenguas Extranjeras-Escuela Nacional Preparatoria $\mathrm{N}^{\circ}$ 6-UNAM organizan la conferencia Las nuevas tecnologías de información en la educación: una experiencia en la Universidad de Texas-Austin impartida por el Doctor en Filosofía Orlando Kelem.

Mayo 12 al 16. Se desarrolla en el Centro el seminario Planificación estratégica de bibliotecas: estudio de casos, impartido por la investigadora invitada Nora Delgado.

Junio 2 al 27. El Centro organiza el Programa de estancias en el área de servicios de información, control bibliográfico y tecnologías de la información, en el que destaca la participación como organizadora y ponente de la Lic. Elsa M. Ramírez con la ponencia Centro Universitario de Investigaciones Bibliotecológicas (proyectos regionales).

Junio 2 al 30. El CUIB/Internacional Federation of Library Association/Consejo Supremo Universitario Centroamericano organizan reuniones de trabajo dentro del marco del Programa de estancia académica en las áreas de información, control bibliográfico y tecnologías de la información.

Junio 16. El CUIB/Universidad Carlos III de Madrid/Université de Toulouse (Francia)/Universidad de Buenos Aires (Argentina) efectúan la Reunión del proyecto ALFA (América Latina. Formación Académica de la Unión Europea).

Junio 16 al 20. El CUIB y Universidad Carlos III de Madrid desarrollan el encuentro Pre-proyecto para la Evaluación de los planes de estudios de Biblioteconomía y Documentación en América Latina.

Junio 24 al 26. Se desarrolla el XV Coloquio de Investigación Bibliotecológica: Uso de los lenguajes documentales en la transferencia de información en un mundo globalizado, en el que destacaron los módulos: Lenguaje y comunicación con relación a la información y conocimiento y Los sistemas de comunicación en el ciberespacio.

Junio 30. El CUIB/Observatorio Astronómico Nacional/Centro de Investigación Científica y Educación Superior de Ensenada organizan la conferencia Uso de indicadores científicos en la evaluación de la ciencia impartida por el investigador Salvador Gorbea Portal. 
Julio. El Centro realiza el cambio de formato de la revista Investigación Bibliotecológica: archivonomía, bibliotecología e información, el cambio no solo afectó la presentación física, sino que rompe con la estructura con la que tradicionalmente se conocía; a partir de este número estará conformada exclusivamente por artículos de investigación, reseñas y por la sección de investigaciones en América Latina, dándole un enfoque más científico y académico, además de integrar esta disciplina al conjunto de saberes que interactúan en las formas globalizadas del conocimiento.

Julio 1. Ingreso de la Mtra. Jane Margaret Russell Barnard como investigadora del CUIB.

Julio 7. Presentación del Cuarto Informe de Actividades por parte de la Directora, la Lic. Elsa M. Ramírez Leyva, para el periodo comprendido entre Julio de 1993 y Junio de 1997. En este informe se refiere al gran esfuerzo realizado por toda la comunidad del Centro, sin la cual no podría ser posible el avance realizado durante estos cuatro años. Por otro lado, pidió iniciar acciones que permitan atender los nuevos retos, reiterando el compromiso y el deseo de participar en el logro de una Universidad cada vez más comprometida con su sociedad.

Julio 15. Se realiza el Seminario para el libro colectivo, CUIB: Acceder y usar la información en medios impresos y electrónicos, en el que participaron las siguientes ponencias: I. Política para facilitar el acceso a la información en una Universidad virtual, II. Información y sociedad, III. Discusión de metodología y contenidos de los capítulos del libro, IV. Comportamiento bibliométrico de la producción y comunicación científica en ciencia bibliotecológica y de la información relativa a América Latina, V. Discusión de metodología y contenidos de los capítulos del libro colectivo a realizar, VI. Entorno a la lectura, VII. El uso de la información en la vinculación universidad-empresa, y VIII. La navegación y la exploración en la información digital del World Wide Web.

Agosto 7. Ingreso del Dr. Héctor Guillermo Alfaro López como investigador del CUIB.

Agosto 11 al 17. El CUIB-Dirección General de Asuntos del Personal Académico-UNAM/Coordinación de Servicios Académicos: United 
States Information Service/ Biblioteca Benjamín Franklin organizan el Seminario Internacional: La investigación en información para la Universidad Virtual, en el que investigadores del Centro participaron con las tres siguientes ponencias: Politicas de información y universidad virtual, impartida por la investigadora Margarita Almada; Experiencia en el uso de nuevas tecnologías para la recuperación de información, impartida por la investigadora Patricia Hernández; y Consideraciones para un sistema integrado de información para la Universidad Virtual, impartida por la investigadora Jane Russell.

Agosto 12. Se da la ratificación como Directora del Centro Universitario de Investigaciones Bibliotecológicas a la Lic. Elsa M. Ramírez Leyva.

Agosto 20. El CUIB y la Universidad de Granada organizan la mesa redonda: Los libros antiguos en las bibliotecas mexicanas en el que participaron como corresponsables: Rosa Ma. Fernández y Manuel Escurrida (invitado).

Septiembre 29. Se desarrolla en el Centro el Seminario sobre lectura y escritura significativa, en el que participa la investigadora Ma. Trinidad Román con la ponencia Propuesta del documento de trabajo: objetivos, metodología y productos.

Octubre 13. Se comisiona a la Lic. Elsa M. Ramírez Leyva como Presidenta de la Asociación Mexicana de Bibliotecarios, A. C.

Octubre 23. El CUIB/Universidad Autónoma del Estado de México organizan la plática sobre Servicios y desarrollo de colecciones de la biblioteca del CUIB.

Noviembre. Publicación del libro coeditado entre el CUIB-UNAM/ Procuraduría General de la República titulado: Terminología de derecho penal, esta obra fue escrita por Surya Peniche de Sánchez McGrégor.

Noviembre 4 al 7. El CUIB realiza el Primer seminario internacional sobre desarrollo de colecciones, en el que participaron un gran número de investigadores del Centro, con las siguientes ponencias: Revisión conceptual de la selección de materiales documentales en el desarrollo de colecciones, impartida por Ma. del Carmen Negrete; Las necesidades de información de la comunidad académica como 
base del desarrollo de colecciones, impartida por Juan José Calva; $E l$ bibliotecólogo en un ambiente de telecomunicaciones: documento introductoria de la mesa redonda, impartida por Roberto Garduño; y El acceso remoto a la información y su valides en la disponibilidad, impartida por Edgardo Ruiz Velasco. Además se contó con la participación de investigadores de las siguientes universidades e instituciones: Claudia Rodríguez de la Cámara Argentina del Libro, Argentina; Carlos A. Cadavid de la Universidad de Antioquia, Colombia; Marta Alicia Pérez de la Escuela Interamericana de Bibliotecología, Universidad de Antioquia, Colombia; Francisco García-Marco y Luisa Orera de la Universidad de Zaragoza, España; Lief Adleson del Centro de Servicios Bibliográficos, S. A. De C. V., USA; Dora Biblarz de Arizona State University Libraries, USA; Jorge Fernández de EBSCO, Internacional, Inc. (Servicios de Información), USA; Oswaldo Parra del Regional Manager Egan Marino Corporation (EMC) Internacional, Inc; Luis Manuel Villar del Baker Library Datmouth Collage, USA; Esther Pailos de la Universidad de la República, Uruguay; Javier Bringas Instituto Venezolano de Investigaciones Científica, Venezuela. Mientras que por las instituciones mexicanas participaron: Shirley Elizabeth del Instituto de Biotecnología- UNAM, Elsa Barbarena de la Facultad de Filosofía y Letras-Posgrado-UNAM, Micaela Chávez de El Colegio de México, Elda Mónica Guerrero del Centro de Investigación y Docencia Económica, Margarita Hupp de la Dirección General Bibliotecas-UNAM, Helen Ladrón de la Universidad de Guadalajara, Enedina Ortega del Instituto Tecnológico de Estudios Superiores Monterrey-Campus Morelos, Álvaro Quijano de El Colegio de México, Lourdes Rovalo de la Dirección General BIBLIOTECAS-UNAM, Saúl Souto del Instituto Tecnológico de Estudios Superiores Monterrey-Campus Querétaro y Pilar Verdejo de la Universidad Iberoamericana.

Noviembre 17. El CUIB y la Escuela Nacional de Biblioteconomía y Archivonomía presentan el libro Seminario latinoamericano sobre formación de usuarios de la información y los estudios de usuarios.

Noviembre 28. El CUIB y la Escuela Nacional de Bibliotecología y Archivonomía presentan el libro Bases teóricas y filosóficas de la bibliotecología. 
Diciembre 1. El CUIB y la Escuela Nacional de Bibliotecología y Archivonomía presentan el libro En el umbral del cambio: las tecnologías de información y la comunicación.

\section{8}

Enero 15. Cambios en el Consejo Interno, el cual quedó constituido de la siguiente forma:

Presidente: Lic. Elsa M. Ramírez Leyva.

Secretario: Lic. Martha A. Añorve Guillén.

Vocales: Mtro. Ramiro Lafuente López.

Lic. Ma. del Carmen Negrete Gutiérrez.

Lic. Susana Sander Villarino.

Lic. Ma. Candelaria Mendoza Galloso.

Marzo 12 y 13. El Mtro. Adolfo Rodríguez Gallardo participa en la organización y modera la VI Reunión sobre Revistas Académicas y de Investigación: La Gestión y el Uso de Publicaciones Electrónicas (Dirección General de Bibliotecas-UNAM), y la mesa redonda: La distribución y comercialización de la publicaciones electrónicas.

Marzo 24 al 27. El Mtro. Adolfo Rodríguez Gallardo participa como coordinador de los grupos de trabajo y presentación de reporte en la Reuniao Regional: Manifesto da UNESCO sobre Bibliotecas Publica; reporte: Organización y Actividades de la Sección Regional de la IFLA.

Abril 16. Se comisiona a la investigadora Martha Alicia Añorve Guillén como Representante del CUIB en la Primera Reunión de Trabajo del PROBETEL (Programa de Becas de Tesis de Licenciatura en Proyectos de Investigación).

Mayo. Participación del Investigador Jaime Ríos Ortega en el desarrollo de la Red de Bibliotecas del Subsistema de Humanidades. Coordinación de Humanidades y Centro Universitario de Investigaciones Bibliotecológicas/UNAM.

Mayo 7 y 8. Se desarrolla en el Centro el Seminario sobre tecnologías de información y educación virtual, en el cual se busca propiciar la discusión que posteriormente conduzcan a la integración de grupos de investigación interdisciplinaria sobre proyectos específi- 
cos; además de apoyar la formación de investigadores a través de la participación en proyectos interdisciplinarios.

Mayo 18 al 29. El CUIB imparte el seminario Metodología de investigación en bibliotecología para la elaboración de tesis de licenciatura, en el que su objetivo fue elaborar el proyecto de investigación de tesis con el fin de concluirla en un periodo de seis meses.

Junio 8 al 12. Por medio del Programa de Intercambio Académico se imparte el seminario Teoría del Documento, el cual estuvo impartido por el Dr. Juan Antonio Martínez Comeche de la Escuela Universitaria de Bibliotecología y Documentación y de la Universidad Complutense de Madrid, España.

Junio 15 y 17. Se imparte en el CUIB el seminario El impacto de las nuevas tecnologías, impartido por el Dr. Juan Antonio Martínez Comeche, de la Escuela Universitaria de Bibliotecología y Documentación y de la Universidad Complutense de Madrid, España.

Julio. Publicación del libro coeditado entre el CUIB-UNAM/Comisión Nacional de los Estados Unidos Mexicanos para la Organización de las Naciones Unidas para la Ciencia, la Educación y la Cultura/Universidad Autónoma del Estado de México/Universidad Autónoma del Estado de Hidalgo titulado: Memoria del mundo, esta obra fue escrita por Abdelaziz Abid.

Agosto 3 y 4. El Centro organiza el seminario pre-coloquio Sistema de metadatos y organización de la información en la era electróni$c a$, en el que participaron los ponentes: Dr. Michael Gorman, Mtro. Ferry McKiernan, Mtra. Robin Wendler, Dra. Judith Hopkins, Dr. Filiberto F. Martínez y Lic. Lina Escalona.

Agosto 5 al 7. Se desarrolla el XVI Coloquio de Investigación Bibliotecológica: Internet, metadatos y acceso a la información en bibliotecas y redes en la era electrónica; en el que se buscó como objetivo el discutir la tendencias, en el ámbito internacional, sobre la organización de información electrónica con el fin de propiciar el intercambio de ideas en esta línea de investigación. La conferencia magistral del mencionado coloquio se abrió a la modalidad de videoconferencia a universidades e instituciones de educación superior. El seminario sobre Tecnologías de Información y Educación virtual, se creó con la finalidad de que los especialistas en este campo intercambia- 
ran ideas en los temas del mismo, desde una perspectiva interdisciplinaria y se realizó en diferentes sesiones presenciales y a distancia a través de Internet a lo largo del año, a las que se integraron diferentes grupos de profesionales del país y del extranjero.

Agosto 20. Se desarrolla la mesa redonda Servicios de información en el sector industrial, el cual fue organizado por la Mtra.Guadalupe Carrión Rodríguez; teniendo como objetivo el ofrecer un panorama general sobre la situación que guardan los servicios de información en y para empresas en el sector industrial del D. F. y el Estado de México.

Agosto 24 al 28. Se organiza en el Centro el seminario Fundamentos de la ciencia bibliotecológica (filosóficos y teóricos), el cual tuvo como objetivo el analizar los principales problemas epistemológicos de la fundamentación de la ciencia bibliotecológica y examinar algunas respuestas a dicha problemática con el propósito de delimitar un marco teórico para la investigación en la disciplina.

Agosto 26. La investigadora Estela M. Morales Campos obtiene el Doctorado en Estudios Latinoamericanos por la Universidad Nacional Autónoma de México. Graduada con Mención Honorífica.

Septiembre 10. Se desarrolla en el Centro la mesa redonda Biblioteca digital, información y medios de comunicación en la educación a distancia, en al que se buscó el debatir en torno a la educación a distancia sobre la biblioteca digital, la información y los medios de comunicación como elementos sustantivos en ésta.

Septiembre 21 al 23. El Mtro. Roberto Garduño coordina el Seminario internacional sobre control bibliográfico universal. El control bibliográfico en América Latina y el Caribe bacia el tercer milenio; el cual tuvo como objetivo el analizar la situación del control bibliográfico en América Latina y el Caribe a fin de identificar problemas de investigación relacionados con el uso de normas, formatos bibliográficos y tecnologías de información y comunicación, con el fin de encontrar propuestas encaminadas a coadyuvar a una mayor cooperación bibliográfica en la región.

Septiembre 24 y 25. EL CUIB organiza el Seminario-taller sobre el uso del Tesauro Latinoamericano en Bibliotecología y Ciencias de la información. El objetivo de este curso fue el de dar a conocer el 
Centro Universitario de Investigaciones Bibliotecológicas. Cronología ...

Tesauro Latinoamericano sobre Bibliotecología y Ciencias de la Información y proporcionar los elementos de los métodos de indización, así como propiciar el análisis de literatura de la especialidad que se encuentra en la colección latinoamericana relativa a la disciplina bibliotecológica.

Septiembre 30 a octubre 2 . Se realiza el seminario sobre Investigación de mercados en bibliotecas y unidades de información; en este se buscó ofrecer a los participantes conceptos fundamentales de la mercadotecnia, así como proporcionar información sobre la importancia de la investigación de mercado en bibliotecas y unidades de información.

Octubre. Se le otorga a la Q.F.B. Elisa Margarita Almada de Ascencio la Beca de la Dirección General de Asuntos del Personal Académico, UNAM, para realizar estudios de posgrado en City University, London, School of Informatics, Department of Information Science.

Octubre. Publicación del libro coeditado entre el CUIB-Programa Universitario de Estudios sobre la Ciudad-UNAM titulado: Memoria del encuentro latinoamericano sobre la biblioteca, la lectura y el niño callejero: México, D.F., 24 al 28 de Junio de 1996, esta obra fue compilada por María Trinidad Román Haza.

Octubre 19 al 23. El Centro organiza el curso La formación de usuarios y las nuevas tecnologías, el cual tuvo como finalidad que el personal que labora en unidades de información analice el uso de la nuevas tecnologías de la información en el diseño y funcionamiento de sistemas de información y la relación que guarda con el proceso denominado formación de usuarios; así como tener un mejor acceso a la información electrónica.

Octubre 26 al 30. Se desarrolla en el Centro el seminario-taller Métodos para detectar las necesidades de información de los usuarios, el cual fue coordinado por el Dr. Juan José Calva González; y el cual tuvo como objetivo analizar los diferentes métodos y técnicas que se pueden emplear para detectar las necesidades de información de los usuarios en bibliotecas universitarias y especializadas.

Noviembre 18. El Consejo Universitario aprueba la propuesta de creación del nuevo Posgrado en Bibliotecología y Estudios de la Información, incluyendo los estudios de maestría y por vez primera 
los estudios de doctorado; dicho posgrado es de responsabilidad conjunta entre el CUIB y la Facultad de Filosofía y Letras.

Diciembre 3. El investigador José Adolfo Rodríguez Gallardo obtiene el Doctorado en Pedagogía con la tesis intitulada: Hacia la recuperación bumanística de la educación bibliotecológica por la Universidad Nacional Autónoma de México. Graduado con Mención Honorífica.

\section{9}

Enero. Publicación del libro coeditado entre el CUIB-Programa Universitario de Estudios sobre la CIUDAD-UNAM titulado: Mapa Bibliotecario y de Servicios de Información de la Ciudad de México, esta obra fue coordinada por la investigadora Rosa María Fernández de Zamora.

Febrero. Cambios en el Consejo Interno, el cual quedó constituido de la siguiente forma:

Presidente: Lic. Elsa M. Ramírez Leyva.

Secretario: Lic. Martha A. Añorve Guillén.

Vocales: $\quad$ Mtro. Ramiro Lafuente López.

Dr. Juan José Calva González.

Febrero 23. Se le otorga el grado de Doctor en Filosofía (PhD) a la investigadora Jane Margaret Russell Barnard con la tesis intitulada: Collaboration and research performance in science: a study of scientists at the National University of México (UNAM), por la City University, Londres, Inglaterra.

Marzo 15 al 17. El Dr. Adolfo Rodríguez Gallardo es miembro del comité organizador y modera el II Seminario Latinoamericano de Asociaciones Bibliotecarias y Profesionales Afines (Las Asociaciones del Futuro), organizado por el CUIB/Section of Regional Activities for Latin America and The Caribbean (IFLA-LAC)/Asociación Mexicana de Bibliotecarios A.C.

Abril. Publicación del libro coeditado entre el CUIB-UNAM/Federación Internacional de Asociaciones de Bibliotecarios e Instituciones titulado: II Seminario Latinoamericano de Asociaciones de Bibliote- 
Centro Universitario de Investigaciones Bibliotecológicas. Cronología ...

carios y Profesionales Afines, esta obra fue coordinada por la investigadora Rosa María Fernández de Zamora.

Abril 5. Ingreso de la Dra. María Idalia García Aguilar como investigadora del CUIB.

Junio 1. El CUIB y la Facultad de Psicología desarrollan el primer Simposio Internacional: Investigación sobre la comunicación científica: un enfoque multidisciplinario, el cual fue organizado por la Q.F.B. Elisa Margarita Almada de Ascencio.

Agosto 26. Se comisiona a la Lic. Elsa M. Ramírez Leyva como Miembro del Consejo Técnico de la Asociación Mexicana de Bibliotecarios, A.C.

Septiembre 6 al 10. Se desarrolla el XVII Coloquio de Investigación Bibliotecológica: Contribución al desarrollo de la sociedad del conocimiento.

Septiembre 30. El Dr. Adolfo Rodríguez Gallardo participa como organizador y como ponente en la $7^{a}$ Reunión sobre Revistas Académicas y de Investigación: las nuevas tendencias en la educación electrónica y los servicios de información. 7th Meeting on Scholary and Research Journals: New trends in electronic publishing and information services (Dirección General de Bibliotecas-UNAM); ponencia: La experiencia de la UNAM en la selección, adquisición y administración de revistas electrónicas de texto completo.

Diciembre. Publicación del libro coeditado entre el CUIB-UNAM/ International Federation Library Assiciation/ ALFAGRAMA titulado: Control Bibliográfico Universal: el control bibliográfico en América Latina, esta obra fue compilada por el investigador Roberto Garduño Vera.

Diciembre 2. El CUIB y la Universidad Complutense de Madrid, España, entregan los diplomas de terminación de estudios de doctorado a investigadores del CUIB.

Diciembre 10. La investigadora Georgina Araceli Torres Vargas obtiene el Doctorado en Ciencias de la Información con la tesis intitulada: El concepto de biblioteca virtual y su relación con el acceso universal a los documentos, por la Universidad Complutense de Madrid, España. Sobresaliente Cum Laude. 


\section{0}

Enero. Publicación del libro coeditado entre el CUIB-UNAM/Plaza y Valdés Editores titulado: Historia de las librerías de la Ciudad de México, esta obra fue escrita por Juana Zahar Vergara. Cabe señalar que se trata de la segunda edición, ya que la primera fue publicada en Diciembre de 1995 únicamente con la participación del CUIB.

Enero. Publicación del libro coeditado entre el CUIB-UNAM/Fideicomiso para la Cultura México-EUA/ Información Científica Internacional/ ALFAGRAMA titulado: Introducción general al Servicio de Consulta: libro de texto para el estudiante de bibliotecología y manual para el bibliotecario de consulta, esta obra fue escrita por Richard E. Bopp y Linda C. Smith, con la traducción de Carlos C. Compton García.

Enero 16. El Dr. Adolfo Rodríguez Gallardo participa como organizador y como conferencista de la Reunión de Invierno de la American Library Association organizada por la Dirección General de Bibliotecas-UNAM y la American Library Association; conferencia: Videoconferencia El impacto de los recursos electrónicos en la colaboración bibliotecaria internacional.

Febrero. Se comisiona al Dr. Adolfo Rodríguez Gallardo como Representante del Comité Académico del Colegio Nacional de Bibliotecarios A.C.

Febrero. Cambios en el Consejo Interno, el cual quedó constituido de la siguiente forma:

Presidente: Lic. Elsa M. Ramírez Leyva.

Secretario: Lic. Martha A. Añorve Guillén.

Vocales: $\quad$ Mtro. Ramiro Lafuente López.

Dr. Juan José Calva González.

Lic. Miguel Ángel Rendón Rojas.

Lic. Emma Norma Romero Tejeda.

Febrero 18. Se comisiona al Mtro. Jaime Ríos Ortega como Secretario Técnico de Seguimiento e Información de la Coordinación de Humanidades, UNAM.

Marzo 27 al 29. Se organiza el seminario Diseño de un esquema de clasificación, el cual se desarrolló en la Sala de Seminarios del CUIB. 
Centro Universitario de Investigaciones Bibliotecológicas. Cronología ...

Marzo 28. El Centro organiza la presentación del Diccionario de bibliotecólogos latinoamericanos y especialistas afines: una aproximación, desarrollada en el Auditorio 4 del Palacio de Minería de la UNAM.

Marzo 31. Participación del CUIB en la mesa redonda Salvaguardia de la riqueza bibliográfica y documental de México: importancia de la cooperación, desarrollada en el Palacio de Minería de la UNAM. Marzo 31. Presentación del Tesauro latinoamericano en ciencia bibliotecológica y de la información, el cual se realizó en el Auditorio 4 del Palacio de Minería de la UNAM.

Marzo 31. El Centro organiza la presentación del libro Control bibliográfico universal: el control bibliográfico en América Latina y El Caribe hacia el tercer milenio, desarrollada en la Academia de la Investigación del Palacio de Minería de la UNAM.

Mayo. Publicación del libro coeditado entre el CUIB-UNAM/ Infoconsultores titulado: Internet, metadatos y acceso a la información en bibliotecas y redes en la era electrónica, esta obre fue compilada por los investigadores Filiberto Felipe Martínez Arellano y Lina Escalona Ríos.

Mayo 26. El CUIB-Palacio de Minería organizan la mesa redonda La digitalización del patrimonio documental: problemática y perspectiva, desarrollado en el Auditorio "Mario de la Cueva" de la Torre II de Humanidades de la UNAM.

Julio. Se designa al Dr. Adolfo Rodríguez Gallardo como Miembro del Consejo Interno del CUIB.

Septiembre 6 al 8. Se organiza el curso Control de calidad en bases de datos bibliográficas, la cual se desarrolló en la sala de computo del Instituto de Investigaciones Económicas y la Sala de Seminarios de CUIB, UNAM.

Octubre. Se comisiona al Dr. Adolfo Rodríguez Gallardo como Miembro Externo de la Comisión Evaluadora de Primas al Desempeño del Personal Académico de Tiempo Completo (PRIDE) del Centro Coordinador y Difusor de Estudios Americanos, UNAM.

Octubre 2 al 4. El Centro organiza el Segundo Simposio Internacional: Investigación sobre la comunicación científica: un enfoque multidisciplinario, el cual contó con la participación de las siguien- 
tes instituciones extranjeras: City University, Queen Margaret University Collage, Loughborogh University y Universidade de Brasil; así como la participaciones de diferentes instituciones nacionales.

Octubre 5. Se realiza el XVIII Coloquio Internacional de Investigación Bibliotecológica. El medio digital en el siglo XXI: retos y perspectivas para los bibliotecólogos, investigadores, educadores $y$ editores, el cual se celebró en el Auditorio "José Vasconcelos" del Centro de Estudios para Extranjeros de la UNAM; además se contó con la participación de especialistas nacionales y internacionales. En esta ocasión se presentaron las siguientes ponencias: I. El libro electrónico: desafíos para bibliotecas y lectores The eBook: Challenges for libraries and readers, II. Conferencia en educación a distancia, III. Educación y medios digitales: algunas consideraciones, IV. El bibliotecólogo como organizador y como proveedor de información electrónica, V. Modelos en conflicto en la formación del bibliotecólogo mexicano.

Noviembre. Se comisiona al Dr. Adolfo Rodríguez Gallardo como miembro de la Comisión Revisora del Proyecto de Reglamento de la Asociación Mexicana de Bibliotecarios, A.C.

Noviembre. Se nombra a la Mtra. Elsa M. Ramírez Leyva como Miembro de la Comisión para Revisión y Propuestas para el Reglamento Interno del CUIB.

Noviembre 15. Se imparte la conferencia Antecedentes latinoamericanos de atención a la problemática de servicios bibliotecarios a las comunidades indígenas, el cual se impartió en el Auditorio del Instituto de investigaciones Antropológicas de la UNAM.

Noviembre 15 y 16. Se desarrolla el Encuentro Latinoamericano sobre la atención bibliotecaria a las comunidades indigenas, el cual mereció el apoyo de la Internacional Federation Library Association y la participación de un gran número de universidades de América Latina y diferentes universidades y dependencias del país.

Diciembre 6 y 7. Se efectúa el Seminario sobre tecnologías de información y educación virtual, el cual se desarrolló en la Sala de Seminarios del CUIB. 
Centro Universitario de Investigaciones Bibliotecológicas. Cronología ...

2001

Enero. Publicación del libro coeditado entre el CUIB-UNAM/Información Científica Internacional, S.A. de C.V. titulado: Librerías infantiles: un espacio para la lectura, esta obra estuvo bajo la coordinación y dirección editorial de la Dra. Estela Mercedes Morales Campos.

Febrero 19 y 20. Se realiza la primera sesión, de cinco a lo largo del año, del Seminario Permanente: Tecnologías de información y educación virtual, desarrollada en el Salón de Seminarios del Centro.

Marzo 5 a Agosto 31. Se organiza el Diplomado: Problema Teóricos y Metodológicos de la Investigación en Ciencias Bibliotecológicas y de la Información.

Junio. Se comisiona al Dr. Filiberto Felipe Martínez Arellano como Presidente del Comité para la Certificación Bibliotecológica del Colegio Nacional de Bibliotecarios A.C.

Junio. Publicación del libro coeditado entre el CUIB-UNAM/Federación Internacional de Asociaciones de Bibliotecarios e Instituciones titulado: Encuentro Latinoamericano sobre la atención bibliotecaria a las comunidades indígenas, esta obra fue compilada por la investigadora María del Rocío Graniel Parra.

Julio. Se publica el volumen 30 de la revista Investigación Bibliotecológica: Archivonomía, Bibliotecología e Información publicada por el CUIB, este es el primer número dentro del Índice de Revistas Mexicanas de Investigación Científica y Tecnológica del Consejo Nacional de Ciencia y Tecnología.

Julio 1. Se designa a la Dra. Georgina Araceli Torres Vargas como Investigador Nacional Nivel I por el Sistema Nacional de Investigadores.

Agosto. Cambios en el Consejo Interno, el cual quedó constituido de la siguiente forma:

Presidente: Dr. Filiberto Felipe Martínez Arellano.

Secretario: Dr. Juan José Calva González.

Vocales: Dr. Héctor Guillermo Alfaro López

Dra. Patricia Hernández Salazar.

Mtra. Ma. del Carmen Negrete Gutiérrez.

Lic. Emma Norma Romero Tejeda. 
Centro Universitario de Investigaciones Bibliotecológicas. Cronología ...

Ing. Edgardo Ruiz Velasco Romo.

Invitada: Mtra. Martha A. Añorve Guillén.

Agosto. La Mtra. Elsa M. Ramírez Leyva es nombrada Representante en México del Comité Permanente de la Sección de América Latina y el Caribe de la Federación Internacional de Asociaciones e Instituciones Bibliotecarias (IFLA).

Agosto 16 al 24. El Dr. Adolfo Rodríguez Gallardo participa como organizador de mesas y ponente en la 67 IFLA Council of General Conference organizado por la IFLA (Federación Internacional de Asociaciones e Instituciones Bibliotecarias) Annual General Meeting Boston y el Foro Abierto de la Región América Latina; ponencia: The digital divide: a view from Latin America and the Caribbean, mesas organizadas: Open Meeting Latin America and theCaribbean, Open Forum Disivision 8 Digital Divide $y$ Workshop on Latinamerican Collections in the USA and Cooperation.

Agosto 22. El Dr. Filiberto Felipe Martínez Arellano toma posesión como Director del CUIB. Uno de los principales puntos de su programa de trabajo es la consolidación cualitativa de la planta de investigación del Centro y su proyección en el ámbito internacional, a través del incremento en la participación de los investigadores en eventos académicos y congresos internacionales, pero sobre todo en publicaciones a nivel internacional.

Agosto 27. Se realiza la conferencia Acceso al patrimonio cultural como derecho democrático la cual se impartió en el Salón de Seminarios del CUIB.

Agosto 28 al 30. El Centro organiza el XIX Coloquio Internacional de Investigaciones Bibliotecológicas y de la Información. Los grandes problemas de la información en la sociedad contemporánea. Este Coloquio se inició con las Palabras de Inauguración del XIX Coloquio Internacional de Investigaciones Bibliotecológicas y de Información ofrecidas por el Director del CUIB el Dr. Filiberto Felipe Martínez Arellano, seguida de la Conferencia Magistral: iInformación o Improvisación? Impartida por la Dra. Estela M. Morales. En esta ocasión se trataron las siguientes mesas redondas con los temas: I. Educar para informar, informar para educar; en la que participaron las siguientes ponencias: Investigación en Información y Politi- 
Centro Universitario de Investigaciones Bibliotecológicas. Cronología ...

ca para la sociedad contemporánea, impartida por Margarita Almada de Ascencio del CUIB; Bibliotecas y Educación, impartida por Fernando Álvarez Ortega de la Universidad Iberoamericana; $E d u$ car en la era de la información, impartida por Ángel Díaz Barriga del Centro de Estudios sobre la Universidad; Información: insumo básico del aprendizaje, impartida por Jesús Lau de la Universidad Autónoma de Ciudad Juárez; La sociedad de la información y del conocimiento, impartida por Diana Cecilia Ortega de la Asociación Nacional de Universidades e Instituciones de Educación Superior. II. Las bibliotecas archivos y museos en el derecho a la información: fronteras y relaciones; en la que participaron las siguientes ponencias: Derecho a la información, impartida por Virginia Amella de Aspe del Instituto Nacional de Antropología e Historia; y Las Bibliotecas, Archivos y Museos en el Derecho a la Información: fronteras y relaciones, impartida por Elvia Barberena Blázquez. III. El derecho a la información y su contexto jurídico, en la que participaron las siguientes ponencias: El derecho a la información y su contexto jurídico, impartida por María Pilar Cousido de la Universidad Complutense de Madrid, España; The touchstone of all the freedoms: the right to information and its legal framework, impartida por Alex Byrne de la International Federation of Library Association; El derecho a la información. Panorama de logros en México, impartida por Enrique Molina de la Biblioteca del Congreso de la Unión. IV. La biblioteca y el archivo en el entorno educativo: universidad, en la que se presentaron las siguientes ponencias: Educación, Información y Bibliotecas, impartida por Filiberto Felipe Martínez del CUIB; La Biblioteca como base de la educación en un contexto global, impartida por Lina Escalona del CUIB; Los archivos y el conocimiento, los archivos y la educación, impartida por Cecilia Ramírez del Archivo Histórico de la UNAM; y La biblioteca pública y la tendencia tecnológica a la educación, impartida por Jorge von Ziegler de la Dirección General de Bibliotecas de Consejo Nacional para la Cultura y la Artes/Secretaría de Educación Pública. V. El patrimonio cultural y el mundo de la información, en la que se presentaron las siguientes ponencias: El patrimonio bibliográfico y documental en la sociedad de la información, impartida por Rosa María Fernández 
del CUIB/Biblioteca Nacional de México; Breve mirada a la bistoria del patrimonio documental mexicano, impartida por Ana Rita Valero de la Asociación Mexicana de Archivos y Bibliotecas Privados; Registro y protección del patrimonio bibliográfico documental de la nación, impartida por Rosa María Fernández del CUIB/Biblioteca Nacional de México; y De la memoria de papel al BIT, impartida por Carlos Román García del Archivo General de la Nación.

Septiembre 16. Se imparte la conferencia Presentación de los Programas de Financiamiento de la Comisión Europea para América Latina: el caso de México a través del CONACYT, la cual se llevó a cabo en el Salón de Seminarios del CUIB.

Octubre 4. La investigadora Patricia Hernández Salazar obtiene el Doctorado en Ciencias de la Información por la Universidad Complutense de Madrid, España. Sobresaliente Cum Laude.

Diciembre 7. El Dr. José Adolfo Rodríguez ofrece un discurso por motivo del vigésimo aniversario del CUIB. En este se refirió a la trayectoria por la que ha pasado el Centro a lo largo de estos veinte años, en los cuales se desarrolló un personal profesional, que por medio de sus trabajos de análisis, especulación y difusión académica darían grandes beneficios a la Bibliotecología en general y principalmente a la Bibliotecología mexicana; se resolvieron las necesidades de desarrollar un personal calificado para ofrecer un mejor servicio en las bibliotecas, al que se le reconoció su trabajo como académico y no como administrativo, lo que permitió que a la Bibliotecología se le viera como una disciplina humanística y no solo como una actividad de servicio. Se reconocen los avances obtenidos por el Centro, desde las críticas que se le hacen a la disciplina con el fin de mejorarla cada día para producir mejores estudiantes e investigadores de la misma, hasta los apoyos que hoy brinda a diferentes instituciones de América Latina y el Tercer Mundo para la creación de sus propias bibliotecas y sus propios centros de estudio de esta disciplina.

Diciembre 7. Participación de la Dra. Elsa M. Ramírez en la mesa redonda Las asociaciones bibliotecarias en el II Seminario Latinoamericano de Asociaciones de Bibliotecarios y Profesionales Afines, el cual estuvo organizado por el CUIB y la Federación Internacional de Asociaciones e Instituciones de Bibliotecarios. 
Centro Universitario de Investigaciones Bibliotecológicas. Cronología ...

Diciembre 7 al 11. Se organiza la exposición $X X$ aniversario del Centro en el piso 11 del CUIB.

Diciembre 12. El Centro organiza la presentación del libro Miradas aisladas, visiones conjuntas: defensa del patrimonio documental mexicano, la cual se desarrollo en el Salón de Seminarios del CUIB. Diciembre 12 y 13. El CUIB organiza el curso El fondo antiguo como biblioteca bistórica, impartido por la Dra. María Idalia García. Diciembre 14. El investigador Juan José Calva González obtiene el Doctorado en Ciencias de la Información por la Universidad Complutense de Madrid, España. Sobresaliente Cum Laude.

\section{2}

Enero. Publicación del libro coeditado entre el CUIB-Facultad de Psicología-UNAM titulado: Memorias del Simposio Internacional, investigación sobre la comunicación científica: un enfoque multidisciplinario, esta obra fue compilada por las investigadoras Margarita Almada de Ascencio, Sofía Liberman y Jane Margaret Russell.

Febrero 27 y 28. Se imparte la mesa redonda, dentro de los festejos del vigésimo aniversario del Centro, Pensamiento y educación bibliotecológica, desarrollada en el Salón de Seminarios del CUIB.

Marzo 2 al 9. Como producto de los convenios establecidos con instituciones españolas, el Dr. José López Yepes de la Universidad Complutense de Madrid, España, realizó una estancia en el CUIB en la que impartió el Seminario de Investigación: La Investigación en Bibliotecología y Documentación con respecto al documento, la lectura, el desarrollo de las colecciones documentales y autores.

Abril 9 y 10. Se organiza la mesa redonda, dentro de los festejos del vigésimo aniversario del Centro, Investigación del fenómeno denominado usuarios de la información.

Abril 10. La Dra. Estela Mercedes Morales Campos es designada como directora del Centro Coordinador y Difusor de Estudios Latinoamericanos de la UNAM. 
Centro Universitario de Investigaciones Bibliotecológicas. Cronología ...

Mayo 20 y 21. Se desarrolla el Seminario Permanente: Tecnologías de información y educación virtual, en el que participan investigadores y académicos de otras instituciones y disciplinas.

Mayo 29. Se desarrolla la mesa redonda Tendencias actuales del mercado editorial: productos y servicios.

Mayo 29. Se realiza la mesa redonda Publicación y bibliotecas digitales: hacia una visión integradora, organizada por la Lic. Angélica Ma. Rosas y la Dra. Georgina A. Torres.

Julio-Agosto. Se designa al Dr. Juan Voutssás Márquez como miembro del Comité Académico Internacional para la asignación del nuevo operador mundial del dominio “.org” para ICANN. Internet Corporation for Assigned Names and Numbers. Los Ángeles, California, EUA.

Julio 1. Se designa al Dr. Juan José Calva González como Investigador Nacional Nivel I por el Sistema Nacional de Investigadores.

Julio 2. La investigadora Catalina Naumis Peña obtiene el Doctorado en Ciencias de la Información por la Universidad Complutense de Madrid, España.

Julio 26. Se desarrolla la mesa redonda, dentro de los festejos del vigésimo aniversario del Centro, Comunicación y transferencia de información, impartida en el Salón de Seminarios del CUIB.

Agosto. La Dirección General de Estudios de Posgrado del Programa de Maestría y Doctorado en Bibliotecología y Estudios de la Información otorgan el Diploma de Reconocimiento al Mtro. Jaime Ríos Ortega por la tesis de maestría: Las revistas científicas del Subsistema de Humanidades, UNAM que aparecen en los indices del CONACYT: Estudio sobre su normalización, arbitraje y disponibilidad.

Se comisiona al Dr. Juan Voutssás Márquez como Miembro del Comité Asesor de la Hemeroteca Nacional Digital de México. Coordinador de la Comisión Tecnológica.

Octubre 16 y 17. La Dra. Estela M. Morales Campos coordina el $8^{\circ}$ Coloquio de Investigación del Centro Coordinador y Difusor de Estudios Latinoamericanos, UNAM.

Octubre 21. Como producto de los convenios establecidos con instituciones españolas, el Dr, José López Yepes de la Universidad Complutense de Madrid, España, realizó una estancia en el CUIB en la que 
Centro Universitario de Investigaciones Bibliotecológicas. Cronología ...

impartió el Seminario sobre bistoria de la lectura en México y Espana en la edad contemporánea: cultura impresa, libros, libreros, editores y bibliotecas públicas.

Noviembre 11. El Centro organiza la mesa redonda Historia y autores en Bibliotecología, impartida en la Sala de Juntas del CUIB.

Noviembre 12 al 14. La Dra. Estela M. Morales Campos coordina la Cátedra Extraordinaria José Martí. 1902-2002, del Centro Coordinador y Difusor de estudios Latinoamericanos, UNAM.

Noviembre 13. El Centro organiza la mesa redonda Usuarios, comunidades e información, desarrollado en el Salón de Seminarios del piso 13 de la Torre II de Humanidades.

Noviembre 13 al 15. Se desarrolla el $X X$ Coloquio de Investigación bibliotecológica y de la Información. Investigación Bibliotecológica: Presente y Futuro. En esta ocasión el Coloquio se dedicó a analizar la investigación bibliotecológica realizada en México y en el ámbito internacional, así como su estado actual y su perspectiva futura en los diferentes campos de la disciplina, en el presente Coloquio abordó diferentes vertientes de la investigación bibliotecológica y sus repercusiones en las bibliotecas y otras unidades informativas. El Coloquio fue iniciado con las Palabras de Inauguración del XX Coloquio de Investigación bibliotecológica y de la Información. Investigación Bibliotecológica: Presente y Futuro ofrecidas por el Director del CUIB el Dr. Filiberto Felipe Martínez, seguidas de la Conferencia Magistral: Trends in LIS research in the U. S. Impartida por Leigh S. Estabrook. En esta ocasión se presentaron las siguientes ponencias: El planteamiento de Juana Manrique de Lara a Vasconcelos sobre biblioteca infantiles y juveniles, impartida por Martha Alicia Añorve del CUIB; La Lectura: un campo de investigación con muchas facetas y muchas incógnitas, impartida por Elsa Margarita Ramírez del CUIB; Bibliotecas Digitales impertida por Georgina Araceli Torres; Educación a distancia y Bibliotecología, impartida por Roberto Garduño del CUIB; Práctica profesional e investigación bibliotecológica, impartida por Álvaro Quijano de El Colegio de México; Investigación sobre servicios electrónicos de información, impartida por Margarita Lugo de la Dirección General de Bibliotecas de la UNAM; Investigación sobre servicios técnicos, impartida por Esperanza Mo- 
lina de la Facultad de Filosofía y Letras y Dirección General de Bibliotecas de la UNAM; Bibliotecas Públicas e Información, impartida por Juan Domingo Argüelles de la Dirección General de Bibliotecas de la UNAM; Los temas de los trabajos recepcionales en la licenciatura en Bibliotecología en la UNAM, impartida por Carmen Yasmina López de El Colegio de México; Fomento y apoyo a la investigación en el Centro de Investigaciones en Ciencias de la Información-CICINF- de la Escuela Interamericana de Bibliotecología, impartida por Nora Elena Rendón de la Universidad de Antioquia, Colombia; y Líneas de investigación en el porgrado de Bibliotecología y Estudios de la Información, impartida por Elsa Barberena de la Facultad de Filosofía y Letras de la UNAM. Además se presentaron las siguientes mesas redondas: I. La investigación en los planes de estudio de las escuelas mexicanas de bibliotecología, en la que participaron: Cesar Augusto Ramírez del CUIB/UNAM, Rosa María Martínez de la U. Autónoma de San Luis Potosí, Silvana Elisa Cruz de la U. Autónoma del Estado de México, Rosa Alba Chacón de la U. Autónoma de Chiapas y Rita Virginia Ramos Castro de la U. Autónoma de Chiapas. II. Bibliotecología, Educación y Sociedad, en la que participaron: Estela M. Morales del CUIB/UNAM, Jaime Ríos del CUIB/UNAM, Beatriz Casa de la UNAM, Hugo Figueroa de la UNAM, José de Jesús Hernández de la Escuela Nacional de Archivonomía y Biblioteconomía, Rosa María Martínez de la U. Autónoma de San Luis Potosí, Celia Mireles de la U. Autónoma de San Luis Potosí, Eduardo Salas de la Escuela Nacional de Archivonomía y Biblioteconomía y Rosa Elba Chacón de la U. Autónoma de Chiapas. Usuarios, comunidades e información, en la que participaron: Juan José Calva del CUIB/UNAM, Patricia Hernández del CUIB/UNAM, María del Rocío Graniel de la U. Autónoma del Estado de México y Jane Margaret Russell del CUIB/UNAM. Organización de la información documental, en la que participaron: Angélica María Rosas de la UNAM, Susana Sander del CUIB/UNAM, Sofía Brito de la UNAM, Isabel Espinosa de la UNAM, Jorge Gómez de la UNAM, María Teresa González de la UNAM, María Patricia de la Rosa de la UNAM, Ariel Alejandro Rodríguez del CUIB/UNAM, Blanca E. Sánchez de la UNAM y Reinaldo Figueroa de El Colegio de México. Investigación en sistemas y servicios de información, en la que participan: 
Juan Voutssás del CUIB/UNAM, Clara López de la UNAM y Alma Rivera de la Universidad Iberoamericana. Historia y autores de la bibliotecología mexicana, en la que participan Margarita Bosque de la UNAM, Jorge Cabrera de la U. Autónoma del Estado de México, Griselda Gómez de la U. Autónoma de San Luis Potosí, José Alberto Juárez de U. Autónoma de San Luis Potosí y Archivo Histórico del Estado de San Luis Potosí, Linda Sametz de Marcel Dekker/ América Latina y Ana María Sánchez de la UNAM. La investigación en el patrimonio documental: reflexiones sobre un problema multidisciplinar, en la que participaron: Ana Rita Valero de la Asociación Mexicana de Archivos y Bibliotecas Privados, A.C, Celia Ramírez de la UNAM, Elke Köppen de la UNAM, Griselda Gómez de la U. Autónoma de San Luis Potosí, José Alberto Juárez de la U. Autónoma de San Luis Potosí y Miguel Ángel Rendón del CUIB/UNAM.

Noviembre 15. Se desarrolla la mesa redonda Investigación en organización de la información documental y del conocimiento, impartida en el Salón de Seminarios del Centro.

Diciembre. Publicación del libro coeditado entre el CUIB-UNAM/Benemérita Universidad Autónoma de Puebla titulado: Legislación sobre bienes culturales muebles: protección del libro antiguo, esta obra fue escrita por la Dra. María Idalia García Aguilar.

Diciembre 12. El investigador Roberto Garduño Vera obtiene el Doctorado en Ciencias de la Información por la Universidad Complutense de Madrid, España.

\section{3}

Designan a la Dra. Catalina Naumis Peña como Investigador Nacional Nivel I por el Sistema Nacional de Investigadores.

Designan al Dr. Héctor Guillermo Alfaro López como Investigador Nacional Nivel I por el Sistema Nacional de Investigadores.

Designan al Dr. Roberto Garduño Vera como Investigador Nacional Nivel I por el Sistema Nacional de Investigadores.

Enero. Se designa al Mtro. Jaime Ríos ortega como Miembro del Comité Editorial de la Revista El Bibliotecario del CONACULTA. Consejo Nacional para la Cultura y las Artes. 
Centro Universitario de Investigaciones Bibliotecológicas. Cronología ...

Febrero 17 al 21. Se organiza el curso Publicación digital en red en las bibliotecas académicas, impartido en el Salón de Seminarios del Centro.

Febrero 24. Se desarrolla en el Centro la mesa redonda La enseñanza de la investigación bibliotecológica: retos y alternativas.

Febrero 25. Se organiza en el Centro la presentación del libro Legislación sobre bienes culturales muebles: protección del libro.

Marzo 7. Se le otorga el Reconocimiento Laureana Wright de la Sociedad Mexicana de Geografía y Estadística, Academia Nacional de la Mujer a la Q.F.B. Margarita Almada de Ascencio.

Marzo 8. Se le otorga el premio Juana Ramírez de Asbaje de la UNAM a la Dra. Estela M. Morales Campos.

Mayo. Publicación del libro coeditado entre el CUIB-UNAM/Asociación Mexicana de Bibliotecarios, A.C. titulado: Memorias de las XXXIII Jornadas Mexicanas de Biblioteconomía: Monterrey, Nuevo León 5 al 7 de Junio de 2002, esta obra fue compilada y editada por los investigadores Filiberto Felipe Martínez Arellano y Saúl Armendáriz Sánchez.

Mayo 20. Ingreso del Lic. César Augusto Ramírez Velásquez como investigador del CUIB.

Junio. Se designa a la Mtra. Elsa M. Ramírez Leyva como Jurado Calificador del Concurso Internacional de Arquitectura de la Biblioteca de México "José Vasconcelos". Consejo Nacional para la Cultura y las Artes.

Julio. Se designa al Dr. Adolfo Rodríguez Gallardo como Miembro de la Comisión Dictaminadora del CUIB/UNAM.

Julio 15 a Diciembre 11. La Lic. Silvia Calzada de la University of California, USA, realiza una estancia de investigación en el CUIB, bajo la asesoría del Dr. Filiberto Felipe Martínez Arellano.

Agosto. El Dr. Adolfo Rodríguez Gallardo en nombrado Coordinador del Posgrado en Bibliotecología y Estudios de la Información de la Facultad de Filosofía y Letras de la UNAM.

Agosto 11 a Febrero 11 del 2004. El investigador Francisco Mateos Rodríguez de la Universidad de Granada, España, realiza una estancia de investigación, en la cual queda bajo la asesoría de la Dra. Jane M. Russell Barnard. 
Centro Universitario de Investigaciones Bibliotecológicas. Cronología ...

Agosto 25 al 29. Se desarrolla el curso Comunicación organizacional en bibliotecas en el Salón de seminarios del Centro.

Septiembre 1. Cambios en el Consejo Interno, el cual quedó constituido de la siguiente forma:

Presidente: Dr. Filiberto Felipe Martínez Arellano.

Secretario: Dr. Juan José Calva González.

Vocales: Dr. Héctor Guillermo Alfaro López

Dra. Patricia Hernández Salazar.

Mtra. Ma. del Carmen Negrete Gutiérrez.

Lic. Emma Norma Romero Tejeda.

Ing. Edgardo Ruiz Velasco Romo.

Invitada: Dra. Catalina Naumis Peña.

Septiembre 24. El Centro organiza la mesa redonda La investigación bibliotecológica en América Latina, desarrollado en el Salón de Seminarios.

Septiembre 24 al 26. Se desarrolla el XXI Coloquio de Investigación Bibliotecológica y de la Información. La investigación bibliotecológica en la era de la información. El objetivo para esta ocasión es el de identificar y analizar los problemas y fenómenos de investigación que la sociedad de la información ha traído consigo, así como los métodos y técnicas a partir de los cuales pueden ser abordados; además de las técnicas a seguir por las investigaciones bibliotecológicas para enfrentar el creciente número de fenómenos y objetos de estudio relacionados con la evolución continua de la tecnología. El presente Coloquio fue iniciado con las Palabras de Inauguración del XXI Coloquio de Investigación Bibliotecológica y de la Información. La investigación bibliotecológica en la era de la información ofrecidas por el Director del CUIB el Dr. Filiberto Felipe Martínez, seguidas posteriormente de las Conferencias Magistrales: De la Práctica a la Investigación impartida por el Dr. Adolfo Rodríguez del CUIB/UNAM y Uma proposta conceitual para a massa documental considerando o ciclo de interação entre tecnologia e o registro do conbecimento impartida por Antonio Miranda e Elmira Simeão de la Universidad de Brasilia, Brasil. En esta ocasión se presentaron las siguientes ponencias: Evaluación cualitativa de la investigación bibliotecológica y de la información, impartida por José López Yepes de la 
Centro Universitario de Investigaciones Bibliotecológicas. Cronología ...

Universidad Complutense de Madrid, España, y Judith Prat Sedeño de la Universitat de Lleida; Juana Manrique de Lara 1924, una propuesta integral para la formación de bibliotecarios, impartida por Martha Alicia Añorve del CUIB/UNAM. Las mesas redondas: La investigación bibliotecológica y las comunidades científicas en un contexto colombiano, impartida por Edilma Naranjo y Nora Elena Rendón de la Universidad de Antioquia, Colombia; La investigación bibliotecológica en Argentina, impartida por Susana Romanos de la Universidad de Buenos Aires, Argentina; Tendencias en la investigación española: métodos avanzados de recuperación de información, impartida por Juan Ros de la Universidad de Murcia, España; Aproximaciones a la investigación bibliotecológica en los programas de licenciatura, impartida por Lina Escalona del CUIB/UNAM, Docencia e investigación: congruencia en la Escuela Interamericana de Bibliotecología, Edilma Naranjo y Nora Elena Rendón de la Universidad de Antioquia, Colombia; La investigación bibliotecológica en el siglo XXI, impartida por Rosa María Martínez de la U. Autónoma de San Luis Potosí; Cronología de la licenciatura en Ciencias de la Información de la Universidad Autónoma de Chibuabua, impartida por Teresa de Jesús Núñez e Irma Perea de la Universidad Autónoma de Chihuahua; La investigación bibliotecológica en el plan de estudios de la licenciatura en Bibliotecología y Estudios de la Información: Colegio de Bibliotecología de la UNAM, impartida por César Augusto Ramírez del CUIB/UNAM.

Septiembre 24 al 26. En el marco del XXI Coloquio de Investigación Bibliotecológica y de la Información. La investigación bibliotecológica en la era de la información se desarrollan los "Diálogos de Investigación”, en los que se trataron los siguientes temas: I. El fenómeno de los usuarios de la investigación, II. Lectura y Sociedad, III. Patrimonio bibliográfico, IV. Educación bibliotecológica y V. Organización de la Información.

Septiembre 22 al 24. Se desarrolla el curso De la gestión de la información a la gestión del conocimiento, impartido por el Dr. Juan Ros García de la Universidad de Murcia, España.

Septiembre 29 a Octubre 2. Se organiza el primer seminario Lectura: Pasado, Presente y Futuro, organizado por la Mtra. Elsa M. Ramírez y en 
el que destacan la participación de: Dr. José López Yepes de la Universidad Complutense de Madrid, España; Dr. Juan Ros García de la Universidad de Murcia, España; Dr. Noé Jutrik de la Universidad de Buenos Airea, Argentina; Lic. Didier Álvarez Zapata de la Universidad de Antioquia, Colombia; y Dra. Michèle Petit de la Universidad de París 1.

Octubre 1. Ingreso del Mtro. Ariel Alejandro Rodríguez García como investigador del CUIB.

Noviembre 10 al 13. Se imparte en el Centro, por el Dr. Ageo García, el taller El formato MARC21-Bibliográfico: su aplicación en la catalogación automatizada de publicaciones monográficas.

Noviembre 21. Se desarrolla la Mesa redonda sobre El Programa Internacional de Catalogación Cooperativa PCC/LC, impartida en el Auditorio "Mario de la Cueva" de la Torre II de Humanidades de la UNAM.

Noviembre 24 al 27. El Centro organiza el curso La formación de usuarios de la información en un contexto académico, impartido por Patricia Hernández y Edilma Naranjo Vélez de la Universidad de Antioquia, Colombia.

Noviembre 25. La investigadora Elsa Margarita Ramírez Leyva obtiene el Doctorado en Ciencias de la Información por la Universidad Complutense de Madrid, España. Sobresaliente Cum Laude.

Diciembre 3. Se le otorga el premio Bibliotecario 2003 a la Mtra. Rosa María Fernández de Zamora en el marco de la Feria Internacional del Libro de Guadalajara.

\section{4}

Se designa a la Dra. Elsa Margarita Ramírez Leyva como Investigador Nacional Nivel II por el Sistema Nacional de Investigadores.

Enero. Designan a la Dra. Patricia Hernández Salazar como Investigador Nacional Nivel I por el Sistema Nacional de Investigadores.

Enero 15. Cambios en el Consejo Interno, el cual quedó constituido de la siguiente forma:

Presidente: Dr. Filiberto Felipe Martínez Arellano.

Secretario: Dr. Juan José Calva González.

Vocales: $\quad$ Q.F.B. Elisa Margarita Almada Navarro.

Dra. Patricia Hernández Salazar. 
Mtra. Ma. del Carmen Negrete Gutiérrez.

Ing. Edgardo Ruiz Velasco Romo.

Invitada: Dra. Catalina Naumis Peña

Enero 24. El Centro organiza la presentación del libro Factores de influencia en el aprovechamiento del estudiante de Biblioteconomía, desarrollada en el Salón de la Academia de Ingeniería del Palacio de Minería.

Marzo 8. La UNAM otorga el Reconocimiento Sor Juana Inés de la Cruz 2004 a la investigadora Rosa María Fernández Esquivel.

Abril 20. Ingreso del Mtro. Egbert John Sánchez Vanderkast como investigador del CUIB.

Mayo 3 al 7. Se desarrolla en el Centro el primer curso La Biblioteca Digital: Colecciones, Recursos y Servicios, impartido por la Dra. Georgina Araceli Torres.

Junio. Se otorga a la investigadora Rosa María Fernández Esquivel el reconocimiento y medalla de la Asociación Mexicana de Bibliotecarios, A.C. en el 50 aniversario de AMBAC.

Junio 14 al 18. La Dra. Jane M. Russell imparte el curso La Bibliometría en la Evaluación de la Ciencia.

Junio 17. La investigadora Martha Alicia Añorve Guillén obtiene el Doctorado en Ciencias de la Información por la Universidad Complutense de Madrid, España. Sobresaliente Cum Laude.

Junio 24 y 25. El CUIB y la Sección de Catalogación de la Federación Internacional de Asociaciones e Instituciones Bibliotecarias -IFLA- organizan la Primera Reunión Nacional sobre un Código Internacional de Catalogación. Cuyos objetivos fueron: 1) La revisión y actualización del documento preliminar del 2003 sobre las Declaraciones de los Principios Internacionales de Catalogación elaborados en Frankfurt, Alemania, 2) Discutir los problemas de interpretación y aplicación de las Reglas de Catalogación Angloamericanas en las bibliotecas mexicanas para considerar las posiciones de los catalogadores mexicanos respecto a estas normas y 3) Preparar el documento que el grupo Mexicano de Catalogación presentaría en la $2^{\text {a }}$ Reunión IFLA de Expertos sobre Código Internacional de Catalogación. 
Centro Universitario de Investigaciones Bibliotecológicas. Cronología ...

Junio 28 a Julio 2. El Centro organiza el curso Mapas Conceptuales como berramientas de acceso a la Información Digital, impartida por el Dr. Cristófol Rovira de la Universitat Pompeu Fabra.

Julio 20 a Agosto 20. El CUIB organiza el seminario Usuarios de Información: El fenómeno de las necesidades de información: las comunidades de usuarios y su investigación.

Agosto. Rosa María Fernández Esquivel (de Zamora) in recognition of distinguished service to IFLA, especially within the Latin American Library Community, Buenos Aires. 68 International Congress and General Conference.

Agosto 9 al 20. Se desarrolla en el Centro el quinto curso Estudios Métricos de la Información. En esta ocasión contó con la participación de investigadores de universidades españolas, esto gracias al programa de Cooperación Interuniversitaria/ Agencia Española de Cooperación Internacional, con la finalidad de fomentar el establecimiento de redes temáticas entre universidades españolas y latinoamericanas. Los investigadores que impartieron el curso: Dr. Elías Sanz Casado de la Universidad Carlos III de Madrid, Dra. Carmen Martín Moreno de la Universidad Carlos III de Madrid, Dra. María Luisa Lascuráin Sánchez de la Universidad Carlos III de Madrid, Dr. Antonio Pulgarin Guerrero de la Universidad de Extremadura, Dra. Isabel Iribarren Maestro de la Universidad de Extremadura, Dr. Miguel Ángel Esteban Navarro de la Universidad de Zaragoza y Dr. Miguel Moreno Vernis de la Universidad de Zaragoza.

Agosto 16 al 18. Se imparte en el CUIB el curso Catalogación de Publicaciones Seriadas Electrónicas.

Agosto 19 y 20. La Mtra. Lisa Furubotten imparte el Taller de Formación de entrenadores para la catalogación de Publicaciones Seriales.

Agosto 23 al 27. Se imparte el curso Las Políticas de Información en la monarquía bispana: archivos, bibliotecas y cultura escrita entre los siglos XVI y XVII, impartido por el Dr. Diego Navarro Bonilla de la Universidad Carlos III de Madrid, España.

Agosto 30 a Septiembre 3. El Dr. Juan Carlos Marcos de la Universidad Complutense de Madrid imparte el curso Uso de las tecnologías en el apoyo educativo en Bibliotecología y Documentación, como 
Centro Universitario de Investigaciones Bibliotecológicas. Cronología ...

parte de programa de intercambio académico con universidades españolas.

Septiembre 22 y 23. Se desarrolla el seminario Educación a distancia, el cual forma parte de los siete seminarios permanentes que se imparten por investigadores el CUIB.

Septiembre 22 al 24. Se desarrolla el XXII Coloquio de Investigación Bibliotecológica y de la información: Sociedad, Información y Bibliotecas. La preocupación para este Coloquio fue el acceso a la información por diversas comunidades sociales, el derecho que tienen a ella según los instrumentos jurídicos, y como las diversas unidades de información deben prestar atención a dichas comunidades para darles acceso a toda la información que necesiten. El presente Coloquio fue iniciado con las Palabras de Inauguración del XXII Coloquio de Investigación Bibliotecológica y de la información: Sociedad, Información y Bibliotecas ofrecidas por el Director del CUIB el Dr. Filiberto Felipe Martínez, posteriormente se inició la Conferencia Magistral: El bombre y la sociedad como centro de los servicios de información, impartida por la Dra. Estela M. Morales del CUIB/ UNAM. En esta ocasión se presentaron las ponencias tituladas: Políticas de información en México: los archivos y las bibliotecas, impartida por Egbert J. Sánchez del CUIB/UNAM; Políticas de información y documentación en España, impartida por María Teresa Fernández de la Universidad Complutense de Madrid, España; El Libro Electrónico, impartida por Juan Voutssás del CUIB/UNAM; Recursos electrónicos de información periodística: el caso de la prensa digital mexicana, impartida por María Ángeles Jiménez de la Universidad Autónoma de Barcelona, España; El acceso a los documentos y su relación con la biblioteca digital, impartida por Georgina Araceli Torres del CUIB/UNAM; Criterios de evaluación de las tesis doctorales en Bibliotecología y Estudios de Información: Situación en España, impartida por José López, María Teresa Fernández y Judit Prat de la Universidad Complutense de Madrid, España; Hacia un Código Internacional de Catalogación, impartida por Filiberto Felipe Martínez y Ariel Alejandro Rodríguez del CUIB/UNAM. Por su parte se desarrollaron las siguientes mesas redondas: I. Servicios Bibliotecarios $y$ de la Información para Comunidades Indígenas, dirigida por César 
Centro Universitario de Investigaciones Bibliotecológicas. Cronología ...

Augusto Ramírez del CUIB/UNAM. II. El multiculturalismo y los servicios de la información, en la que participan las ponencias: El multiculturalismo y los servicios de la información, impartida por Beatriz Casa de la UNAM; Multiculturalismo e identidad en la Sociedad Red: una perspectiva bibliotecológica, impartida por Hugo Alberto Figueroa de la UNAM; Igualdad y democracia en la biblioteca, medidas inaplazables frente al multiculturalismo, impartida por José de Jesús Hernández de la Escuela Nacional de Biblioteconomía y Archivonomía, Secretaria de Educación Pública; La información multicultural de la sociedad global en la aldea local, impartida por Celia Mireles de la Escuela de Bibliotecología e Información de la U. Autónoma de San Luis Potosí y El multiculturalismo y los servicios de información, impartida por Homero Quezada del CUIB/UNAM. III. El uso de las tecnologías en la educación bibliotecológica, en la que participan las siguientes ponencias: El uso de las tecnologías en la educación bibliotecológica, impartida por Lina Escalona del CUIB/UNAM; Tecnologías de información y educación a distancia: ¿qué prometen y qué exigen?, impartida por Roberto Garduño del CUIB/UNAM; Herramientas docentes al servicio de la bibliotecología mexicana, impartida por Juan Carlos Marcos de la UNAM y La tecnología en la enseñanza de la bibliotecología, impartida por José Adolfo Rodríguez del CUIB/UNAM.

Septiembre 28. El investigador Salvador Gorbea Portal obtiene el Doctorado en Documentación por la Universidad Carlos III de Madrid, España. Premio Extraordinario de Doctorado.

Noviembre 17. El CUIB organiza la presentación del libro Gestión del patrimonio cultural: realidades y retos.

Noviembre 22 al 24. Se desarrolla el segundo seminario Lectura: Pasado, Presente y Futuro: las prácticas sociales de lectura.

Diciembre. Publicación del libro coeditado entre el CUIB/Facultad de Filosofía y Letras/UNAM titulado: Organización bibliográfica $y$ documental, esta obra fue coordinada por los investigadores Hugo Alberto Figueroa Alcántara y César Augusto Ramírez Velásquez.

Diciembre 15. La investigadora Lina Escalona Ríos obtiene el Doctorado en Bibliotecología y Estudios de la Información por la Universidad Nacional Autónoma de México. 
Centro Universitario de Investigaciones Bibliotecológicas. Cronología ...

\section{5}

Se designa a la Dra. Lina Escalona Ríos como Investigador Nacional Nivel I por el Sistema Nacional de Investigadores.

Se designa a la Dra. Martha Alicia Añorve Guillén como Investigador Nacional Nivel I por el Sistema Nacional de Investigadores.

Se designa al Dr. Salvador Gorbea portal como Investigador Nacional Nivel I por el Sistema Nacional de Investigadores.

Febrero 26. La Dra. Patricia Hernández Salazar presenta el libro Modelo para generar programas sobre la información en al uso de tecnologías de la información, la cual se llevó a cabo en la Palacio de Minería de la Ciudad de México.

Febrero 26. Se presenta el libro La biblioteca digital de la Dra. Georgina Araceli Torres Vargas.

Marzo. Se le otorga a la Q.F.B. Elisa Margarita Almada de Ascencio el Reconocimiento Sor Juana Inés de la Cruz por su trayectoria académica en la UNAM.

Marzo 14 a Agosto 30. El Centro organiza el Diplomado Virtual: La Administración de Archivos y la Transparencia en la Información Pública: Análisis Estratégico y Cambio Organizacional.

Marzo 16 al 18. Se desarrolla el Seminario INFOBILA como apoyo a la investigación y educación bibliotecológica en América Latina y el Caribe. El cual tuvo como objetivo el analizar la situación y perspectivas de la investigación y educación bibliotecológica en Latinoamérica y el Caribe, además de analizar el papel de INFOBILA como apoyo al desarrollo de la investigación y educación bibliotecológica en la Región.

Abril 22 a Septiembre 3. La Dra. Ma. Idalia García organiza el diplomado Gestión Cultural del Libro Antiguo: Políticas para su Conservación, Protección y Difusión. Impartido por diferentes instructores de variadas instituciones españolas.

Abril 25 y 26. El Dr. Adolfo Rodríguez Gallardo es el Coordinador General en el Cuarto Coloquio de Doctorados, Posgrado en Bibliotecología y Estudios de la Información, Facultad de Filosofía y Letras y CUIB. 
Abril 25 al 29. La Dra. Georgina Araceli Torres imparte el segundo curso La Biblioteca Digital: Colecciones, Recursos y Servicios.

Mayo. Publicación del libro coeditado entre el CUIB-UNAM/Colegio Nacional de Bibliotecarios, A.C. titulado: La educación bibliotecológica en México a través de sus Instituciones Educativa, esta obra fue compilada por la investigadora Lina Escalona Ríos.

Mayo 2 al 6. La Dra. María Luisa Lascuráin Sánchez de la Universidad Carlos III de Madrid imparte el curso Aplicación de los indicadores bibliométricos a la gestión bibliotecaria, la cual se desarrolló en el CUIB bajo los convenios establecidos con universidades españolas.

Mayo 30 a Junio 3. Se desarrolla en el Centro el curso Inventarios y Catalogación del Patrimonio Documental: libros antiguos y documentos bistóricos.

Junio 27. El investigador Juan Voutssás Márquez obtiene el Doctorado en Bibliotecología y Estudios de la Información por la Universidad Nacional Autónoma de México. Graduado con Mención Honorífica.

Agosto. Se designa como miembro de la American Library Association al Dr. Filiberto Felipe Martínez Arellano.

Agosto. Publicación del libro coeditado entre el CUIB-UNAM/Federación Internacional de Asociaciones e Instituciones de Bibliotecarios titulado: Seminario: INFOBILA como apoyo a la investigación y adulación bibliotecológica en América Latina y el Caribe, esta obra fue compilada por los investigadores Filiberto Felipe Martínez Arellano y Juan José Calva González.

Septiembre 5 al 9. Se imparte el curso Digitalización de documentos para desarrollar colecciones virtuales.

Octubre 19 al 21. Se desarrolla el XXIII Coloquio de Investigación Bibliotecológica y de la Información. Problemas y Métodos de Investigación en Bibliotecología e Información: una perspectiva interdisciplinaria. En esta ocasión el objetivo fue el analizar los problemas de investigación actuales y los que están surgiendo en la Bibliotecología y estudios de la información y las formas en cómo pueden ser abordados a través de diversas metodologías, así como identificar posibles proyectos de investigación colectivos e interdisciplinarios. El presente Coloquio fue iniciado con las Palabras de Inau- 
Centro Universitario de Investigaciones Bibliotecológicas. Cronología ...

guración del XXIII Coloquio de Investigación Bibliotecológica y de la Información. Problemas y Métodos de Investigación en Bibliotecología e Información: una perspectiva interdisciplinaria ofrecidas por el Director del CUIB el Dr. Filiberto Felipe Martínez, seguido de la Conferencia Magistral: Las ciencias, la bibliotecología y la interdisciplina, impartida por José Adolfo Rodríguez del CUIB/UNAM. En esta ocasión se presentaron las ponencias: Perspectivas interdisciplinarias de los Estudios Métricos de la Información, impartida por Salvador Gorbea del CUIB/UNAM; Investigación interdisciplinaria sobre los servicios en la biblioteca digital, impartida por Georgina Araceli Torres del CUIB/UNAM; Didáctica de la bibliotecología y la necesidad de la interdisciplina, impartida por Jaime Ríos del CUIB/UNAM; Objetos de aprendizaje: una propuesta para la innovación educativa virtual en bibliotecología, impartida por Roberto Garduño del CUIB/UNAM; Investigación sobre educación bibliotecológica y acreditación, impartida por Lina Escalona del CUIB/UNAM; Tendencias y perspectivas para la enseñanza de la bibliotecología en la cibersociedad, impartida por Johann E. Pirela de la Escuela de Bibliotecología y Archivología de la Universidad del Zulia, Venezuela; Metodología e interdisciplina, impartida por Miguel Ángel Rendón del CUIB/UNAM; Para una lectura multidisciplinaria de la lectura, impartida por Héctor Guillermo Alfaro del CUIB/UNAM; Interacción entre la bibliotecología y la terminología, impartida por Catalina Naumis del CUIB/UNAM; Investigación sobre la organización de las entidades de información, impartida por Ariel Alejandro Rodríguez del CUIB/UNAM; Los objetos de investigación bibliotecológica en la UASLP, impartida por Agustín Gutiérrez de la U. Autónoma de San Luis Potosí; Servicios bibliotecarios y de información en comunidades indigenas: una perspectiva interdisciplinaria, impartida por César Augusto Ramírez del CUIB/UNAM; La formación de usuarios en un contexto latinoamericano, impartida por Edilma Naranjo de la Escuela Interamericana de Bibliotecología de la Universidad de Antioquia, Colombia y Nora Elena Rendón de la Universidad Pontificia Bolivariana, Medellín, Colombia; La interdisciplina en la investigación bibliotecológica, impartida por Elisa Margarita Almada del 
Centro Universitario de Investigaciones Bibliotecológicas. Cronología ...

CUIB/UNAM e Investigación multidisciplinaria sobre la comunicación científica, impartida por Jane Margaret Russell del CUIB/UNAM. Noviembre 17 y 18. El Centro organiza el Encuentro Latinoamericano de Programas de Doctorado de la Región, desarrollado en el Auditorio Mario de la Cueva de la Torre II de Humanidades.

Noviembre 21 al 23. La Dra. Elsa M. Ramírez organiza el tercer seminario Lectura: Pasado, Presente y Futuro. ¿Extinción o transformación del lector? Cuyo objetivo fue: examinar los conocimientos sobre los cambios supuestos o reales, inspirados en el título del texto de Roger Chartier ¿Muerte o transformación del lector?, y así analizar y discutir las prácticas sociales de la lectura. En este evento se contó con la participación de investigadores nacionales y extranjeros como: Dra. Michèlle Petit de la Universidad de París I, Francia; Dr. Klaus Schönbach de la Universidad Zeppelín, Friedrichshafen, Alemania, y Universidad de Ámsterdam, Holanda; Dr. Didier Álvarez Zapata de la Universidad de Antioquia, Colombia; Mtra. Carmen P. De Aguinaga Vázquez del Departamento de Desarrollo Social de la Universidad de Guadalajara, México; Mtra. Margarita Palacios Sierra de la Facultad de Filosofía y Letras de la UNAM; Dra. Emilia Gallego Alfonso del Comité Cubano del Organización Internacional para el Libro Juvenil -IBBY-; Mtro. Alejandro Zenker Director General de Solar, Servicios Editoriales, Ediciones del Ermitaño, México; Mtro. Rodolfo Castro Asesor de la Colección de Libros Infantiles y Juveniles, Fondo de Cultura Económica, México y Mtro. Juan Domingo Argüelles de la Dirección General de Bibliotecas, Consejo Nacional para la Cultura y las Artes, México.

Noviembre 21 al 25. El Centro organiza el curso Tendencias para la formación del profesional de la información en la Sociedad del Conocimiento, la comunicación y el aprendizaje, el cual se impartió por el Dr. Johann Pirela, de la Escuela de Bibliotecología y Archivología de la Universidad del Zulia, Venezuela.

Noviembre 24. Ingreso de la Mtra. Brenda Cabral Vargas como investigadora del CUIB.

Diciembre 4. Se designa al Dr. Adolfo Rodríguez Gallardo como Miembro de la Comisión Dictaminadora del Colegio de Bibliotecología de la Facultad de Filosofía y Letras de la UNAM. 
Diciembre 7. Se organiza la conferencia magistral Códices Novobispanos. Arte, Escritura y Repositorios, impartida en el Salón de Seminarios del CUIB.

\section{6}

Se designa al Dr. Juan Voutssás Márquez como Investigador Nacional Nivel I por el Sistema Nacional de Investigadores.

Se designa a la Dra. María del Carmen Negrete Gutiérrez como Investigador Nacional Nivel I por el Sistema Nacional de Investigadores. El CUIB participa en el Macroproyecto de la UNAM: "Tecnologías para la Universidad de la Información y la Computación," cuyo objetivo es "Investigar, diseñar y desarrollar infraestructura integral, tecnología y cultura para la transformación del campus universitario en un modelo del aprovechamiento de la información digital, la conectividad y las técnicas emergentes de la computación y la inteligencia computacional”. En este Macroproyecto, el doctor Roberto Garduño Vera es Corresponsable del proyecto "Biblioteca digital de material didáctico" y participante en el proyecto "Modelo sistémico de la educación a distancia"; la doctora Jane M. Russell Barnard es Corresponsable de los proyectos "Observatorio Informétrico" y "Desarrollo y aplicación de interfaces de las bases de datos de CLASE y PERIÓDICA"; asimismo, el doctor Salvador Gorbea Portal es Miembro del Comité de Expertos de este Macroproyecto.

Dentro de los proyectos interinstitucionales que se desarrollan en el CUIB, sobresale el proyecto Humanindex (Índice de Citas en Humanidades y Ciencias Sociales), el cual es auspiciado por la Coordinación de Humanidades, teniendo como objetivo desarrollar un Sistema de Información Académica que permita identificar la producción científica generada en todas y cada una de las entidades pertenecientes al Subsistema de Humanidades y Ciencias Sociales de esta Universidad, así como conocer la difusión, impacto y visibilidad de esta producción.

El proyecto "Encuesta Internacional de Lectura para la Región de América Latina y el Caribe”, coordinado por la doctora Elsa Ramírez Leyva, ha recibido el apoyo económico de la Internacional Federa- 
tion of Library Associations and Institutions (IFLA), puesto que éste forma parte del proyecto global "Encuesta Internacional de Lectura", auspiciado por esta organización. El objetivo del proyecto coordinado por la doctora Ramírez Leyva es conocer y documentar la contribución de las bibliotecas públicas de América Latina y el Caribe en el desarrollo del lector y la promoción de la lectura a fin de formular programas de perfeccionamiento y actualización del personal bibliotecario; asimismo, coadyuvar al fortalecimiento de los programas de las escuelas de Bibliotecología, asociaciones y bibliotecas para la solución de problemas de lectura y alfabetización de los ciudadanos; adicionalmente, tener elementos para participar en las políticas y programas de fomento a la lectura.

Febrero 8. La investigadora María del Carmen Negrete Gutiérrez obtiene el Doctorado en Ciencias de la Información por la Universidad Complutense de Madrid, España.

Febrero 13 al 17. Se realiza el curso Control de Autoridades de Materiales en Catálogos Automatizados, impartido por la Lic. Blanca Estela Sánchez.

Marzo 2. La investigadora Rosa María Fernández Esquivel obtiene el Doctorado en Bibliotecología y Estudios de la Información por la Universidad Nacional Autónoma de México.

Marzo 27 al 31. Se organiza el curso E-Consulta: Recursos y Servicios de Consulta Electrónica, impartido por la Mtra. Patricia Rodríguez.

Marzo 29 al 31. Por medio de los convenios e intercambios con universidades españolas el CUIB organiza el Zer. Seminario Hispano-Mexicano de Investigación en Bibliotecología y Documentación; el objetivo de este seminario fue examinar las líneas de investigación de las universidades españolas y mexicanas dentro de la Bibliotecología, la documentación y las ciencias de la información, con la finalidad de identificar proyectos de investigación conjunta, tanto de forma individual como colectiva, así como propiciar la movilidad e intercambio de investigadores, profesores y estudiantes de posgrado entre ambos países. Los participantes españoles fueron: Dr. Félix del Valle Gastaminza de la Universidad Complutense de Madrid, Dra. Angélica Zapatero Lourniho de la Universidad Complutense de Madrid, Dr. Félix de 
Moya Anegón de la Universidad de Granada, Dr. José López Yépes de la Universidad Complutense de Madrid, Dra. Rosario Arquero Avilés de la Universidad Complutense de Madrid, Dr. Juan Antonio Martínez Comeche de la Universidad Complutense de Madrid, Dr. Agustín Vivas Moreno de la Universidad de Extremadura, Dra. Luisa Orera Orera de la Universidad de Zaragoza, Dra. María Teresa Fernández Bajón de la Universidad Complutense de Madrid, Dra. Esperanza Martínez Montalvo de la Universidad de Alcalá, Dr. Juan Ros García de la Universidad de Murcia y Dr. Luis Fernando Ramos Simón de la Universidad Complutense de Madrid. Mientras que los investigadores mexicanos fueron: Dra. Elsa Barberena Blázquez de la Facultad de Filosofía y Letras de la UNAM y 19 investigadores del Centro.

Abril 7. El investigador Jaime Ríos Ortega obtiene el Doctorado en Bibliotecología y Estudios de la Información por la Universidad Nacional Autónoma de México.

Abril 24 al 28. Se imparte el curso La Biblioteca Digital como Apoyo a la Educación a Distancia.

Mayo 16- junio 30. Curso de autoridades y tesauros, Dr. Filiberto Felipe Martínez Arellano y Lic. Sergio Arreguín Meneses en la Suprema Corte de Justicia.

Agosto. Publicación del libro coeditado entre el CUIB/Dirección General de Bibliotecas/UNAM titulado: Forjadores e impulsores de la Bibliotecología Latinoamericana, esta obra fue escrita por la Dra. Estela Mercedes Morales Campos.

Agosto 14 al 18. El Centro organiza el curso Los derechos de autor en México: retos y oportunidades en el entorno virtual.

Agosto 21- septiembre 1. La Mtra. Hortensia Constanza Tercero y Vega imparte el curso Introducción a la organización y conservación de archivos Modalidad a Distancia.

Agosto 28- septiembre 1. Se imparte el curso Formato MARC 21 bibliográfico: nivel básico, por la Asesora Independiente Rosenda Ruiz Figueroa

Septiembre 12-14. Se lleva a cabo el II Encuentro Internacional de Catalogación: Tendencias en la teoría y práctica de la catalogación bibliográfica. Este evento se realizó en colaboración con el Instituto de Investigaciones Bibliográficas de la UNAM y la Biblioteca Nacional 
del Perú. Los objetivos del encuentro fueron: 1. Compartir e intercambiar experiencias sobre la teoría y práctica catalográfica en las bibliotecas de América Latina y de otros países del extranjero; 2. Discutir las tendencias de la catalogación en el marco de las nuevas tecnologías de información y a la luz de la revisión de los Principios Internacionales de Catalogación; 3. Fomentar la participación en programas de cooperación de catalogación y de control de autoridades en el ámbito internacional; 4 . Delinear pautas, recursos y procedimientos para la catalogación y el control de las autoridades en forma cooperativa y 5 . Discutir el perfil para la formación del bibliotecario en el área de la catalogación y de la organización de la información. En este participaron académicos de distintas instituciones del país, así como de Argentina, Brasil, Colombia, Cuba, Estados Unidos, Guatemala y Perú. Entre los participantes extranjeros destacan de Argentina: Noemí Norma Caballo de la Biblioteca Nacional de la República de Argentina; María Elena Amanda Lucero de la Biblioteca Nacional de la República de Argentina; Elsa Barber y Silvia L. Pisano de la Universidad de Buenos Aires. En representación de Brasil: Fernanda Passini y Marisa Braschër de la Universidad de Brasilia; Cicília Conceiçao de María de la Universidad Estatal de Maringa. De Colombia: Rosa López de la Biblioteca Luis Ángel Arango. De Cuba: Isaura María González Correa y Maricela Molina Piñeiro de la Universidad de la Habana. De los Estados Unidos de América: Barbara Tillet de la Biblioteca del Congreso-División IV (Control Bibliográfico) de IFLA; Sandra Roe de Cataloging and Classification Quaterly; David Miller de Association of Library Collections and Technical Services, Cataloging and Classification Section; Ana Cristian de la Biblioteca del Congreso; Ageo García de Tulane University; Michael Kreyche de Kent State University; Lisa Furubotten de Texas A \& M University. De Guatemala: Nora Domínguez Rodríguez y Grete Pasch de la Universidad Francisco Marroquín. De Perú: Catalina Meriluz Zavala Barrios y Lidia Berrocal Quijhua de la Biblioteca Nacional del Perú; Teresa Rossio Bejar Apaza y Gloria Samamé Mancilla de la Universidad Nacional Mayor de San Marcos; Ana María Talavera Ibarra de la Pontificia Universidad Católica del Perú. Entre los participantes nacionales se encuentran por el Instituto de Investigaciones Bibliográficas (UNAM): 
Silvia Salgado Ruelas, Evelia Santana Cavaría, Ángel Villalba Roldán, Sofía Brito Ocampo, Aurora Serrano Cruz, Daniel de Lira Luna. Por el Posgrado en Bibliotecología y Estudios de la Información (UNAM. Facultad de Filosofía y Letras) la Doctora Elsa Barberena Blázquez. Por el Colegio de Bibliotecología (UNAM. Facultad de Filosofía y Letras) Hugo Alberto Figueroa Alcántara, María Teresa González Romero, Esperanza Molina Mercado. Por la Universidad Autónoma de San Luis Potosí: Julia Margarita Martínez y Agustín Gutiérrez Chiñas. Por el El Colegio de México, Reinaldo D. Figueroa Servín. Por la Escuela Nacional de Biblioteconomía y Archivonomía: Adriana Monroy Muñoz, María Graciela Tecuatl Quechol, César M. Trahyn Hernández, Hugo Martín Vargas Aguado y María Gabriela Vázquez Santa Ana. Del Centro Universitario de Investigaciones Bibliotecológicas (UNAM) coordinaron y participaron: Filiberto Felipe Martínez Arellano, Ariel Alejandro Rodríguez García y Catalina Naumis Peña.

Septiembre 18-22. Se imparte el curso Catalogación de recursos continuos electrónicos, por la Maestra Lisa Furubotten de la Texas A\&M University

Octubre 2 al 6. Se lleva a cabo el curso La lectura secreta: una inmersión en el sonido del texto para acercarse a la teoría y práctica de leer y contar cuentos, por el Maestro Rodolfo Castro.

Octubre 18-20 Se desarrolla el XXIV Coloquio de Investigación Bibliotecológica y de la Información. Este evento es uno de los foros académicos que por tradición organiza año con año el Centro. Teniendo como base la participación de los investigadores del CUIB, conjuntamente con la de otros académicos del país y del extranjero, este coloquio se realizó del 18 al 20 de octubre de 2006, en esta ocasión bajo la temática "XXV años de Investigación Bibliotecológica y Estudios de la Información en México”. Su objetivo principal fue: Analizar la situación actual y tendencias de la investigación en Bibliotecología y Estudios de la Información, así como las aportaciones del CUIB, durante 25 años, al desarrollo de la disciplina. Se contó con la participación de los investigadores del CUIB y con la de los siguientes invitados: Doctora Martha Valencia de Veizaga y maestra Edilma Naranjo Vélez del Centro de Investigaciones Bibliotecológicas e información, Universidad de Antioquia, Colombia; de la licenciada Ruth 
Soledad Alejos Aranda del Centro de Investigaciones Bibliotecológicas y Desarrollo Bibliotecario, Perú; de la maestra Rosa María Rider de la Universidad Autónoma de San Luis Potosí; del licenciado Nahúm Pérez Paz de la Escuela Nacional de Biblioteconomía y Archivonomía. Así como de los investigadores del Centro.

Octubre 28- noviembre 12. Se llevó a cabo el curso: Recursos electrónicos en el área de enfermería, impartido por la maestra Patricia Rodríguez Vidal de la División del Sistema de Universidad Abierta, Facultad de Filosofía y Letras, UNAM / Posgrado en Bibliotecología y Estudios de la Información, UNAM.

Noviembre 6-8 Se llevó a cabo el Encuentro de Educación e Investigación Bibliotecológica en América Latina y el Caribe: La Formación Profesional y los retos de la sociedad de la información donde conjuntamente con la Escuela de Bibliotecología de la Universidad Mayor de San Marcos de Perú y la Sección de América Latina y del Caribe de la Federación Internacional de Asociaciones de Bibliotecarios (IFLA), el CUIB organizó este evento académico, el cual se llevo a cabo del 6 al 8 de noviembre de 2006 en las instalaciones de Universidad Mayor de San Marcos, en Lima Perú. El objetivo de este evento fue analizar la formación del pre y postgrado, la investigación bibliotecológica de los países participantes, así como el intercambio y actualización de los avances en la disciplina con la finalidad de contribuir al fortalecimiento de la integración entre los investigadores, docentes y la comunidad bibliotecológica de América Latina y el Caribe. Participaron en este evento, además de los investigadores del CUIB, académicos de los siguientes países e instituciones: México: Centro Universitario de Investigaciones Bibliotecológicas: Filiberto Felipe Martínez Arellano, Adolfo Rodríguez Gallardo, Lina Escalona Ríos, Roberto Garduño Vera, César Augusto Ramírez Velázquez, Jaime Ríos Ortega; Universidad Autónoma de San Luis Potosí: Agustín Gutiérrez Chiñas; Argentina: Universidad de Buenos Aires Elsa Barber; Bolivia: Universidad Mayor de San Andrés: Arzil Aramayo Gómez, Teresa Zelaya de Villegas. Brasil: Universidad de Brasilia: Sueli Angélica Do Amaral; Chile: Universidad Tecnológica Metropolitana: Carmen Pérez Ormeño. Colombia: Universidad de Antioquia: María Teresa Múnera Torres; Pontificia Universidad Javeriana: Adriana J. 
Ordoñez Paz; Universidad de La Salle: Ruth Elena Vallejo Sierra. Costa Rica: Universidad Nacional de Costa Rica: Karla Rodríguez Salas. Ecuador: Universidad Cristiana Latinoamericana: María Eugenia Mieles. El Salvador: Universidad Panamericana de El Salvador :Pedro Pineda; Universidad de El Salvador: Jesús Macala Padilla. España: Universidad Autónoma de Madrid: Emilia Currás; Universidad Carlos III de Madrid: José Antonio Moreiro Gonzáles; Universidad de Zaragoza: Jesús Tramillas; Universidad Complutense de Madrid: María Teresa Fernández Bajón. Guatemala: Universidad de San Carlos de Guatemala: Eloisa Amelia Yoc Smith. Panamá: Universidad de Panamá: Lidia Pérez Salazar y Octavio Castillo. Perú: Universidad Nacional Mayor de San Marcos: Marcos Martos Carrera, Isabel Miranda Meruvia, Luis Izquierdo Vásquez, Alonso Estrada Cuzcazo, Rosalía Quiroz de García, Elizabeth Huisa V.

Noviembre 21- 24. Tuvo lugar el curso Control de autoridades y tesauros, a cargo del Doctor Filiberto Felipe Martínez Arellano y del licenciado Sergio Arreguín Meneses.

Noviembre 28. La Dra. Estela Morales Campos y el doctor Adolfo Rodríguez Gallardo ingresaron como miembros a la Academia Mexicana de Ciencias, lo cual significa un reconocimiento a su trayectoria académica y contribución a la investigación bibliotecológica.

Noviembre 27 a 5 de diciembre. Se llevó a cabo el curso: Las trayectorias de la lectura. Por el doctor Héctor Guillermo Alfaro López. Noviembre 30. Tuvo lugar la Ceremonia Conmemorativa del XXV Aniversario del CUIB. El 14 de diciembre de 1981, la Universidad Nacional Autónoma de México estableció el Centro Universitario de Investigaciones Bibliotecológicas (CUIB). El 30 noviembre de 2006 se llevó a cabo en el auditorio "Mario de la Cueva", ubicado en el piso 14 de la Torre de Humanidades, la Ceremonia Conmemorativa del XXV Aniversario del CUIB. En este evento se contó con la presencia y participación de la Coordinadora de Humanidades, doctora Mari Carmen Serra, además de la de tres de los investigadores fundadores del Centro, la doctora Martha Añorve Guillén, el doctor Roberto Garduño Vera y la doctora Estela Morales, quienes presentaron una serie de reflexiones personales y profesionales acerca de lo que como grupo de investigación hemos logrado, pero también sobre los retos que 
tenemos ante nosotros. Asimismo, en esta ceremonia se entregaron reconocimientos a los investigadores fundadores del CUIB y se dio inicio formal a un año de actividades académicas que enmarcan los festejos de los 25 años del Centro. Es importante señalar que con motivo de esta celebración, también se ofreció un concierto en la Sala Nezahualcóyotl.

En este rubro, es importante mencionar que el Centro Universitario de Investigaciones Bibliotecológicas se ha convertido en un espacio de discusión en nuestra disciplina en donde convergen académicos no solamente de las instituciones de nuestro país sino también de otras latitudes. Asimismo, que la participación de los académicos del extranjero es financiada en el 80 por ciento de los casos por sus propias instituciones y en el 20 por ciento restante a través de los convenios de colaboración académica. 
Centro Universitario de Investigaciones Bibliotecológicas. Cronología 1981-2006. La edición consta de 300 ejemplares. Coordinación editorial, Zindy E. Rodríguez Tamayo. Formación editorial, Carlos Ceballos Sosa. Centro Universitario de Investigaciones Bibliotecológicas/UNAM. Fue impreso en papel cultural de 90 gr. en Publidisa Mexicana S. A. de C. V., México D. F. Se terminó de imprimir en el mes de diciembre de 2007. 